Universidad de Lima

Facultad de Ingeniería y Arquitectura

Carrera de Ingeniería Industrial

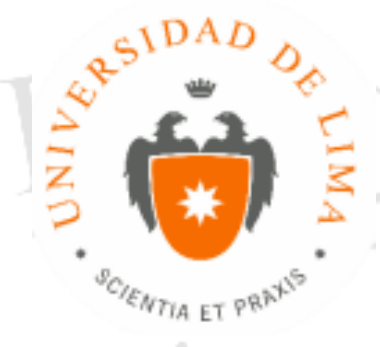

\title{
ESTUDIO DE PRE-FACTIBILIDAD PARA LA INSTALACIÓN DE UNA PLANTA PRODUCTORA DE BETÚN PARA CALZADO A BASE DE CÁSCARA DE PLÁTANO
}

Trabajo de investigación para optar el título profesional de Ingeniero Industrial

Claudia Teresa Mere Vidal

Código 20061772

\section{Asesor}

Edmundo Arroyo Benites

Lima - Perú

Junio 2017 


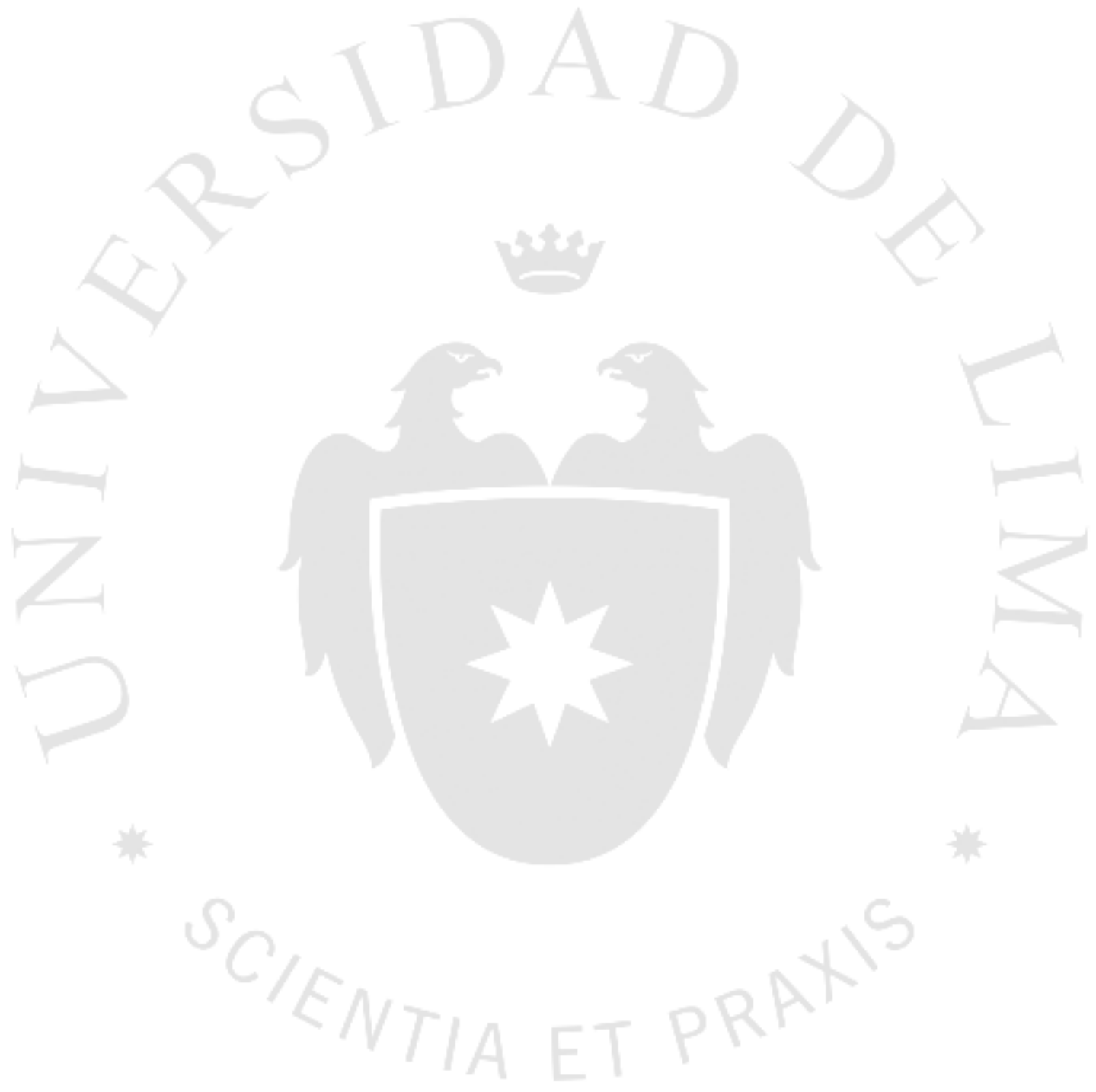




\section{ESTUDIO DE PRE-FACTIBILIDAD PARA LA}

INSTALACIÓN DE UNA PLANTA PRODUCTORA DE BETÚN PARA CALZADO A BASE DE CÁSCARA DE PLÁTANO 


\section{TABLA DE CONTENIDO}

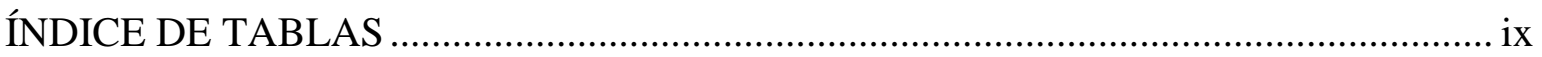

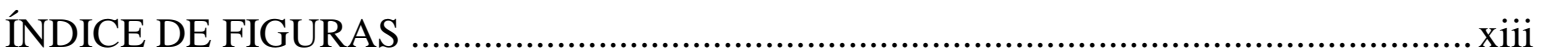

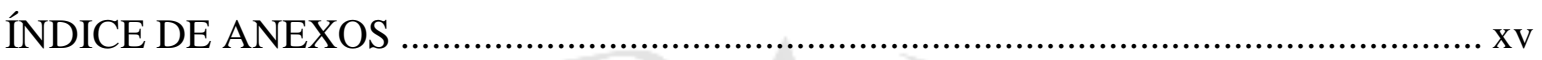

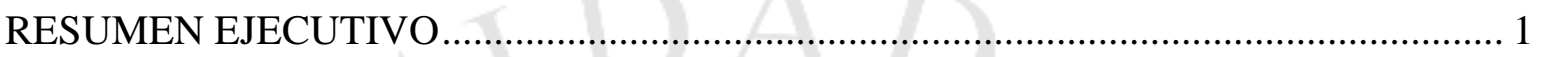

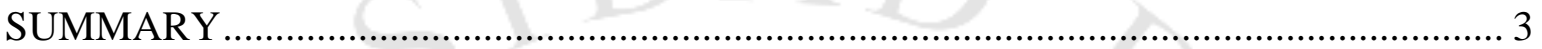

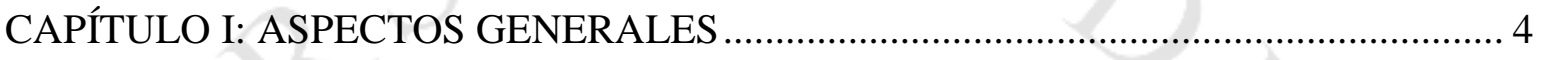

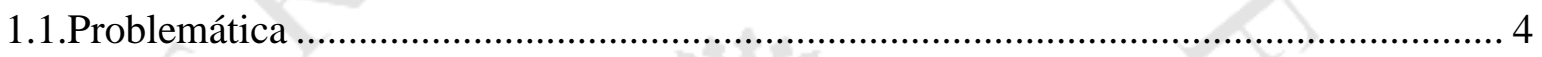

1.2. Objetivos de la investigación ..................................................................................... 5

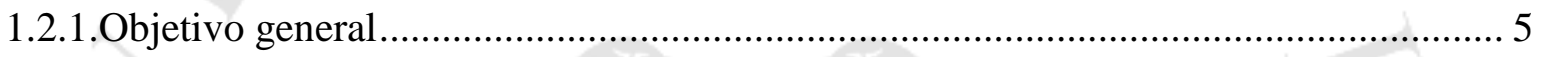

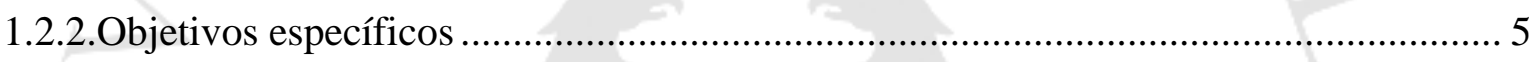

1.3.Alcance y limitaciones de la investigación .................................................................. 6

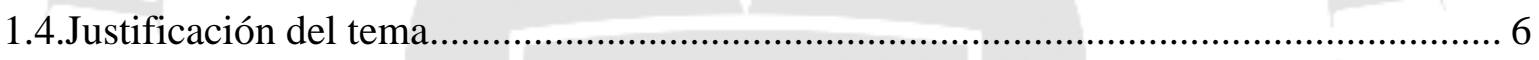

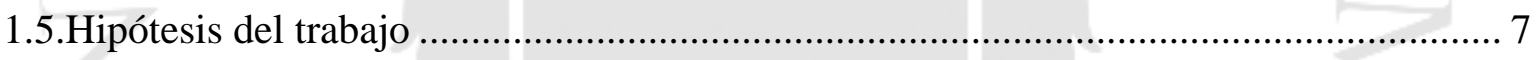

1.6.Marco referencial de la investigación ...................................................................... 8

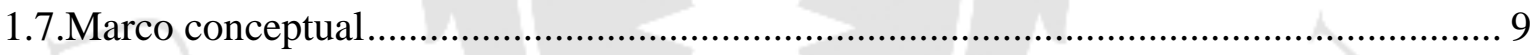

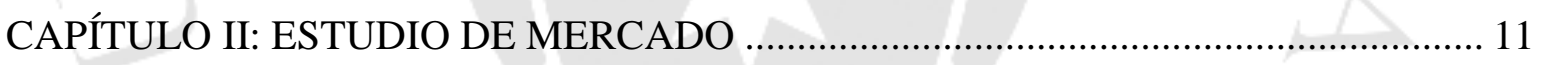

2.1.Aspectos generales del estudio de mercado.................................................................. 11

2.1.1.Definición comercial del producto ....................................................................... 11

2.1.2.Principales características del producto ............................................................. 12

2.1.3.Determinación del área geográfica que abarcará el estudio ....................................... 12

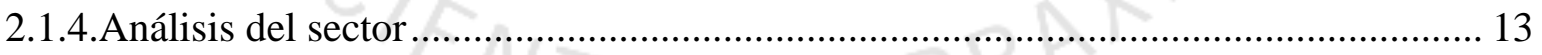

2.1.5.Determinación de la metodología que se empleará en la investigación de mercado.. 16

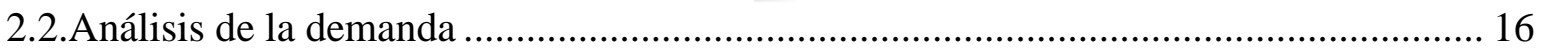

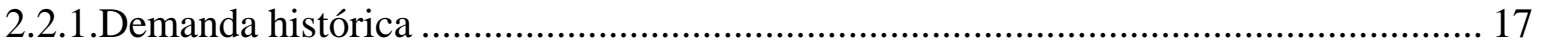

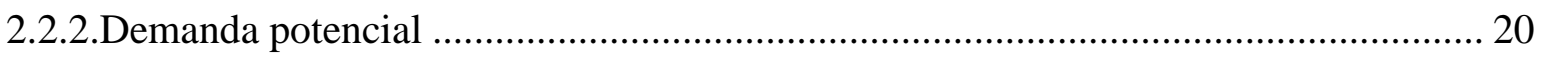

2.2.3.Demanda mediante fuentes primarias...................................................................... 23

2.2.4.Proyección de la demanda ......................................................................................... 23

2.2.5.Consideraciones sobre la vida útil del proyecto ....................................................... 24 


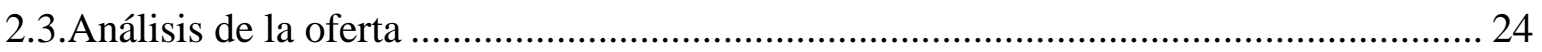

2.3.1.Empresas productoras, importadoras y comercializadoras .......................................... 24

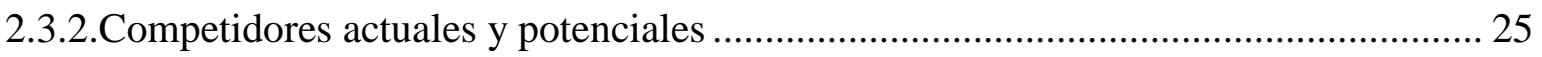

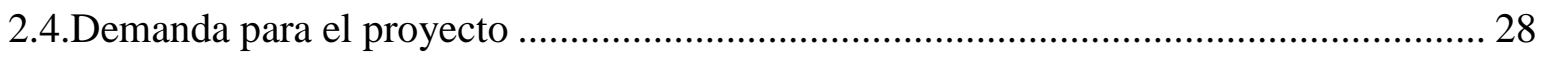

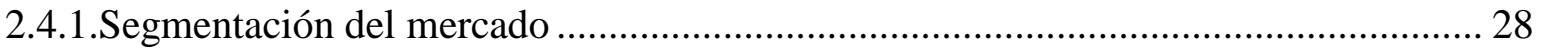

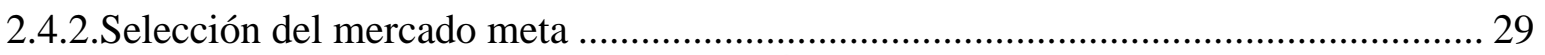

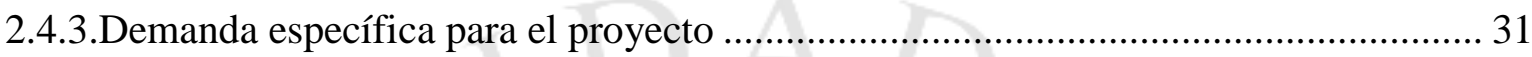

2.5.Definición de la Estrategia de Comercialización............................................................ 32

2.5.1.Políticas de comercialización y distribución ................................................................ 32

2.5.2.Publicidad y promoción ....................................................................................... 33

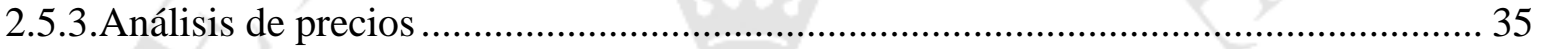

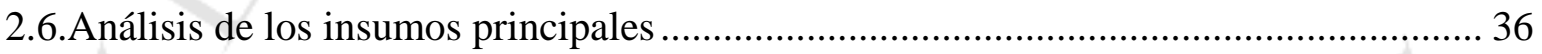

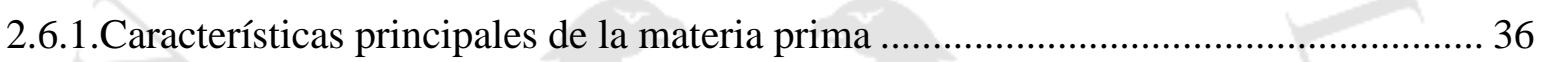

2.6.2.Disponibilidad de la materia prima........................................................................ 37

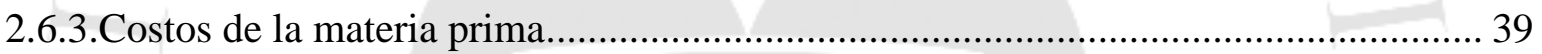

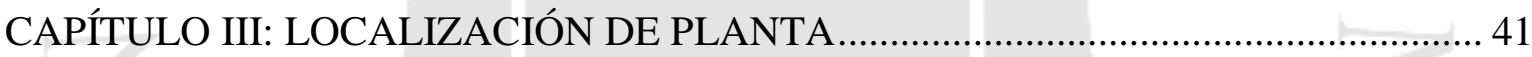

3.1.Identificación y análisis detallado de los factores de localización .................................. 41

3.2.Identificación y descripción de las alternativas de localización ...................................... 42

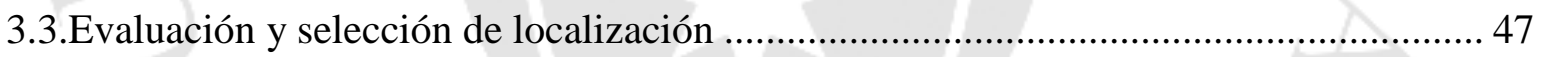

3.3.1.Evaluación y selección de la macro localización.......................................................... 47

3.3.2.Evaluación y selección de la micro localización ......................................................... 49

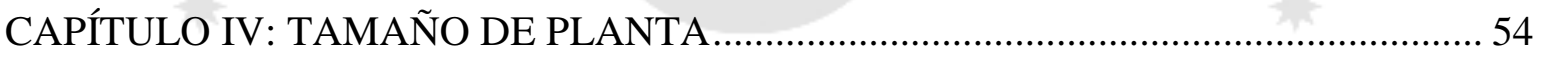

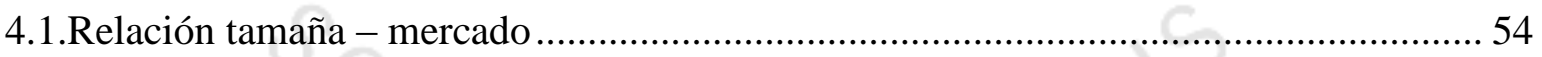

4.2.Relación tamaña - recursos productivos ...................................................................... 55

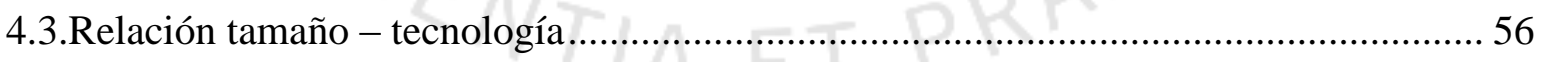

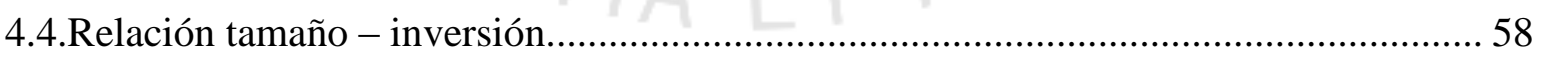

4.5.Relación tamaño - punto de equilibrio …………………….......................................... 59

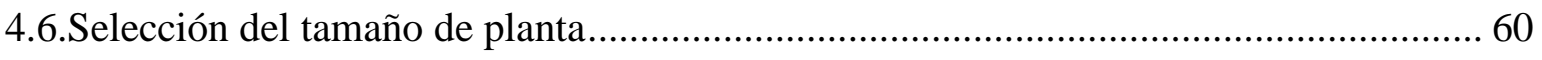

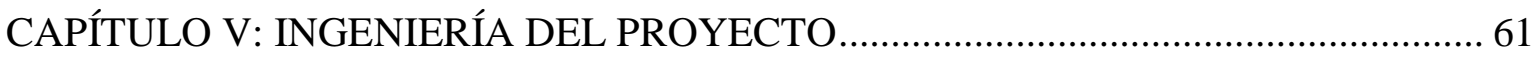

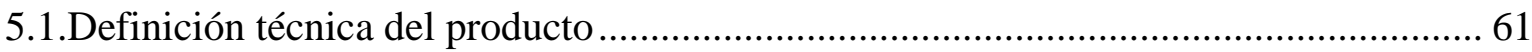

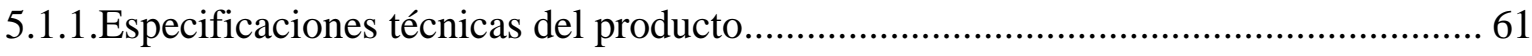




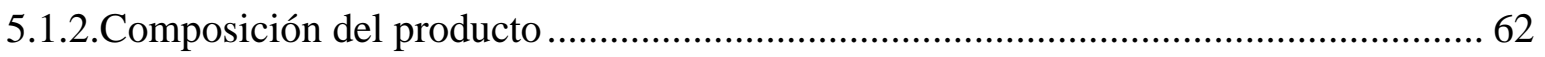

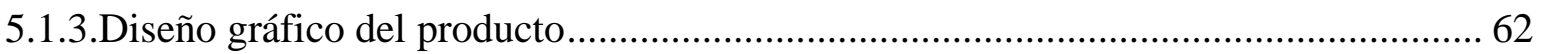

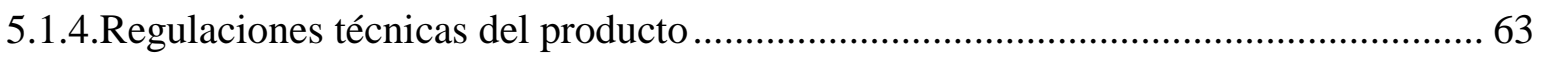

5.2.Tecnologías existentes y proceso de producción ............................................................. 64

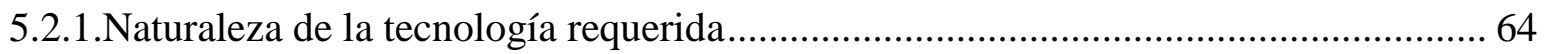

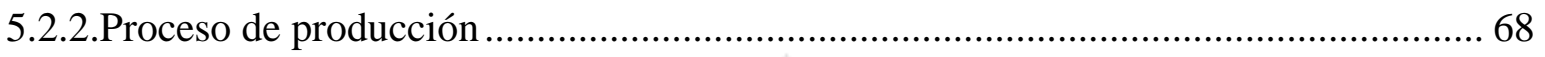

5.3.Características de las instalaciones y equipos............................................................... 73

5.3.1.Selección de la maquinaria y equipos........................................................................ 73

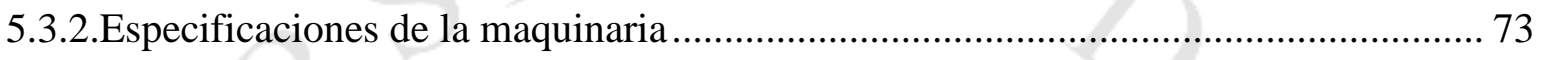

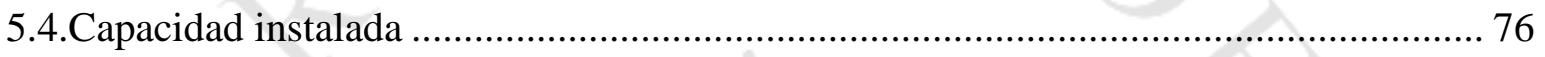

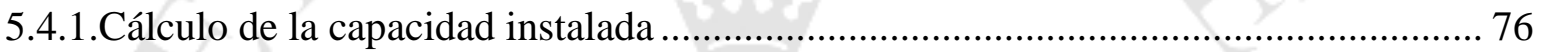

5.4.2.Cálculo detallado del número de máquinas requeridas ........................................... 79

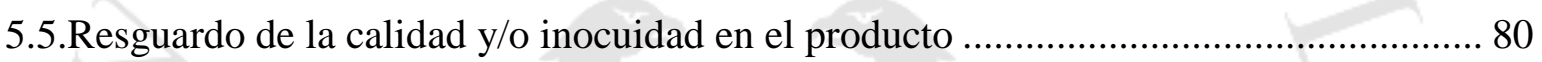

5.5.1.Calidad de la materia prima, de los insumos, del proceso y del producto................... 80

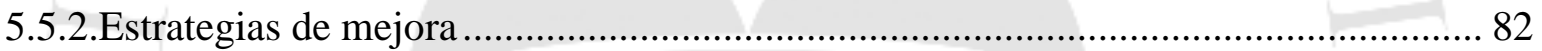

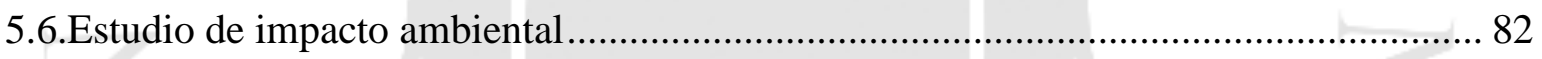

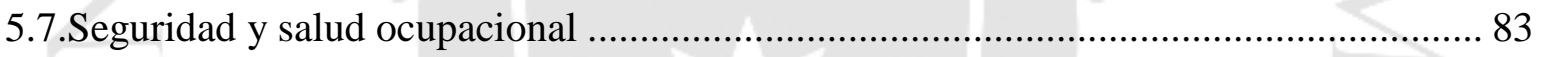

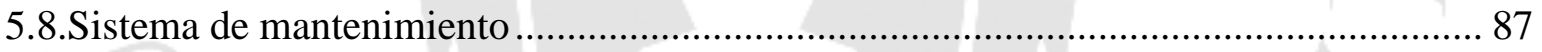

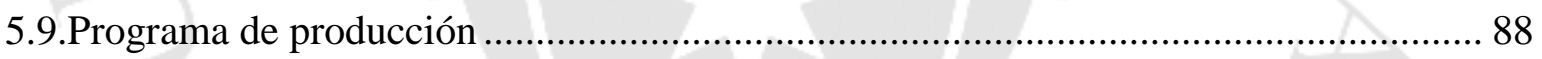

5.9.1.Factores para la programación de la producción .......................................................... 88

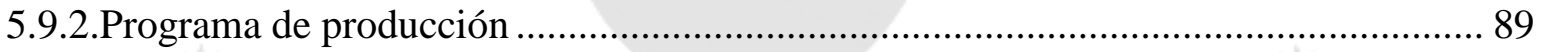

5.10.Requerimiento de insumos, servicios y personal...................................................... 90

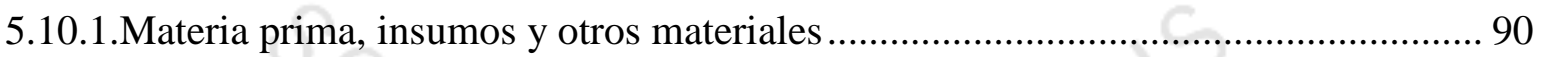

5.10.2.Servicios: Energía eléctrica, agua, vapor, combustible, etc....................................... 92

5.10.3.Determinación del número de operarios y trabajadores indirectos............................ 93

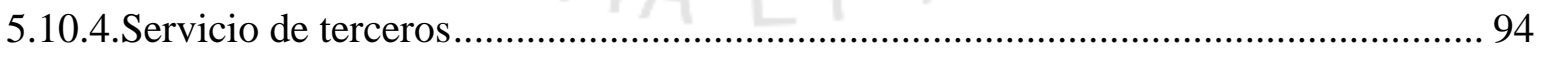

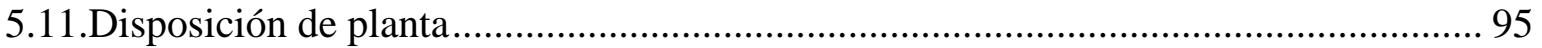

5.11.1.Características físicas del proyecto ....................................................................... 95

5.11.2.Determinación de las zonas físicas requeridas ....................................................... 99

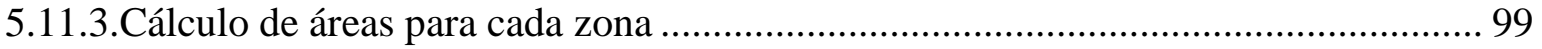

5.11.4.Dispositivos de seguridad industrial y señalización ................................................... 101 


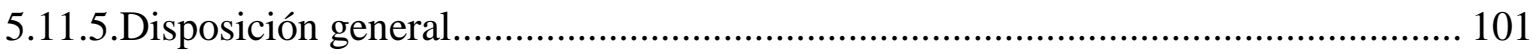

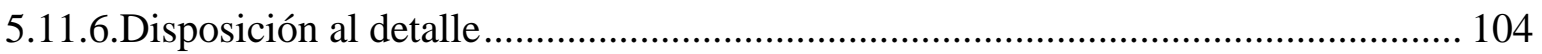

5.12.Cronograma de implementación del proyecto ...................................................... 105

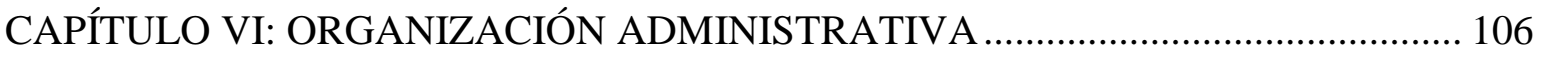

6.1.Formación de la Organización empresarial .................................................................. 106

6.2.Requerimientos de personal ............................................................................... 106

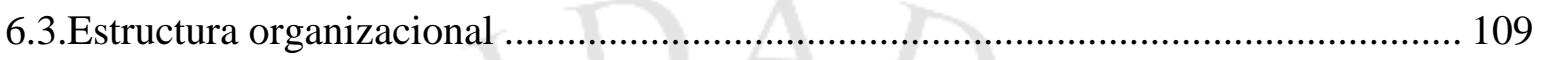

CAPÍTULO VII: ASPECTOS ECONÓMICOS Y FINANCIEROS ….............................. 110

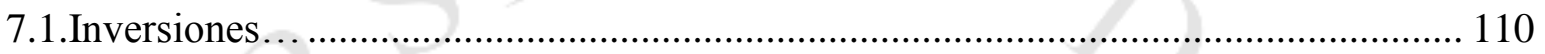

7.1.1.Estimación de las inversiones de largo plazo (tangibles e intangibles) ..................... 110

7.1.2.Estimación de los inversionistas de corto plazo (Capital de trabajo) ........................ 113

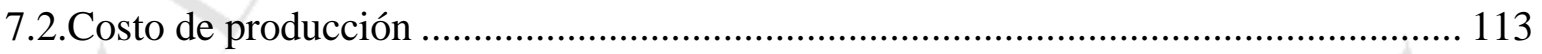

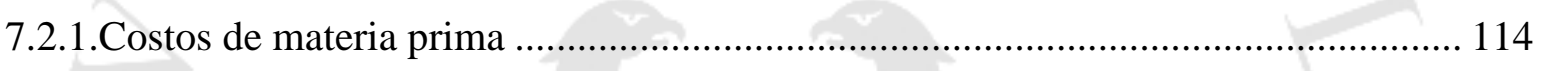

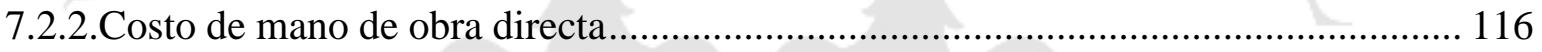

7.2.3. Costo indirecto de fabricación (materiales indirectos, mano de obra indirecta, y costos

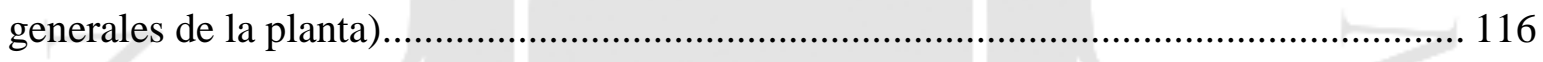

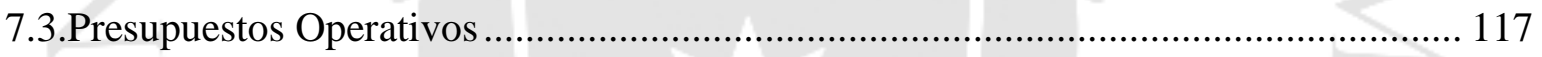

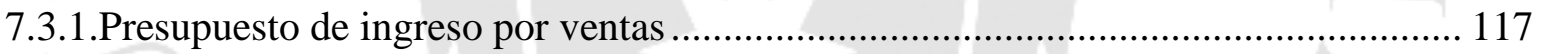

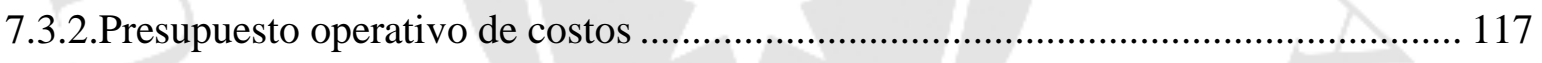

7.3.3.Presupuesto operativo de gastos ........................................................................ 119

7.4.Presupuestos financieros.................................................................................. 120

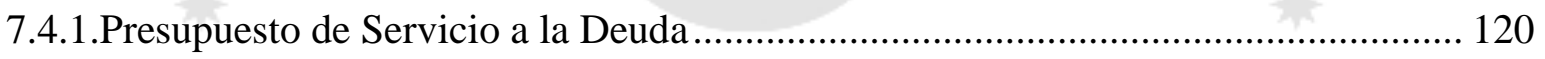

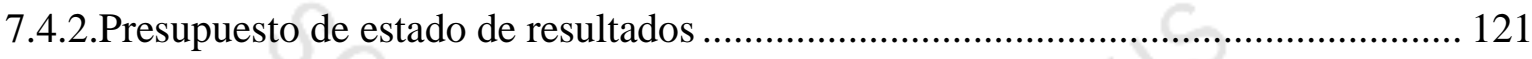

7.5.Flujo de fondos netos ....................................................................................... 122

7.5.1.Flujo de fondos económicos ...................................................................... 122

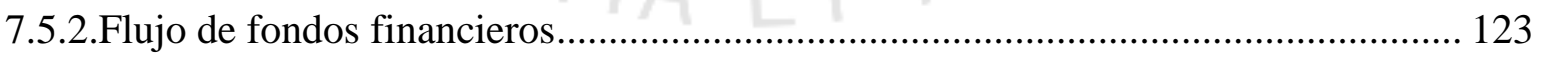

CAPÍTULO VIII: EVALUCIÓN ECÓNOMICA Y FINANCIERA DEL PROYECTO . 124

8.1.Evaluación económica: VAN, TIR, B/C, PR…………………………………....... 124

8.2.Evaluación financiera: VAN, TIR, B/C, PR …………………………………...... 124

8.3.Análisis de ratios (liquidez, solvencia, rentabilidad) e indicadores económicos y

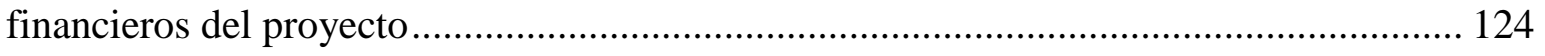


8.4.Análisis de sensibilidad del proyecto.................................................................. 125

CAPÍTULO IX: EVALUACIÓN SOCIAL DEL PROYECTO.................................... 127

9.1.Identificación de las zonas y comunidades de influencia del proyecto ...................... 127

9.2.Impacto en la zona de influencia del proyecto ..................................................... 127

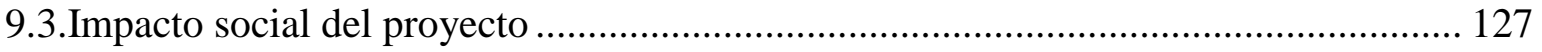

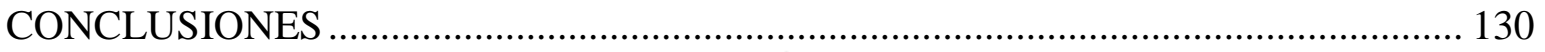

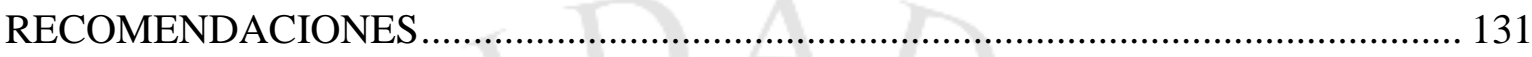

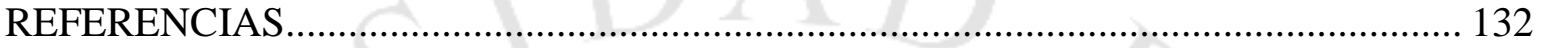

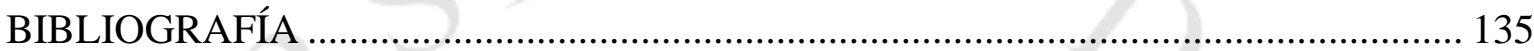

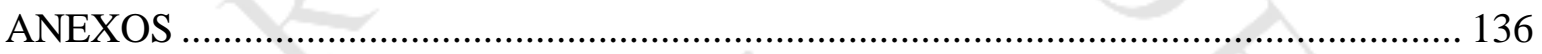




\section{ÍNDICE DE TABLAS}

Tabla 1. 1 Información tóxicológica de los componentes del betún comercial.................... 4

Tabla 2. 1 Distribución de personas por niveles socioeconómicos 2015 (\%) ................... 13

Tabla 2. 2 Consumo de betún por niveles socioeconómicos $2015(\%)$.............................. 13

Tabla 2. 3 Venta histórica de betún para calzado en el Perú (Miles de S/.) ...................... 16

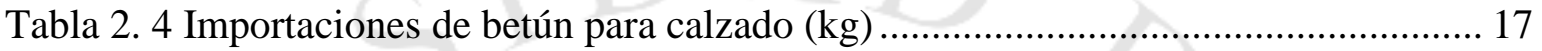

Tabla 2. 5 Exportaciones de betún para calzado $(\mathrm{kg})$................................................ 17

Tabla 2. 6 Producción nacional del betún para calzado $(\mathrm{kg})$.......................................... 18

Tabla 2. 7 Producción histórica nacional del betún para calzado $(\mathrm{kg})$.............................. 18

Tabla 2. 8 Demanda interna aparente del betún para calzado $(\mathrm{Kg})$................................ 19

Tabla 2. 9 Utilización semanal de calzado ................................................................ 22

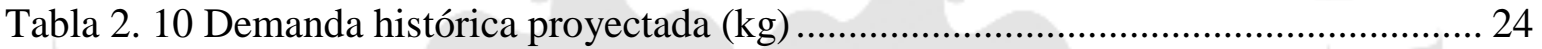

Tabla 2. 11 Participación de las empresas importadoras de betún para calzado (2015)..... 25

Tabla 2. 12 Participación de las empresas exportadoras de betún para calzado (2015) ...... 25

Tabla 2. 13 Sectores y sub sectores a considerar para el mercado meta........................... 28

Tabla 2. 14 Factores de selección del mercado meta....................................................... 29

Tabla 2. 15 Porcentajes de cada criterio de segmentación hasta el año 2023 .................... 30

Tabla 2. 16 Resultado de la encuesta: Grado de intención de compra de betún orgánico... 31

Tabla 2. 17 Demanda específica del proyecto ........................................................ 32

Tabla 2. 18 Consumo del servicio de internet $(\%)$........................................................ 34

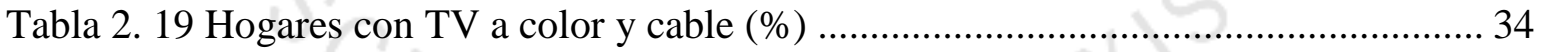

Tabla 2. 20 Precios actuales del betún para calzado (S/. / presentación) ........................... 36

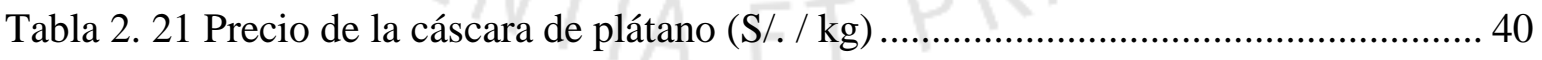

Tabla 3. 1 Distancia de las provincias en estudio hacia los proveedores ........................ 42

Tabla 3. 2 Distancia de las provincias hacia el mercado ........................................... 43

Tabla 3. 3 Población desocupada: Mano de obra por provincia ...................................... 43

Tabla 3. 4 Tarifa BT5B (no residencial) por zona (sin igv) ....................................... 44

Tabla 3. 5 Nivel de cobertura de las EPS (2014) ........................................................ 45

Tabla 3. 6 Estructura tarifaria para el suministro de agua potable ................................ 45 
Tabla 3. 7 Factores para el análisis de macro localización ........................................... 47

Tabla 3. 8 Matriz de enfrentamiento de los factores de macro localización ...................... 48

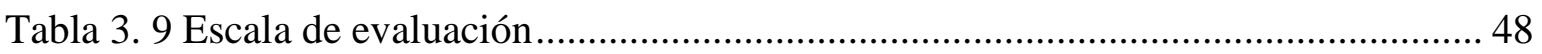

Tabla 3. 10 Matriz de evaluación de localidades de macro localización............................ 49

Tabla 3. 11 Factores para el análisis de la micro localización.......................................... 50

Tabla 3. 12 Precio de $\mathrm{m}^{2}$ de terreno por distrito ...................................................... 51

Tabla 3. 13 Cantidad de denuncias por delitos (2014) ................................................. 51

Tabla 3. 14 Matriz de enfrentamiento de factores ....................................................... 53

Tabla 3. 15 Matriz de localidades de micro localización ................................................ 53

Tabla 4. 1 Demanda del mercado en unidades de producto final ................................... 55

Tabla 4. 2 Consumo de plátano y banano equivalente en cáscara 2012 (miles de toneladas)

Tabla 4. 3 Cantidad de cáscara a utilizar en el último año del proyecto ........................... 56

Tabla 4. 4 Tiempo estándar de producción................................................................... 57

Tabla 4. 5 Tamaño de planta por tecnología...................................................................... 57

Tabla 4. 6 Inversión total para la implementación del proyecto ..................................... 58

Tabla 4. 7 Costos variables unitarios considerados por cada envase de $50 \mathrm{gr}$................... 59

Tabla 4. 8 Costos fijos anuales considerados $(\mathrm{S} / \mathrm{)}$...................................................... 59

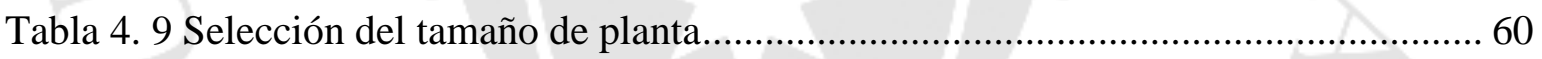

Tabla 5. 1 Composición del betún ecológico por envase de 50gr .................................... 62

Tabla 5. 2 Selección de la tecnología por etapa del proceso …...................................... 68

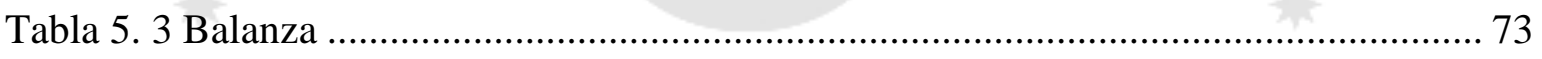

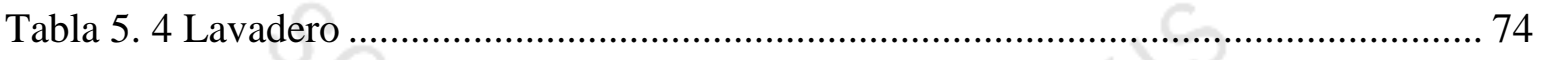

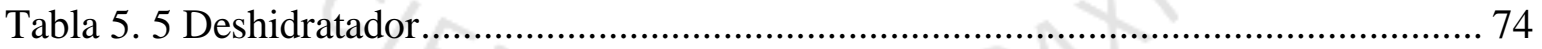

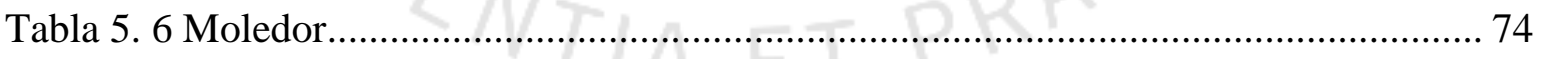

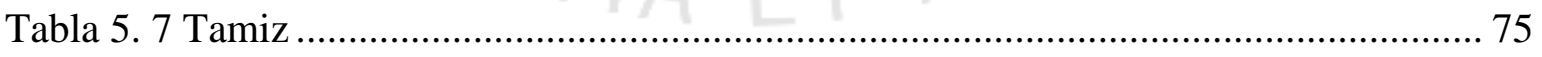

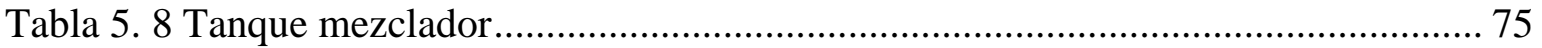

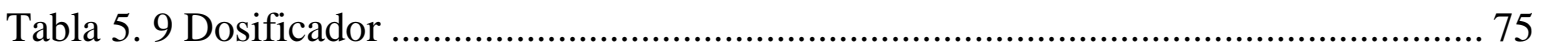

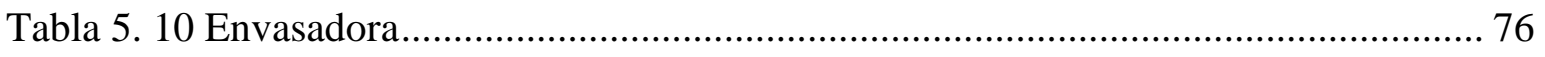

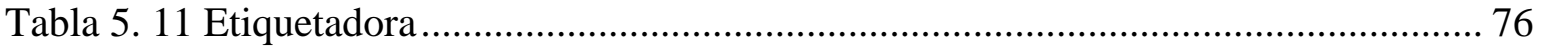

Tabla 5. 12 Cálculo del factor de utilización .............................................................. 77 
Tabla 5. 13 Cálculo de la capacidad de planta con balance de materia ............................ 78

Tabla 5. 14 Cálculo del número de máquinas requeridas ............................................. 79

Tabla 5. 15 Número de máquinas y equipos adicionales.............................................. 80

Tabla 5. 16 Características de calidad ..................................................................... 81

Tabla 5. 17 Aspectos e impactos ambientales ......................................................... 83

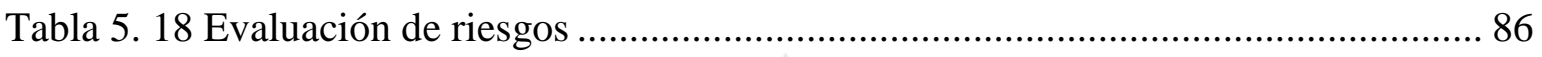

Tabla 5. 19 Cronograma de mantenimiento preventivo de equipos ................................ 87

Tabla 5. 20 Cronograma de mantenimiento preventivo de máquinas ............................. 88

Tabla 5. 21 Porcentaje de utilización de planta ........................................................... 89

Tabla 5. 22 Programación de producción .................................................................... 90

Tabla 5. 23 Requerimiento de materia prima, insumos y otros materiales durante los 6 años

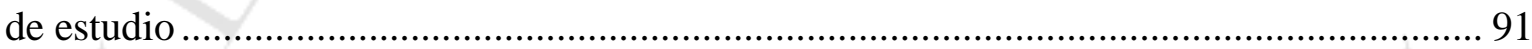

Tabla 5. 24 Requerimiento de agua durante el primer año de estudio $\left(\mathrm{m}^{3}\right)$..................... 92

Tabla 5. 25 Consumo de energía eléctrica durante el año 2017 (kWh)........................... 93

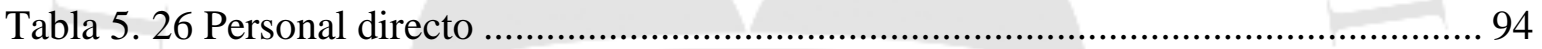

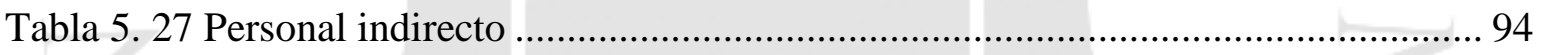

Tabla 5. $28 \mathrm{~N}^{\mathrm{o}}$ pallets requeridos para almacenaje de cáscara de plátano ........................ 97

Tabla 5. $29 \mathrm{~N}^{\mathrm{o}}$ pallets requeridos para almacenaje de insumos ..................................... 98

Tabla 5. 30 Análisis de Guerchet para elementos estáticos ......................................... 100

Tabla 5. 31 Análisis de Guerchet para elementos móviles ............................................. 100

Tabla 5. 32 Cálculo del coeficiente de evolución $(\mathrm{k})$.................................................... 100

Tabla 5. 33 Escala de valores................................................................................... 102

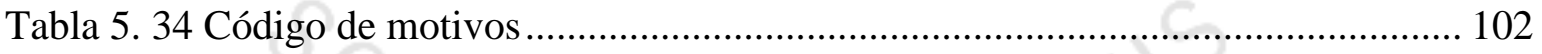

Tabla 7. 1 Inversión total de la compra e instalación de equipos y maquinaria ................ 110

Tabla 7. 2 Inversión por compra de terreno y edificación: Terreno $500 \mathrm{~m}^{2} \ldots \ldots \ldots \ldots \ldots \ldots \ldots . \ldots \ldots 11$

Tabla 7. 3 Inversión por compra de muebles y equipos de oficina ............................... 111

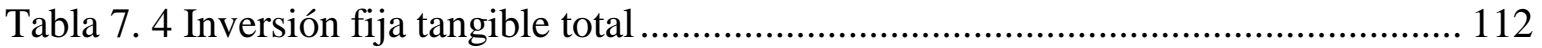

Tabla 7. 5 Costo fijo intangible ....................................................................... 113

Tabla 7. 6 Costo unitario de insumos y materia prima (S/.) ...................................... 114

Tabla 7.7 Costo total anual de insumos y materia prima (S/.) ................................... 115

Tabla 7. 8 Costo de venta unitario .......................................................................... 116 
Tabla 7.9 Presupuesto anual de mano de obra directa ............................................. 116

Tabla 7. 10 Presupuesto anual de mano de obra indirecta......................................... 117

Tabla 7. 11 Presupuesto de ingresos por ventas ....................................................... 117

Tabla 7. 12 Presupuesto de depreciación .................................................................. 118

Tabla 7. 13 Presupuesto operativo de costos ......................................................... 118

Tabla 7. 14 Presupuesto de amortización ................................................................... 119

Tabla 7. 15 Presupuesto operativo de gastos administrativos ...................................... 120

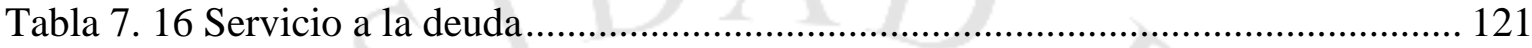

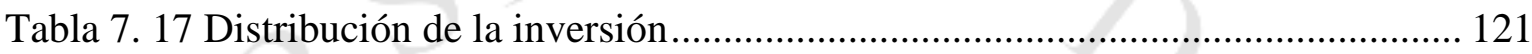

Tabla 7. 18 Estado de Ganancias y Pérdidas ............................................................ 122

Tabla 7.19 Flujo de fondos Económicos ................................................................. 122

Tabla 7. 20 Flujo de fondos financieros ..................................................................... 123

Tabla 8. 1 Evaluación económica: VAN, TIR, B/C, PR ............................................ 124

Tabla 8. 2 Evaluación financiera: VAN, TIR, B/C, PR .............................................. 124

Tabla 8. 3 Análisis de sensibilidad por variación de precios ......................................... 126

Tabla 8. 4 Análisis de sensibilidad por variación de costo unitario de venta ................... 126

Tabla 8. 5 Análisis de sensibilidad por variación de costo unitario de venta .................. 126

Tabla 9. 1 Valor agregado del proyecto.................................................................. 128

Tabla 9. 2 Intensidad de capital ........................................................................ 128

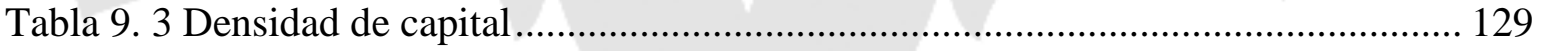

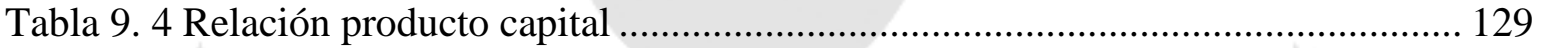




\section{ÍNDICE DE FIGURAS}

Figura 1. 1 Resultado de la encuesta: Incidencias con betún tradicional .......................... 5

Figura 2. 1 Tendencia de la Demanda Interna Aparente $(\mathrm{Kg})$........................................ 19

Figura 2.2 Resultado de la encuesta: ¿Utiliza calzado que requiera betún para ser limpiado? 21

Figura 2. 3 Resultado de la encuesta: ¿En promedio, cuantas veces a la semana usa este tipo de calzado? 21

Figura 2. 4 Resultado de la encuesta: ¿Cada cuánto tiempo limpia este tipo de calzado? .. 22 Figura 2. 5 Principales presentaciones del betún marca Kiwi ......................................... 26

Figura 2. 6 Principales presentaciones de betún marca Sapolio ...................................... 26

Figura 2. 7 Principales presentaciones del betún marca Nugget .................................. 27

Figura 2. 8 Participación de venta de betún por marcas (Perú 2015) ............................... 27

Figura 2.9 Resultado de la encuesta: ¿Limpiaría su calzado con un betún ecológico a base

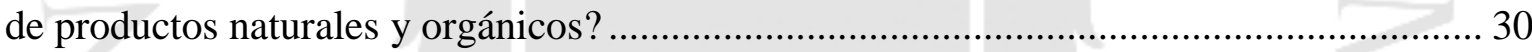

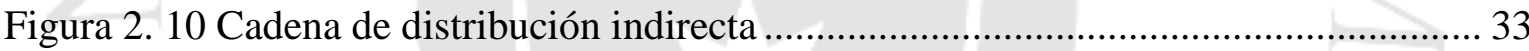

Figura 2. 11 Precios históricos de importaciones y exportaciones (US\$ / kg) .................. 35

Figura 2. 12 Ejemplo de plátano y banano respectivamente .......................................... 37

Figura 2. 13 Producción nacional del banano (miles de toneladas)................................... 38

Figura 2. 14 Producción nacional del plátano (miles de toneladas) ................................... 38

Figura 2. 15 Consumo nacional del banano (miles de toneladas) .................................... 39

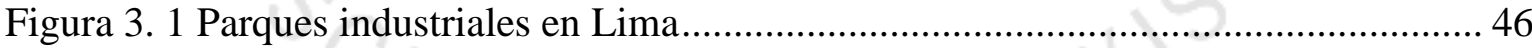

Figura 3. 2 Distritos en estudio para la localización de planta: Los Olivos, Ate y Villa

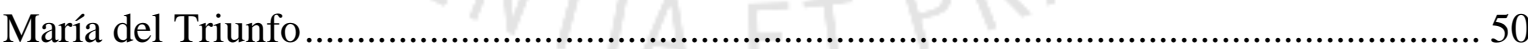

Figura 3. 3 Oferta existente de propiedades industriales (2011) ................................... 52

Figura 4. 1 Resultado de la encuesta: ¿Qué tamaño de betún para calzado consume con

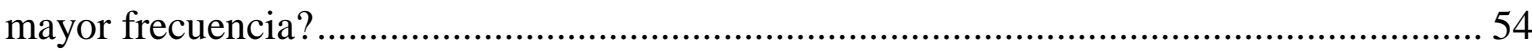

Figura 5. 1 Diseño del envase del betún ecológico de 50gr. ......................................... 63

Figura 5. 2 Diagrama de operaciones del proceso de producción de betún ecológico a base

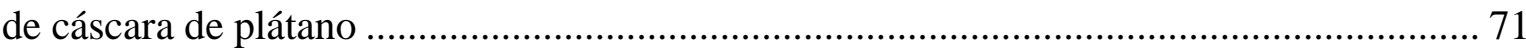


Figura 5. 3 Diagrama de bloques para la producción de betún ecológico a base de cáscara de plátano 72

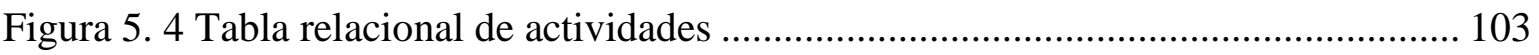

Figura 5. 5 Diagrama relacional de actividades............................................................... 103

Figura 5. 6 Disposición al detalle $\left(500 \mathrm{~m}^{2}\right)$................................................................... 104

Figura 5. 7 Cronograma de implementación del proyecto............................................... 105

Figura 6. 1 Organigrama de la empresa ...................................................................... 109

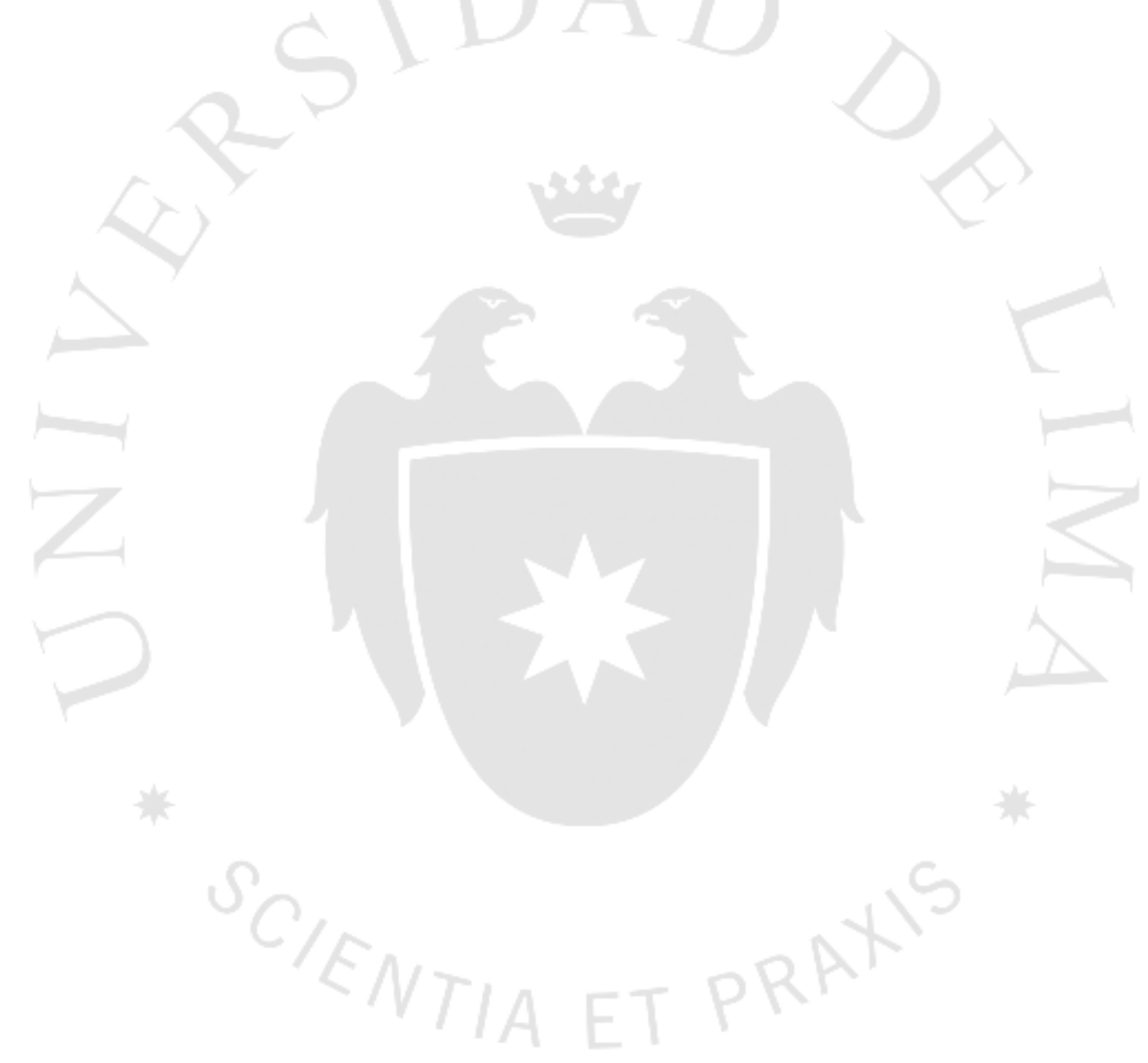




\section{ÍNDICE DE ANEXOS}

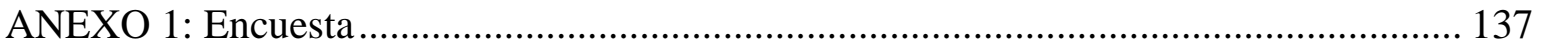

ANEXO 2: Pruebas experimentales de laboratorio .................................................... 139

ANEXO 3: Población anual de Lima y Perú ................................................................ 143

ANEXO 4: Producción per cápita de betún para calzado.............................................. 144

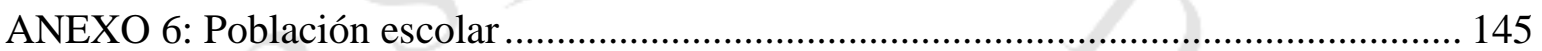




\section{RESUMEN EJECUTIVO}

El presente trabajo de investigación comprende nueve capítulos en los que se desarrollan y analizan las diversas herramientas estudiadas a lo largo de la carrera.

El capítulo uno comprende los aspectos generales del proyecto en estudio, la problemática actual, los objetivos de la investigación, la hipótesis y el análisis del sector.

En el capítulo dos se definen las principales características del producto; además, se realiza el estudio de mercado con el objetivo de determinar el área geográfica que abarcará el proyecto, así como la demanda del producto desde el primer año hasta el último de estudio.

En el capítulo tres se determina la ubicación de planta aplicando el método "Ranking de factores", donde se analizan cada uno de los factores que influyen en la determinación de la ciudad y distrito en el que se ubicará la planta.

En el capítulo cuatro se analizan las relaciones tamaño de mercado, materia prima, tecnología y punto de equilibrio con el fin de determinar el tamaño de planta adecuado para el proyecto.

En el capítulo cinco se presenta el proceso de producción; además, se realiza el cálculo de requerimiento de mano de obra, insumos, servicios y maquinaria en base a su capacidad y utilización; también, se analizan las medidas de resguardo de la calidad en la producción y se realiza el estudio de impacto en cada una de las etapas de operación; finalmente se realiza la disposición de planta y la distribución de señalización.

En el capítulo seis se define el organigrama de la empresa y se establecen las funciones de cada puesto.

En los capítulos siete y ocho se realiza el análisis económico y financiero donde se muestra el presupuesto de ingresos por ventas, el presupuesto operativo de costos de materia prima y gastos administrativos, así como el flujo de fondos netos. 
En estos capítulos, también se muestra el resultado del estudio mediante los indicadores que nos permiten determinar la viabilidad del proyecto: VAN, TIRE, B/C y periodo de recupero.

En el último capítulo del estudio, se desarrollan indicadores económicos que nos permiten cuantificar la inversión desde una perspectiva social.

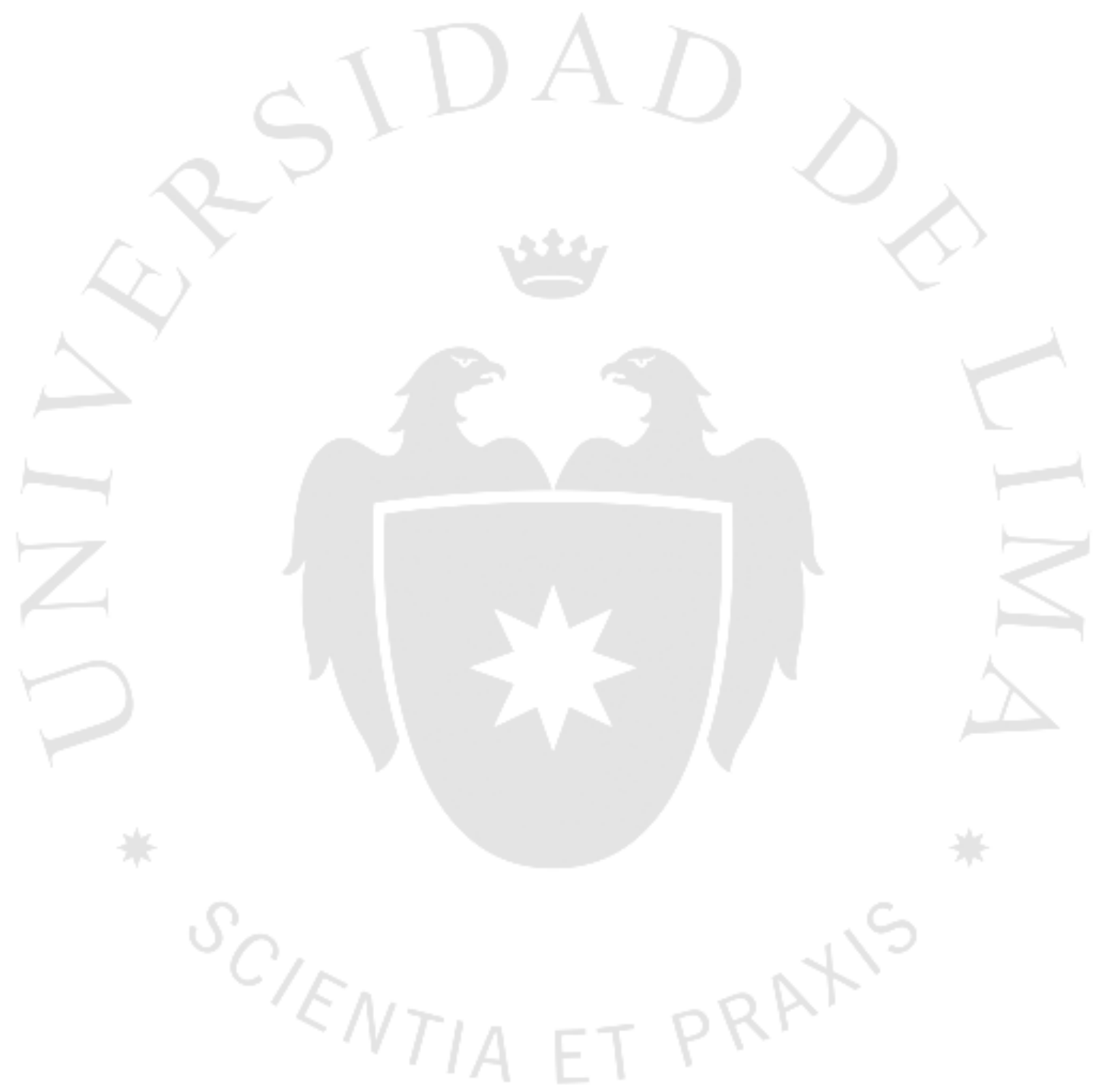




\section{SUMMARY}

The present research study contains nine chapters in which it develops and analyzes the diversity of tools studied in the industrial engineering career.

Chapter one presents the general aspects of this project, current problematic, the investigation goals, hypothesis and the sector's analysis.

Chapter two describes the main characteristics of the product and the market research in order to decide the geographic area of this project and the demand of the product since the first year until the last one of this study.

Chapter three contains the study of plant location using the method of ranking factors in which we can analyze all of the factors that influence in the choice of the city and district in where the factory will be located.

Chapter four shows the analysis of the relationship of market size, productive resources, technology and the point of balance in order to decide the adequate size in this project.

In the chapter five is presented the production process and is calculated the main requirements or raw materials, supplies, labor and service. In addition, in this chapter are analyzed quality measures and the impact in each of the stages of the production process. Finally, it shows the factory layout and the signal distribution.

Chapter six contains the organization chart of the company and the functions of each work position.

In chapters seven and eight are presented the economic and financial analysis where we can see the sales and costs budget and the net cash flow. This chapter also shows the result of the study through indicators that let us to know if the project would be profitable.

The last chapter of this study shows some economic indicators that let us quantify the investment from a social perspective. 


\section{CAPÍTULO I: ASPECTOS GENERALES}

\subsection{Problemática}

Las personas que utilizan calzado de cuero, cuerina o similares son los alumnos de colegios, trabajadores de oficina, trabajadores independientes como vigilantes y mozos; trabajadores del Estado tales como policías y militares, trabajadores relacionados con el gobierno como ministros y congresistas; además, médicos, abogados, profesores y demás profesionales que usan ropa de vestir o uniforme y buscan mejorar su apariencia personal. Además, el uso de este tipo de calzado en las mujeres incrementa en invierno con la tendencia de uso de botas y botines.

La búsqueda de la limpieza, el cuidado y la buena apariencia personal exige el uso de productos de limpieza y conservación para el calzado, que además le brinden suavidad, elasticidad y brillo. La piel del calzado mal cuidado acaba secándose, quebrándose y resquebrajándose, y tiene una vida relativamente corta dependiendo del uso que se le dé. El producto comercial mayormente utilizado a través de los años para dar lustre, impermeabilizar, mejorar la apariencia y aumentar la vida útil del calzado es el betún; sin embargo, es un producto tóxico que se consume y seca en presencia del aire por la naturaleza volátil de alguno de sus componentes, lo cual hace que disminuya su vida útil.

En la tabla 1.1 se muestran los principales insumos del betún comercial y sus efectos secundarios.

Tabla 1.1

Información toxicológica de los componentes del betún comercial

\begin{tabular}{|c|ll|}
\hline Insumo & & \multicolumn{1}{c|}{ Efectos secundarios } \\
\hline & $\bullet$ & Puede ser nocivo por inhalación, ingestión o absorción a través de la piel. \\
& $\bullet$ & Puede causar irritación en ojos y piel. \\
& $\bullet$ & Por exposición prolongada puede producir irritación en los pulmones \\
\hline Cera de carnauba & $\bullet$ & Puede producir irritación y sensibilidad en la piel \\
\hline Trementina & $\bullet$ & Líquido inflamable. \\
\hline Vaselina & $\bullet$ & En caso de aspiración, puede provocar neumonía lipoidea \\
\hline
\end{tabular}

Fuente: ACOFARMA, (2010, 2012, 2014)

Elaboración propia 
Como observamos en la tabla anterior, los compuestos del betún son tóxicos, su uso incorrecto puede afectar la piel o mancharla y en contacto con los ojos causar irritación.

En una encuesta realizada a 200 personas, se preguntó si alguna vez habían sufrido alguna incidencia con el betún para calzado que utilizaban. El resultado se muestra en la figura 1.1.

Figura 1.1

Resultado de la encuesta: Incidencias con betún tradicional

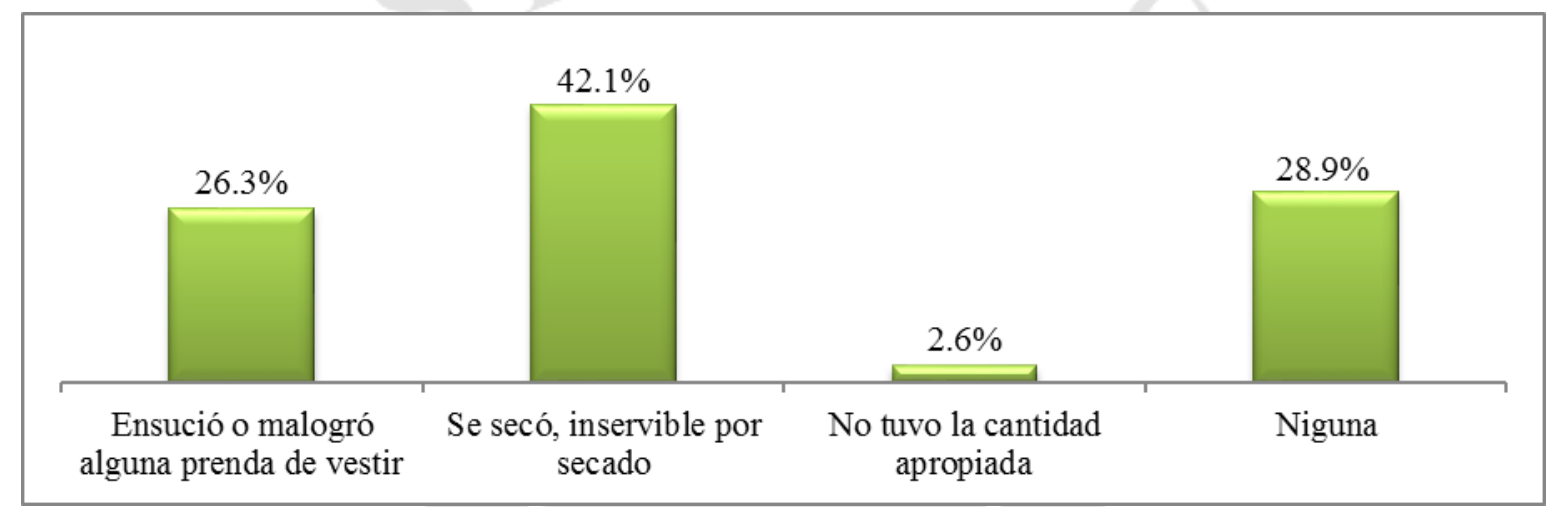

Elaboración propia

\subsection{Objetivos de la investigación}

\subsubsection{Objetivo general}

Determinar la viabilidad, tecnológica, económica, ambiental y social para la instalación de una planta productora de betún ecológico a base de cáscara de plátano.

\subsubsection{Objetivos específicos}

- Realizar un estudio del consumo de betún para calzado elaborado a base de cáscara de plátano.

- Determinar el mercado al cual estará dirigido el producto y estimar la demanda que será cubierta por la producción.

- Determinar la viabilidad tecnológica, evaluando la maquinaria y el proceso de producción. 
- Determinar si el proyecto es económica y financieramente viable analizando los costos fijos, variables, directos e indirectos para la instalación de la planta.

\subsection{Alcance y limitaciones de la investigación}

El alcance de este proyecto es evaluar la factibilidad técnica y financiera de una planta procesadora de betún ecológico para calzado a base de cáscara de "musa paradisiaca", nombre científico del plátano. El proceso empieza con la recolección de la cáscara de plátano, para lo cual contaremos con el apoyo de los productores de harinas y otros productos elaborados a base de plátano, hasta la obtención del betún ecológico. El estudio de pre factibilidad desarrollado comprende las siguientes etapas: Estudio de mercado, estudio técnico y evaluación financiera.

Como limitaciones tenemos que el presente proyecto en estudio se llevará a cabo en Lima por ser la ciudad con mayor densidad en los sectores de manufactura y servicios, además la tendencia de la población limeña y el mercado es creciente. Por otro lado, la recolección de materia prima se llevará a cabo básicamente en la costa norte y selva del país, ya que es donde se encuentra la mayor producción y consumo de plátano.

\subsection{Justificación del tema}

\section{- Justificación técnica}

La implementación de una planta productora de betún ecológico a base de cáscara de plátano es tecnológicamente factible, ya que la maquinaria y técnicas necesarias para producirlo existen y están al alcance del mercado peruano.

La materia prima principal de este producto es la cáscara del plátano, la cual posee ceras epicuticulares que repele la humedad y crea una propiedad de auto limpieza. Gracias a estas ceras se puede elaborar un producto que puede ser untado directamente al cuero dándole brillo y una resistencia al agrietamiento, así como excelentes cualidades de penetración.

La obtención de cáscara de plátano comprende la recolección en lugares estratégicos como las plantas o zonas productoras de harina, dulces, jugos, puré, 
hojuelas fritas (chifles) y otros productos elaborados a base de pulpa de plátano; ya que en estos lugares se deposita gran cantidad de cáscara. Las principales máquinas requeridas para la implementación de la planta son: Deshidratador, molino y tanque mezclador.

\section{- Justificación económica}

En el presente proyecto, el costo de la materia prima principal (cáscara de plátano) es aproximadamente $\mathrm{S} / .0 .35$ por $\mathrm{kg}$, considerando que por cada producto terminado se requiriere de $0.081 \mathrm{~kg}$ de cáscara, el costo de este insumo será de S/.0.03 por cada unidad de producto terminado; tomando en cuenta este costo y el de los otros insumos, cada betún de $50 \mathrm{~g}$ tendrá un costo de $\mathrm{S} / .1 .10$ y el precio de venta que se le asignará será S/. 2.00.

Al realizar el presente proyecto se espera que sea rentable; para lo cual se debe obtener un VAN positivo y una TIR mayor al costo de capital.

\section{- Justificación social}

La instalación de una planta de betún ecológico a base de cáscara de plátano generará nuevos puestos de trabajo en las zonas donde va a ser ubicada la planta y distribuido el producto final, considerando que se requieren personas trabajadoras tanto para el área de producción como para el área administrativa; además, se generará un nuevo mercado en las localidades en las que se produce y consume gran cantidad de plátano, adquiriendo un producto al que actualmente no le dan valor.

En relación al impacto ambiental, el producto en estudio es orgánico y sostenible con el cuidado del medio ambiente.

\subsection{Hipótesis del trabajo}

La instalación de una planta productora de betún ecológico elaborado a base de cáscara de plátano es factible debido a que existe un mercado en crecimiento el cual aceptará el producto y además es tecnológica, ambiental, social, económica y financieramente viable. 


\subsection{Marco referencial de la investigación}

El material de apoyo que se empleará para el presente trabajo son investigaciones previas que están relacionadas con el producto, tales como:

- Jiménez, Yeins - 2013 "Informe sobre la empresa Intradevco S.A - Betún para calzado Sapolio"

La similitud con el estudio mencionado es que es un producto de limpieza para calzado que protege al cuero contra los elementos naturales como polvo, agua y calor; evitando que éste se reseque y cuartee.

En cuanto a las diferencias, los insumos utilizados en el estudio mencionado son parafina, cera de carnauba, trementina y otras sustancias contaminantes.

- Abad Díaz, Javier Enrique - 2007 "Estudio de prefactibilidad para la obtención de betún a partir de la cáscara de plátano". Trabajo de investigación de la Facultad de Ingeniería Química de la Universidad Nacional de Ingeniería

La similitud con el estudio es que el principal insumo es la cáscara de plátano y el producto final obtenido es utilizado para limpiar, dar resistencia y brillo al calzado.

En cuanto a las diferencias, otros de los insumos utilizados en la investigación nombrada son trementina (aguarrás) y colorantes químicos que lo convierten en un producto tóxico y no ecológico.

- Rojas Manayalle, Mariela - Ruestas Gonzales, Paula - Armijos Mendoza, José 2011 "Producción y elaboración de Betún Ecológico en la planta industrial USS Departamento de Lambayeque:

Las similitudes con el estudio es que se elabora un producto ecológico de calidad a base de cáscara de plátano que no daña el medio ambiente considerando las buenas prácticas de manufactura, higiene, seguridad industrial, etc.

La diferencia es que el mercado al que estamos dirigidos es Lima metropolitana, mientras que en el estudio mencionado es el departamento de Lambayeque. 
- Silva Bertolotti, Jorge Alberto - Maruy Saito, Bruno - 2014 "Estudio de prefactibilidad para implementar una fábrica de crema de calzado con envase giratorio" Trabajo de investigación de la Facultad de Ingeniería Industrial de la Universidad de Lima

La similitud con el estudio elaborado es que el producto final limpia, da brillo y mejorar la calidad del calzado, además el envase en el que será entregado al cliente final es de plástico. La diferencia radica en que el producto del trabajo mencionado no es ecológico.

\subsection{Marco conceptual}

- Plátano: Fruta tropical que contiene vitaminas que brindan energía, tiene mayor contenido de fécula que los bananos, se debe consumir cocida; además, contiene un promedio de 65\% de humedad (Ministerio de Agricultura y Riego, 2014).

- Banano: Fruta tropical para consumo como postre por su sabor dulce, tiene un contenido de humedad de 74\% (Ministerio de Agricultura y Riego, 2014).

- Betún para calzado: El betún para calzado es un producto comercial utilizado para mejorar la apariencia del calzado, darle brillo e incrementar su vida útil; sus presentaciones pueden ser en pasta o líquido.

- Trementina: Conocido también como aguarrás; líquido volátil e incoloro que se usa como disolvente de pinturas o para la fabricación de aromáticos y desinfectantes.

- Petróleo: Mezcla de compuestos orgánicos que se produce en el interior de la tierra por transformación de la materia orgánica acumulada en sedimentos del pasado. Se extrae mediante la perforación de pozos. 
- Materia orgánica: Materia compuesta por compuestos orgánicos que provienen de organismos que alguna vez estuvieron vivos, tales como plantas y animales.

- Pigmento: Material con propiedades ideales para colorear otros materiales. Son utilizados para teñir pintura, tinta, plásticos, cosméticos, alimentos y otros productos.

- Producto ecológico: También se les conoce como productos biológicos y orgánicos. Son aquellos productos naturales obtenidos sin la utilización de elementos químicos.

- Cera: Son esteres de ácidos grasos con alcoholes, de peso molecular elevado; se mantienen en estado sólido, puede ser de color blanco o amarillo, así como de origen animal o vegetal. Es insoluble en el agua.

- Aceite: Líquido graso que no se disuelve en el agua, existen aceites combustibles provenientes del petróleo (aceites minerales) y comestibles provenientes de los animales o vegetales.

- Plástico reciclado: Plástico elaborado con residuos de plástico desechado.

- Borato de Sodio: Cristales blancos y suaves que se disuelven fácilmente en el agua, se utiliza como neutralizante para formulaciones de uso cosmético y regula el ph de la sustancia.

- Benzoato de Sodio: Sal blanca, cristalina y gelatinosa soluble en agua y alcohol. Su uso principal es como conservante de alimentos.

- Glicerina: Compuesto viscoso que se obtiene a partir de los vegetales, es uno de los principales productos de la degradación de los lípidos y su principal uso es en la industria cosmética. 


\section{CAPÍTULO II: ESTUDIO DE MERCADO}

\subsection{Aspectos generales del estudio de mercado}

\subsubsection{Definición comercial del producto}

El producto propuesto para el estudio es un betún para calzado elaborado a partir de cáscara de plátano. Con este producto ecológico se busca aminorar el nivel de contaminación al que estamos expuestos y utilizar insumos que actualmente no tienen gran participación en el mercado.

Este producto brinda al calzado resistencia, insolubilidad e impenetrabilidad de humedad gracias a la formación de una capa protectora que al ser frotada le da lustrosidad y brillo.

La apariencia física del producto final es sólida y de color negro o marrón dependiendo del color del colorante, además su contenedor o envase estará elaborado a base de plástico reciclado. Según los niveles del producto tenemos:

- Beneficio Principal: El beneficio principal que cubre el producto en estudio es dar lustre, impermeabilizar, mejorar la apariencia y aumentar la vida útil del calzado de cuero o similares.

- Producto Real: La presentación del producto en estudio será en envase de plástico reciclado de $50 \mathrm{gr}$ con tapa rosca y etiquetado con el logo de nuestro producto, el cual debe señalar que además de ser un producto para la limpieza y cuidado del calzado, es ecológico.

- Producto Aumentado: En la parte inferior del envase se mostrará al detalle la información y composición del producto, así como las instrucciones de uso y los cuidados que se debe tener, además, se facilitará una línea telefónica y un email al cual el cliente podrá acceder para hacer llegar dudas, reclamos y sugerencias. 


\subsubsection{Principales características del producto}

\subsubsection{Usos y características del producto}

Por sus propiedades físicas y químicas, la cera es la materia prima esencial en la elaboración de betunes para calzado. En esta aplicación, la cera tiene dos funciones primordiales: Conservar en buen estado y brindar limpieza y brillo al cuero de calzado.

El betún ecológico en estudio tiene propiedades importantes que permiten, al igual que los betunes que actualmente se comercializan, dar brillo y resistencia al calzado; además, cuenta con una apariencia atractiva, resistencia al almacenamiento en condiciones ambientales y está elaborado con insumos que no dañan el medio ambiente.

\subsubsection{Bienes sustitutos y complementarios}

Como productos sustitutos, se consideran todos los tipos de betún utilizados para el cuidado del calzado, ya sean en líquido, en pasta, tinta para calzado o esponja auto brillante para calzado.

Como productos complementarios consideramos las escobillas o cepillos aplicadores de betún, escobillas de crin de cabello para sacar brillo y franelas.

\subsubsection{Determinación del área geográfica que abarcará el estudio}

El producto en estudio se fabricará, comercializará y distribuirá inicialmente dentro de la capital, debido a que es donde se encuentra la mayor población en edad de trabajar y estudiar; considerando los datos de INEI, en el 2015 se concentró en Lima el $31.6 \%$ de la población total del Perú (INEI, 2016).

Dentro de la ciudad de Lima, se considerarán los niveles socioeconómicos con mayor población; los cuales se muestran en la tabla 2.1. 
Tabla 2. 1

Distribución de personas por niveles socioeconómicos 2015 (\%)

\begin{tabular}{|c|c|}
\hline NSE & Distribución \\
\hline A & 4.7 \\
\hline B & 19.7 \\
\hline C & 42.0 \\
\hline D & 25.5 \\
\hline E & 8.1 \\
\hline
\end{tabular}

Fuente: APEIM, (2015)

Además, en la tabla 2.2 se observa el porcentaje de consumo de betún por cada nivel socioeconómico tomando como base el total de consumo de betún en Lima Metropolitana.

Tabla 2. 2

Consumo de betún por niveles socioeconómicos 2015 (\%)

\begin{tabular}{|c|c|}
\hline NSE & Consumo \\
\hline A & 18.6 \\
\hline B & 19.2 \\
\hline C & 19.7 \\
\hline D & 22.5 \\
\hline E & 19.9 \\
\hline
\end{tabular}

Nota: Total de amas de casa entrevistadas (644).

Fuente: Ipsos Apoyo, (2015)

En base a la información mostrada, se determina que el área geográfica que abarcará el presente estudio será los niveles socioeconómicos B, C y D de Lima Metropolitana, ya que es donde se concentra la mayor población y son los NSE con mayor $\%$ de consumo de betún para calzado.

\subsubsection{Análisis del sector}

- Amenaza de ingreso de nuevos participantes: Actualmente existen campañas ambientales y se incrementa el consumo de productos que contribuyen al cuidado del medio ambiente debido a la proliferación de residuos tóxicos. 
En el mercado aún no existe el producto en estudio; sin embargo, debido al notable crecimiento del uso de calzado de cuero, la tendencia de limpieza y cuidado personal, y a las facilidades de financiamiento para la constitución de una empresa, el ingreso de nuevas empresas afines podrá darse sin complicaciones, por ello se concluye que la amenaza de nuevos participantes es alta.

- Intensidad de la rivalidad de los competidores: El mercado nacional de betún se encuentra abastecido en su mayoría por la empresa INTRADEVCO, con las marcas "Kiwi" y "Sapolio", las cuales tienen una participación de 55\% en el mercado peruano (Intradevco Industrial S.A). Las estrategias de posicionamiento adoptadas por dicha empresa son la peruanidad, calidad, mejor precio y la constante innovación. Además, INTRADEVCO es una empresa respetuosa con el medio ambiente; muchos de sus productos son biodegradables; sin embargo, la empresa señalada no fabrica productos a base de material orgánico.

Para realizar un análisis más profundo se toma en cuenta los siguientes factores de acuerdo a la empresa INTRADEVCO:

Cobertura: El betún que comercializa tiene una cobertura en todos los rincones de Lima y Callao e incluso a nivel nacional, encontrándose en cualquier bodega, mercado y autoservicio e incluso es vendido por ambulantes.

Precios: Son de bajo precio, se encuentran en distintos tamaños según el poder adquisitivo del consumidor y tienen fácil acceso al mercado objetivo.

Sistema de comercialización: El producto actualmente es vendido a distribuidores quienes lo venden a pequeños comerciantes que se encargan de llevarlos a diferentes y alejados lugares.

Calidad del producto: Debido al tiempo en el mercado, la empresa tiene conocimiento de lo que requiere el consumidor. El betún para calzado que se 
comercializa tiene las propiedades de dar brillo, resistencia, impermeabilizar, resanar y mejorar la vida útil del cazado; además, se presenta en un envase simple y práctico.

Posicionamiento: El betún elaborado por INTRADEVCO tiene más de 40 años en el mercado peruano; debido a la situación económica de años anteriores y a la antigüedad de las marcas, estas se encuentran bien posicionadas.

El producto en estudio tendrá que lidiar con dichos factores y con el reconocimiento que existe en la población; por ello consideramos que la rivalidad entre los competidores es alta.

- Poder de negociación de los proveedores: Para el betún ecológico en estudio, requerimos como insumo principal cáscara de plátano. La relación con los proveedores de cáscara no representa mayor problema al ser el plátano un fruto al cual tenemos acceso durante todo el año. Existen numerosos pequeños proveedores de productos a base de plátano que están dispuestos a enviarnos la cáscara a bajos precios. Los insumos secundarios como el borato de sodio, benzoato de sodio, glicerina y los colorantes orgánicos a utilizar los encontramos a la venta en grandes cantidades y pequeños precios. Por lo tanto, determinamos que este poder es de baja intensidad.

- Amenaza de productos sustitutos: Se considera como productos sustitutos a todos los tipos de betunes para calzado que existen en la actualidad, ya sean en pasta, en líquido, neutrales o de diferentes colores.

Hoy en día existen varias marcas de productos para la limpieza y cuidado del calzado; sin embargo, ninguna de ellas contribuye con el cuidado ambiental. Por ello, determinamos que la amenaza de productos sustitutos es de mediana intensidad.

- Poder de negociación de los clientes: A diferencia de los consumidores finales, las 
grandes empresas tienen un mayor poder de negociación del precio y otras condiciones; sin embargo, considerando que el producto que proponemos está libre de contaminantes, y que como indica una encuesta de integración realizada por RPP noticias, "el $83 \%$ de peruanos practica algún hábito ambientalmente responsable para el cuidado del medio ambiente" (RPP Noticias, 2014); consideramos este poder de intermedia intensidad.

\subsubsection{Determinación de la metodología que se empleará en la investigación de mercado}

Para el presente proyecto se recolectará información de fuentes primarias y secundarias; el método cuantitativo a utilizar como fuente primaria es una encuesta personal y de preguntas cerradas con opción múltiple, lo cual permitirá determinar el nivel de aceptación en el mercado del betún ecológico, así mismo se espera tener resultado de las preferencias del consumidor respecto a marcas, precios, envases y cantidad de compra. Las fuentes secundarias que se consultarán serán INEI, Ipsos Apoyo, Euromonitor, Veritrade, Ministerio de Producción, Tesis y otros estudios.

\subsection{Análisis de la demanda}

El principal competidor en el rubro de betún para calzado es la empresa INTRADEVCO. En la tabla 2.3 se muestra la venta histórica del betún para calzado en unidades monetarias.

Tabla 2. 3

Venta histórica de betún para calzado en el Perú (Miles de S/.)

\begin{tabular}{|c|c|c|c|c|c|c|}
\hline Año & 2010 & 2011 & 2012 & 2013 & 2014 & 2015 \\
\hline Venta de betún & $10,608.0$ & $11,396.6$ & $12,022.8$ & $13,015.0$ & $13,780.3$ & $14,166.9$ \\
\hline
\end{tabular}

El crecimiento de la venta de betún para calzado en los últimos años se dio básicamente por el incremento de la población y la tendencia al cuidado de la apariencia personal. 


\subsubsection{Demanda histórica}

Para determinar la demanda histórica, se considerará el histórico de betún para calzado que se ha producido, importado y exportado.

\subsubsection{Importaciones / Exportaciones}

En el 2015, los principales países de donde se importó betún para calzado al Perú fueron España, Colombia, Italia, México y Estados Unidos, los cuales en conjunto participaron con el $82 \%$ del total de importaciones. En la tabla 2.4 se observan las importaciones históricas desde el año 2009 al 2015.

Tabla 2.4

Importaciones de betún para calzado $(\mathrm{kg})$

\begin{tabular}{|c|r|}
\hline Año & Importaciones \\
\hline 2009 & $110,508.8$ \\
\hline 2010 & $114,178.5$ \\
\hline 2011 & $79,588.8$ \\
\hline 2012 & $103,525.2$ \\
\hline 2013 & $144,787.5$ \\
\hline 2014 & $97,232.9$ \\
\hline 2015 & $110,655.6$ \\
\hline
\end{tabular}

Nota: Partida 3405100000. Betunes, cremas y preparaciones similares para el calzado o para cueros y pieles. Fuente: Veritrade, (2016)

En cuanto a las exportaciones, Bolivia fue el principal destino en el 2015 con el $61 \%$, seguido por Ecuador con el $10 \%$ del volumen total. En la tabla 2.5 se muestran las exportaciones históricas desde el año 2009 al 2015.

\section{Tabla 2.5}

Exportaciones de betún para calzado $(\mathrm{kg})$

\begin{tabular}{|c|c|}
\hline Año & Exportaciones \\
\hline 2009 & $891,681.8$ \\
\hline 2010 & $1,148,207.5$ \\
\hline 2011 & $922,566.5$ \\
\hline 2012 & $614,430.2$ \\
\hline 2013 & $836,659.6$ \\
\hline 2014 & $495,629.9$ \\
\hline 2015 & $458,931.4$ \\
\hline
\end{tabular}

Nota: Partida 3405100000. Betunes, cremas y preparaciones similares para el calzado o para cueros y pieles. Fuente: Veritrade, (2016) 


\subsubsection{Producción Nacional}

En la tabla 2.6 se muestra la producción nacional de betún para calzado (en pasta y líquido) desde el año 2000 hasta el 2007; como se puede observar, la producción aumentó del 2000 al 2001, disminuyó ligeramente en el 2003 y se incrementó año tras año hasta el 2007.

Tabla 2. 6

Producción nacional del betún para calzado $(\mathrm{kg})$

\begin{tabular}{|l|l|}
\hline Año & Producción \\
\hline 2000 & $1,293,940.0$ \\
\hline 2001 & $1,743,987.7$ \\
\hline 2002 & $1,650,330.4$ \\
\hline 2003 & $1,440,401.5$ \\
\hline 2004 & $1,339,116.5$ \\
\hline 2005 & $1,391,945.5$ \\
\hline 2006 & $1,410,059.0$ \\
\hline 2007 & $1,503,110.0$ \\
\hline
\end{tabular}

Fuente: INEI, (2016).

Ya que no contamos con información histórica de la producción desde el año 2008; se consideró la producción per cápita peruana que se ha mantenido constante desde el año 2000 hasta el 2007. En la tabla 2.7 se muestra la producción de betún hasta el 2015 considerando una producción per cápita de $0.05 \mathrm{~kg}$ y la población peruana de cada año.

Tabla 2.7

Producción histórica nacional del betún para calzado $(\mathrm{kg})$

\begin{tabular}{|c|c|c|c|}
\hline Año & $\begin{array}{c}\text { Producción } \\
\text { per cápita }\end{array}$ & Población & $\begin{array}{c}\text { Producción } \\
\text { total }\end{array}$ \\
\hline 2008 & 0.05 & $28,807,034$ & $1,520,268.6$ \\
\hline 2009 & 0.05 & $29,132,013$ & $1,537,419.2$ \\
\hline 2010 & 0.05 & $29,461,933$ & $1,554,830.4$ \\
\hline 2011 & 0.05 & $29,797,694$ & $1,572,549.9$ \\
\hline 2012 & 0.05 & $30,135,875$ & $1,590,397.2$ \\
\hline 2013 & 0.05 & $30,475,144$ & $1,608,301.8$ \\
\hline 2014 & 0.05 & $30,814,175$ & $1,626,193.9$ \\
\hline 2015 & 0.05 & $31,151,643$ & $1,644,003.5$ \\
\hline
\end{tabular}

Fuente: INEI, (2016).

Elaboración propia 


\subsubsection{Demanda Interna Aparente (DIA)}

En la tabla 2.8 se muestra la Demanda Interna Aparente obtenida a partir de los datos históricos de las importaciones, exportaciones y producción desde el año 2009 hasta el 2015. El cálculo se realizó en base a la siguiente fórmula (la diferencia de inventarios se considera cero):

$$
\text { DIA = Producción + Importaciones - Exportaciones +- Dif. de inventarios }
$$

Tabla 2. 8

Demanda interna aparente del betún para calzado $(\mathrm{Kg})$

\begin{tabular}{|c|r|r|r|r|r|}
\hline Año & Producción & Importaciones & Exportaciones & $\begin{array}{c}\text { Diferencia de } \\
\text { inventarios }\end{array}$ & DIA \\
\hline 2009 & $1,537,419.2$ & $110,508.8$ & $891,681.8$ & 0.0 & $756,246.1$ \\
\hline 2010 & $1,554,830.4$ & $114,178.5$ & $1,148,207.5$ & 0.0 & $520,801.5$ \\
\hline 2011 & $1,572,549.9$ & $79,588.8$ & $922,566.5$ & 0.0 & $729,572.2$ \\
\hline 2012 & $1,590,397.2$ & $103,525.2$ & $614,430.2$ & 0.0 & $1,079,492.1$ \\
\hline 2013 & $1,608,301.8$ & $144,787.5$ & $836,659.6$ & 0.0 & $916,429.7$ \\
\hline 2014 & $1,626,193.9$ & $97,232.9$ & $495,629.9$ & 0.0 & $1,227,797.0$ \\
\hline 2015 & $1,644,003.5$ & $110,655.6$ & $458,931.4$ & 0.0 & $1,295,727.8$ \\
\hline
\end{tabular}

Fuente: Veritrade, (2016)

Elaboración propia

En base a los resultados obtenidos de la Demanda Interna Aparente para cada año analizado, se realizó un gráfico de dispersión, (Figura 2.1) en el que se observa la tendencia $\mathrm{y}$ crecimiento lineal.

Figura 2. 1

Tendencia de la Demanda Interna Aparente $(\mathrm{Kg})$

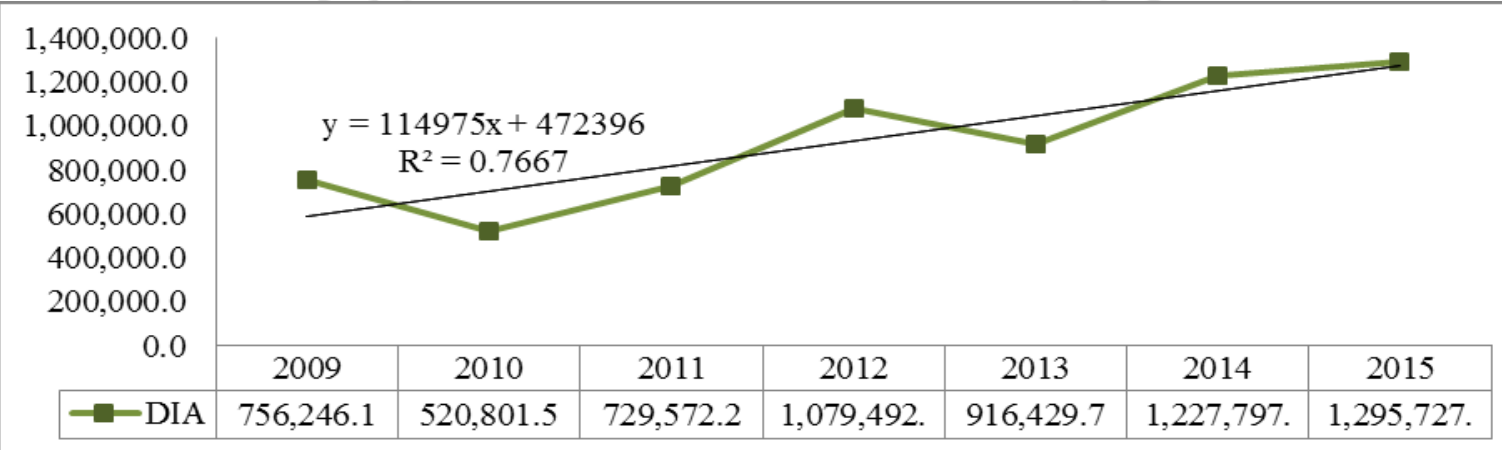

Elaboración propia 


\subsubsection{Demanda potencial}

Definimos demanda potencial como la máxima demanda posible de un bien en un mercado determinado; el objetivo principal es determinar el límite máximo de comercialización al que puede llegar un bien.

\subsubsection{Patrones de consumo}

Actualmente, el uso de calzado de cuero o similares es frecuente en alumnos de colegio, oficinistas, trabajadores del Estado como policías, ministros, jueces; además de profesionales como abogados, médicos, ingenieros, profesores, pilotos; vigilantes, mozos o cualquier ocupación que requiera vestimenta formal o uniforme.

Del Informe Gerencial de Marketing - "Liderazgo en productos de cuidado personal y limpieza del hogar 2015" y "Liderazgo en productos de cuidado personal y limpieza del hogar 2014" del grupo Ipsos Apoyo se obtuvo las siguientes estadísticas importantes acerca del consumo de betún para calzado en el Perú.

\section{5}

- El 87\% de hogares consumen betún.

- Con respecto a las marcas más comunes en el mercado nacional: El 55\% de los encuestados prefieren Nugget, el 23\% Kiwi, el 19\% Santiago y el 3\% Sapolio.

- El 51\% del NSE A, el 50\% del NSE B, el 36\% del C y el 36\% del D elijen un producto en base a su buena calidad; por otro lado, el 49\% del NSE E se basa en precios bajos, cómodos y económicos.

- Con respecto a la frecuencia de consumo: El 75\% de hogares consumen el producto diariamente o varias veces por semana; el $8 \%$ una vez por semana, el $4 \%$ quincenal o mensual, el $7 \%$ ocasionalmente y el $6 \%$ nunca utiliza betún para calzado.

\section{4}

- Los consumidores de betún para calzado presentan una lealtad del $30 \%$ o menos hacia las marcas que consumen frecuentemente. 
- Con respecto al lugar de compra más frecuente para el NSE A y B son los supermercados con un $70 \%$ y $54 \%$ respectivamente y para los NSE C, D y E los mercados con un $54 \%, 54 \%$ y $64 \%$ respectivamente.

\subsubsection{Determinación de la demanda potencial}

Para la determinación de la demanda potencial, se tomó como referencia el uso de calzado que por lo general se limpia con betún. Se consideró que este tipo de calzado es usado por hombres y mujeres desde los 5 años (inicio de la edad escolar) hasta los 70 años (fin de la edad laboral). Para el análisis se realizó una encuesta a 200 personas de todos los NSE entre 5 y 70 años de edad; las preguntas y respuestas se muestran en las figuras 2.2, 2.3 y

\section{4:}

Figura 2.2

Resultado de la encuesta: ¿Utiliza calzado que requiera betún para ser limpiado?

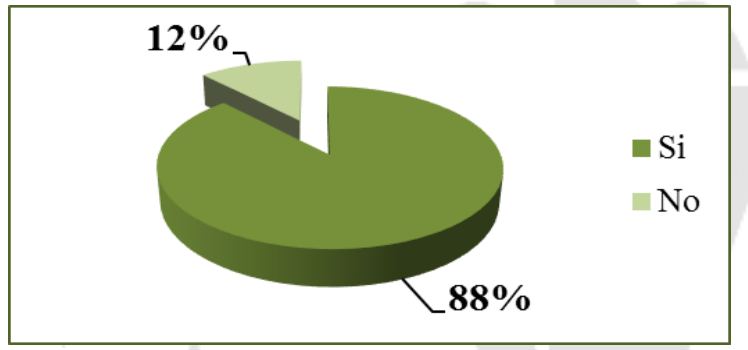

Elaboración propia

Figura 2. 3

Resultado de la encuesta: ¿En promedio, cuantas veces a la semana usa este tipo de calzado?

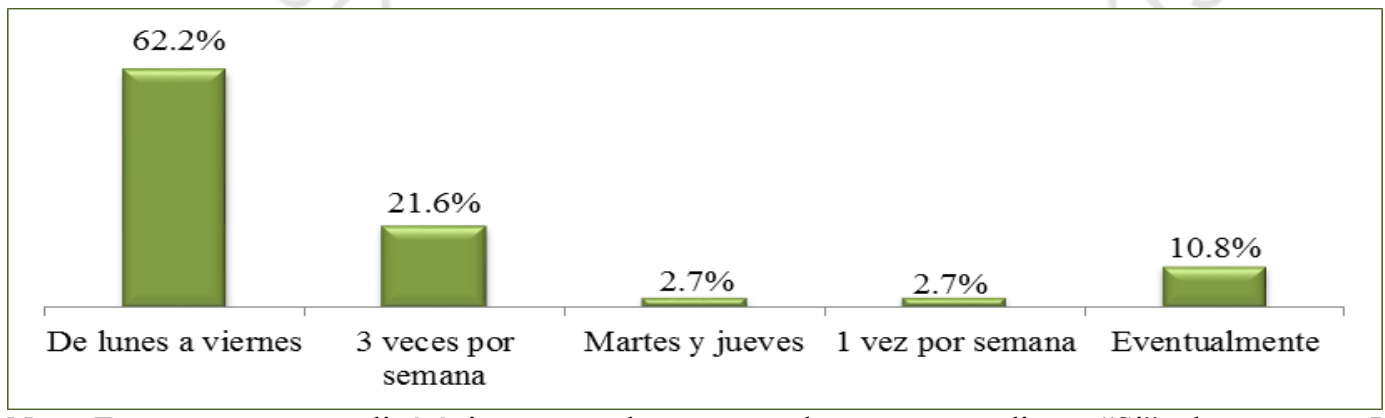

Nota: Esta pregunta se realizó únicamente a los encuestados que respondieron "Si” a la pregunta ¿Utiliza calzado que requiera betún para ser limpiado?

Elaboración propia 
Figura 2. 4

Resultado de la encuesta: ¿Cada cuánto tiempo limpia este tipo de calzado?

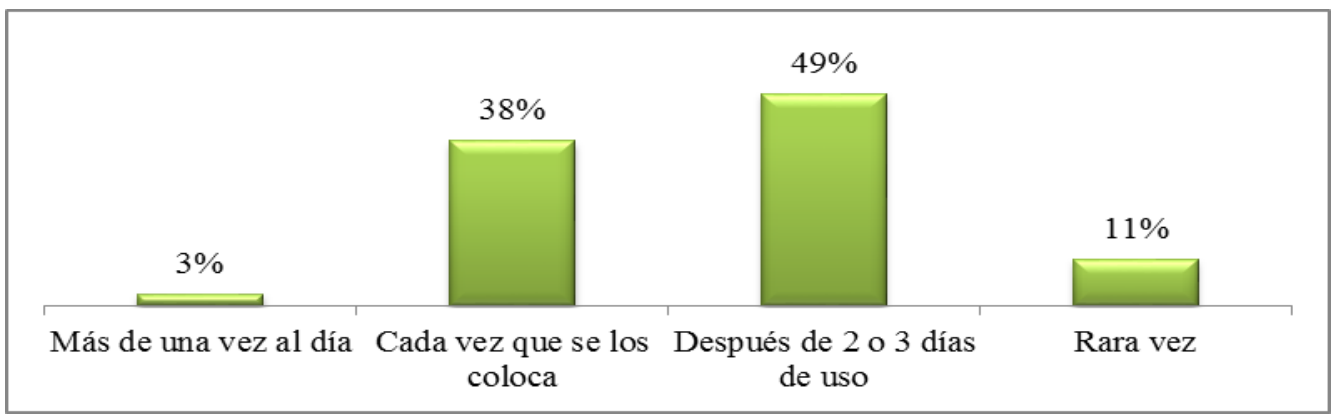

Nota: Esta pregunta se realizó únicamente a los encuestados que respondieron "Si" a la pregunta ¿Utiliza calzado que requiera betún para ser limpiado?

Elaboración propia

Con los resultados obtenidos en la encuesta, tomaremos como demanda potencial a todas las personas del Perú entre 5 y 70 años que utilizan calzado de cuero o similares; además, se considerará que la limpieza con betún se realiza como máximo cada vez que se los colocan. En la tabla 2.9 se muestran los porcentajes de utilización de este tipo de calzado.

Tabla 2. 9

Utilización semanal de calzado

\begin{tabular}{|c|c|c|c|c|c|c|c|}
\hline \multirow[b]{2}{*}{$\begin{array}{l}\text { Población } \\
\text { Perú (2015) }\end{array}$} & \multirow[b]{2}{*}{$\begin{array}{l}\text { Población } \\
\text { entre } 5 \text { y } 70 \\
\text { años }(\%)\end{array}$} & \multirow{2}{*}{$\begin{array}{c}\text { Población que } \\
\text { utiliza calzado de } \\
\text { cuero o similares } \\
(\%)\end{array}$} & \multicolumn{5}{|c|}{ Uso de calzado a la semana (\%) } \\
\hline & & & $\begin{array}{c}5 \\
\text { veces }\end{array}$ & $\begin{array}{c}3 \\
\text { veces }\end{array}$ & $\begin{array}{c}2 \\
\text { veces }\end{array}$ & $1 \mathrm{vez}$ & $\begin{array}{c}1 \text { vez } \\
\text { cada } 2 \\
\text { semanas }\end{array}$ \\
\hline $31,151,643$ & 86.6 & 88.1 & 62.2 & 21.6 & 2.7 & 2.7 & 10.8 \\
\hline
\end{tabular}

Fuente: INEI, (2016)

Elaboración propia

Con la información mostrada en el Tabla 2.9, obtenemos que 14, 776,120 personas utilizan este tipo de calzado cinco veces por semana; 5, 139,520 lo utilizan 3 veces por semana; dos veces por semana y una vez por semana lo utilizan 642,440 personas y 2, 569,760 una vez en dos semanas; multiplicando cada uno de estos resultados por la cantidad de veces de utilización de calzado por semana nos da como resultado que en una semana se utiliza 92, 511,360 veces este tipo de calzado. Además, en base a mediciones realizadas, por cada par de calzado que se lustra correctamente se consume en promedio $1.95 \mathrm{gr}$ de betún, con esta información podemos concluir que el consumo potencial de betún 
es de $1.95 \mathrm{gr}$ por la utilización anual del calzado de este tipo, lo cual nos da como resultado 9, 380,651.9 kg de betún en el año 2015 .

\subsubsection{Demanda mediante fuentes primarias}

\subsubsection{Diseño y aplicación de encuestas}

Como una de las fuentes primarias utilizadas en el presente estudio se realizó una encuesta en Lima Metropolitana. Para el cálculo de tamaño de muestra se consideró la siguiente fórmula:

$$
\mathrm{n}=\left(\mathrm{Z}^{2} \times \mathrm{p} \times \mathrm{q}\right) /\left(\mathrm{E}^{2}\right)
$$

Donde:

- $\mathrm{n}=$ Tamaño de muestra

- p, q: Son la variabilidad positiva y negativa ante la pregunta filtro preliminar que se realizó a 50 personas: ¿Consume betún para calzado?

- Resultado: $\mathrm{p}=92 \%$ y $\mathrm{q}=8 \%$.

- $\mathrm{Z}=1.96$, nivel de confianza $95 \%$.

- E: Margen de error 5\%.

El resultado obtenido como tamaño de muestra fue 113, el cual indicada el número de personas a las que se va a encuestar para que los datos obtenidos sean representativos de la población.

\subsubsection{Determinación de la demanda}

Para la determinación de la demanda se considerará la demanda histórica proyectada multiplicada por los factores que se indican en el punto 2.4.1 (selección de mercado meta) y por la intensidad de compra del betún para calzado que se hallará mediante la encuesta.

\subsubsection{Proyección de la demanda}

Para la proyección de la demanda interna aparente se tomaron en cuenta los datos históricos de la producción, exportaciones e importaciones. Con estos datos y teniendo 
como variable independiente los años históricos de estudio, se obtuvo la siguiente ecuación lineal: $\mathrm{y}=114150 \mathrm{x}+401954$ (Figura 2.1); con la cual se proyecta la demanda para los próximos seis años de estudio. En la tabla 2.10 se muestran los resultados obtenidos.

Tabla 2. 10

Demanda histórica proyectada $(\mathrm{kg})$

\begin{tabular}{|c|c|}
\hline Año & DIA proyectada \\
\hline 2016 & $1,392,196$ \\
\hline 2017 & $1,507,171$ \\
\hline 2018 & $1,622,146$ \\
\hline 2019 & $1,737,121$ \\
\hline 2020 & $1,852,096$ \\
\hline 2021 & $1,967,071$ \\
\hline 2022 & $2,082,046$ \\
\hline
\end{tabular}

Elaboración propia

Como se puede observar, la demanda de betún para calzado de cuero o similares crece anualmente.

\subsubsection{Consideraciones sobre la vida útil del proyecto}

Para el presente estudio se realizará el análisis para los próximos 5 años, ya que es el tiempo mínimo que se requiere para evaluar la factibilidad del proyecto.

\subsection{Análisis de la oferta}

\subsubsection{Empresas productoras, importadoras y comercializadoras}

En el 2015, la empresa con mayor participación en las importaciones de betún fue Reckitt

Benckiser Perú S.A. con la marca "Nugget", seguido por EF \& P Inversiones S.A.C con una marca menos comercial "Barranchina's". En la tabla 2.11 se muestra la participación porcentual en las importaciones del 2015. 
Tabla 2. 11

Participación de las empresas importadoras de betún para calzado (2015)

\begin{tabular}{|c|c|}
\hline Importador & Participación (\%) \\
\hline Reckitt Benckiser Perú S.A. & 31.1 \\
\hline Ef \& P Iinversiones S.A.C & 19.2 \\
\hline Otros & 49.7 \\
\hline
\end{tabular}

Nota: Partida 3405100000. Betunes, cremas y preparaciones similares para el calzado o para cueros y pieles. Fuente: Veritrade, (2016)

Elaboración propia

Entre los principales productores y exportadores de betún en el Perú se encuentra la empresa Intredevco Industrial S.A con la marca Sapolio y Kiwi, y la empresa Industria Química Mendoza E Hijos S.A.C. con la marca Santiago. En la tabla 2.12 se muestra la participación de estas empresas en las exportaciones del 2015.

\section{Tabla 2.12}

Participación de las empresas exportadoras de betún para calzado (2015)

\begin{tabular}{|c|c|}
\hline Exportador & Participación (\%) \\
\hline Intradevco Industrial S.A. & 82.9 \\
\hline Industria Química Mendoza Hijos S.A.C. & 11.3 \\
\hline Otros & 5.8 \\
\hline
\end{tabular}

Nota: Partida 3405100000. Betunes, cremas y preparaciones similares para el calzado o para cueros y pieles. Fuente: Veritrade, (2016)

Elaboración propia

\subsubsection{Competidores actuales y potenciales}

Dentro del sector, las marcas actuales con mayor participación en el mercado y nuestros más grandes competidores son Kiwi, Sapolio y Nugget. Cada una de estas marcas tiene sus propias características relacionadas a la presentación, colores y cantidad; estas se muestran a continuación.

- El betún marca Kiwi en pasta tiene presentaciones en envases de hojalata de 13, 31 y 70 gr de colores negro, marrón y neutral, así como también cuenta con presentaciones de betún en líquido. Estas se muestran en la figura 2.5. 
Figura 2. 5

Principales presentaciones del betún marca Kiwi
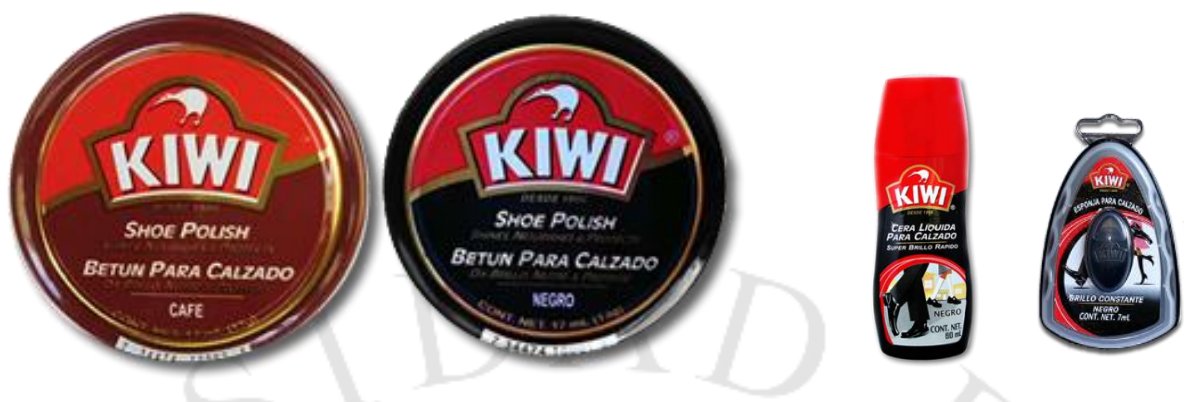

Fuente: Plaza Vea, (2016)

- El betún Sapolio tiene presentaciones en lata hermética de 24, 42 y $88 \mathrm{ml}$ de colores negro, marrón, blanco, amarillo, canela, azul y guinda. Además, cuenta con betún líquido de $60 \mathrm{ml}$ color negro y blanco. En la figura 2.6 se muestran presentaciones.

Figura 2. 6

Principales presentaciones de betún marca Sapolio

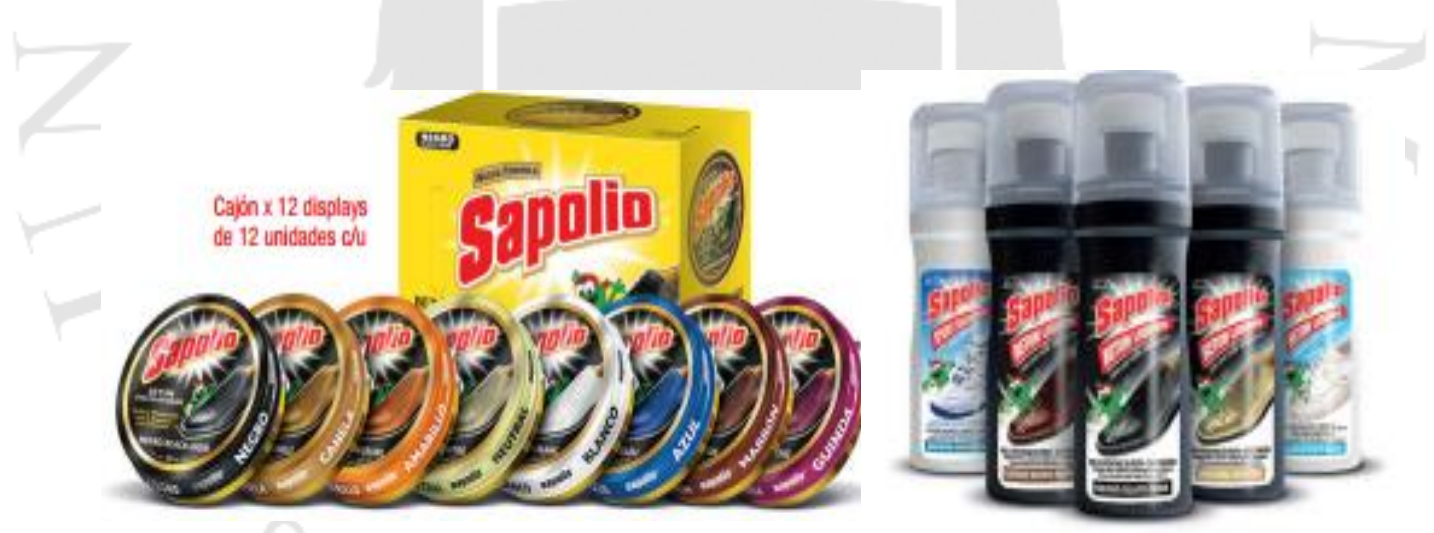

Fuente: INTRADEVCO, (2016)

- El betún Nugget cuenta con presentaciones en líquido de $60 \mathrm{ml}$ y en pasta de 65 y 12 gr de color negro, café y blanco. En la figura 2.7 se muestra sus principales presentaciones. 
Figura 2. 7

Principales presentaciones del betún marca Nugget
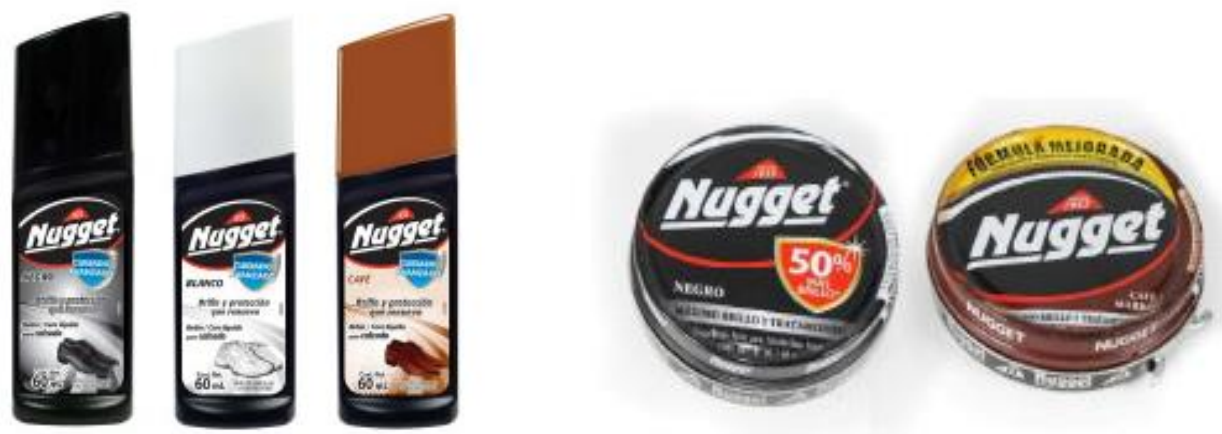

Fuente: PlazaVea, (2016)

De las marcas señaladas, Kiwi lidera el mercado con una venta de 5.1 millones de soles en el 2015, seguido de Sapolio con 3.1 millones y por último las ventas de Nugget con 2.5 millones de soles en el mismo año (Euromonitor 2016). En la figura 2.8 se muestra el porcentaje de participación en el mercado de las marcas líderes.

Figura 2. 8

Participación de venta de betún por marcas (Perú 2015)

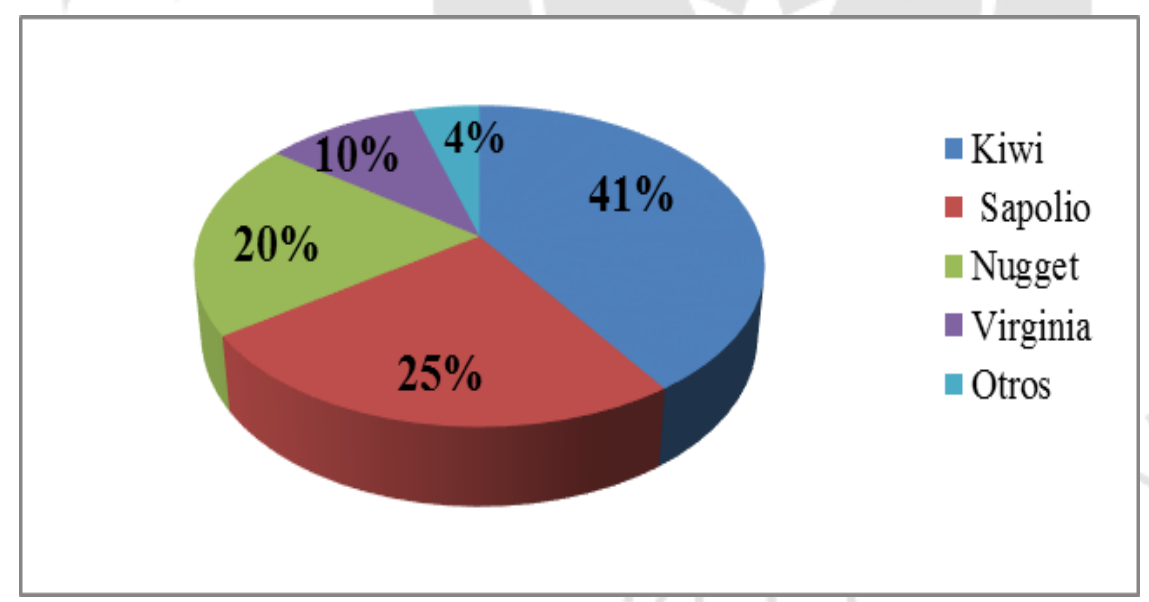

Fuente: Euromonitor, (2016)

Elaboración propia

Para mantener su posicionamiento en el mercado, estas marcas aplican una mezcla de estrategias comerciales, precios, promociones, productos diferenciados y publicidad. 


\subsection{Demanda para el proyecto}

\subsubsection{Segmentación del mercado}

Para la segmentación de mercado se toma como base los tipos de segmentación que propuso Philip Kotler, la cual se detallará a continuación:

- Geográfica: El producto en estudio estará dirigido a Lima por ser la ciudad del Perú que concentra el $31.57 \%$ de la población total; y abarcará los Niveles Socioeconómicos B, C y D.

- Demográfica: Las personas que utilizan frecuentemente calzado de cuero o similares son aquellas que estudian en colegios, las que realizan trabajos en oficinas, bancos, ventas, pilotos, vigilancia, mozos, jueces, fiscales, policías, etc.

En la tabla 2.13, se muestran los sectores demográficos que consideraremos para la selección del mercado.

\section{Tabla 2.13}

Sectores y sub sectores a considerar para el mercado meta

\begin{tabular}{|c|c|}
\hline Sector & Sub sector \\
\hline Alumnos de colegio & Primaria/Secundaria/Escolarizado \\
\hline \multirow{4}{*}{$\begin{array}{c}\text { Trabajadores del } \\
\text { sector privado }\end{array}$} & Vigilantes de seguridad \\
\cline { 2 - 2 } & Empleados de oficina en general \\
\cline { 2 - 2 } & Empleados de bancos \\
\cline { 2 - 2 } & Gerentes \\
\cline { 2 - 2 } & Mepresentantes de ventas \\
\cline { 2 - 2 } & Pilotos y copilotos \\
\hline \multirow{5}{*}{$\begin{array}{c}\text { Trabajadores del } \\
\text { sector publico }\end{array}$} & Diplomáticos \\
\cline { 2 - 2 } & Molicía Nacional \\
\cline { 2 - 2 } & Gerentes públicos \\
\cline { 2 - 2 } &
\end{tabular}

Fuente: Ministerio de Educación y Trabajo, (2015)

Elaboración propia 
El total de la población que pertenece a los sub sectores mencionados en el Tabla anterior es 6, 379,074; lo cual representa el 25.5\% de la población nacional.

- Pictográfica: El consumo de betún para calzado define el estilo de vida de la población, ya que este producto está dirigido a personas que utilizan calzado de cuero o similares para acompañar trajes elegantes o uniformes.

- Conductual: Con esta segmentación se dividirá a los compradores de acuerdo a los beneficios que buscan en el producto, el estatus del usuario y el estatus de la lealtad. Para determinar el estatus del usuario se tomará en cuenta aquellas personas que usualmente utilizan calzado de cuero; en cuanto a la lealtad a la marca, se pueden distinguir tres grupos: Totalmente leales, menos leales y compradores que no exhiben lealtad hacia ninguna marca; según la información obtenida por Ipsos Apoyo, en Lima Metropolitana los consumidores de betún para calzado presentan una lealtad del 30\% o menos hacia las marcas que consumen frecuentemente.

\subsubsection{Selección del mercado meta}

Para la selección del mercado meta, se tomó en cuenta la población seleccionada en la tabla 2.13, que en el 2015 tuvo una participación del 25.5\% del total de la población nacional; además, se consideraron los factores mencionados anteriormente, los cuales se muestran en la tabla 2.14 .

\section{Tabla 2. 14}

Factores de selección del mercado meta

\begin{tabular}{|c|c|}
\hline \multicolumn{2}{|c|}{ Factores de selección del mercado meta } \\
\hline Mercado & Nacional \\
\hline Localidad & Lima Metropolitana \\
\hline NSE & B, C, D \\
\hline Sexo & Femenino y masculino \\
\hline
\end{tabular}

Elaboración propia

En la tabla 2.15 se muestran los porcentajes de cada uno de los factores de selección del mercado meta considerando que se mantienen constantes hasta el año 2022. 
Tabla 2. 15

Porcentajes de cada criterio de segmentación hasta el año 2022

\begin{tabular}{|c|c|c|c|c|}
\hline Año & $\begin{array}{c}\text { Población de } \\
\text { Lima (\%) }\end{array}$ & $\begin{array}{c}\text { NSE B } \\
(\%)\end{array}$ & $\begin{array}{c}\text { NSE C } \\
(\%)\end{array}$ & $\begin{array}{c}\text { NSE D } \\
(\%)\end{array}$ \\
\hline 2016 & 31.6 & 19.7 & 42.0 & 25.5 \\
\hline 2017 & 31.6 & 19.7 & 42.0 & 25.5 \\
\hline 2018 & 31.6 & 19.7 & 42.0 & 25.5 \\
\hline 2019 & 31.6 & 19.7 & 42.0 & 25.5 \\
\hline 2020 & 31.6 & 19.7 & 42.0 & 25.5 \\
\hline 2021 & 31.6 & 19.7 & 42.0 & 25.5 \\
\hline 2022 & 31.6 & 19.7 & 42.0 & 25.5 \\
\hline
\end{tabular}

Nota: Los porcentajes mostrados de cada nivel socioeconómico son referente a Lima.

Elaboración propia

Para el cálculo de la intensidad de compra, primero se realizó una pregunta sobre el consumo de betún ecológico para calzado. Los resultados obtenidos se muestran en la figura 2.9.

Figura 2. 9

Resultado de la encuesta: ¿Limpiaría su calzado con un betún ecológico a base de productos naturales y orgánicos?

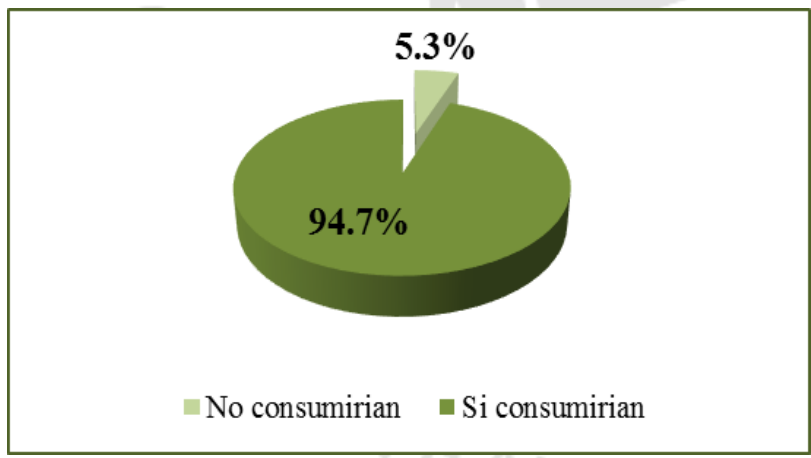

Nota: Esta pregunta se realizó a las personas que respondieron "sí” a la primera pregunta: ¿Utiliza betún para calzado?

Elaboración propia

Luego se realizó la pregunta de intensidad de compra, donde se solicitó al encuestado que marque en una escala del 1 al 10 su intensidad de compra, donde 1 es un nivel muy bajo de deseo de compra y 10 significa que de todas maneras lo compraría. Los resultados se muestran en la tabla 2.16 . 
Tabla 2. 16

Resultado de la encuesta: Grado de intención de compra de betún orgánico

\begin{tabular}{|c|c|c|}
\hline Valor & Frecuencia & Valor por frecuencia \\
\hline 1 & 0 & 0 \\
\hline 2 & 0 & 0 \\
\hline 3 & 4 & 12 \\
\hline 4 & 2 & 8 \\
\hline 5 & 14 & 70 \\
\hline 6 & 15 & 90 \\
\hline 7 & 2 & 14 \\
\hline 8 & 10 & 80 \\
\hline 9 & 10 & 90 \\
\hline 10 & 50 & 500 \\
\hline Total & 107 & 864 \\
\hline \multicolumn{2}{|c|}{ Promedio de intensidad de compra: $864 / 107=8.07$ Porcentaje: } \\
\multicolumn{2}{|c|}{$(8.07 / 10)^{*} 100=84.5 \%$} \\
\hline
\end{tabular}

Nota: Esta pregunta se realizó a las personas que respondieron "sí” a la pregunta: ¿Consumaría betún para calzado orgánico a base de productos naturales?

Elaboración propia

En base a la información obtenida del grado de intención de compra, corregimos la intensidad de compra mostrada en la figura 2.9.

Corrección de intensidad de compra: $94.7 \%$ x 84.5\%, lo que nos da como resultado: $80.0 \%$.

\subsubsection{Demanda específica para el proyecto}

Para determinar la demanda específica del proyecto se utilizará la demanda interna aparente proyectada y determinada en la sección 2.2.4, la cual se debe ajustar con los porcentajes obtenidos en el punto 2.4.2 (selección del mercado meta) mostrados en la tabla 2.15. El cálculo fue el siguiente:

Demanda proyectada $x$ población de Lima $x($ NSE B + NSE C + NSE D) $x$ porcentaje de los factores seleccionados para hallar el mercado meta $\mathrm{x}$ corrección de intención de compra: Demanda proyectada x $31.6 \%$ x $(19.7 \%+42.0 \%+25.5 \%)$ x $25.5 \%$ x $80.0 \%$. 
Tabla 2. 17

Demanda específica del proyecto

\begin{tabular}{|c|c|c|}
\hline Año & $\begin{array}{c}\text { Demanda } \\
\text { proyectada } \\
(\mathbf{k g})\end{array}$ & $\begin{array}{c}\text { Demanda del } \\
\text { proyecto }(\mathrm{kg})\end{array}$ \\
\hline 2016 & $1,392,196$ & 55,881 \\
\hline 2017 & $1,507,171$ & 60,496 \\
\hline 2018 & $1,622,146$ & 65,111 \\
\hline 2019 & $1,737,121$ & 69,726 \\
\hline 2020 & $1,852,096$ & 74,341 \\
\hline 2021 & $1,967,071$ & 78,956 \\
\hline 2022 & $2,082,046$ & 83,571 \\
\hline
\end{tabular}

Nota: La demanda proyectada se determinó en el punto 2.2.4 "Proyección de la demanda" Elaboración propia

\subsection{Definición de la Estrategia de Comercialización}

\subsubsection{Políticas de comercialización y distribución}

Las políticas son el conjunto de normas que forman parte de los procesos de la empresa, las referidas a la comercialización y distribución se describen a continuación:

- Políticas de precio: La presentación que se plantea desarrollar es en envases de plástico reciclado de 50gr debidamente etiquetado. El precio al que se ofrecerá el producto a nuestros clientes (bodegas y supermercados) inicialmente será de 2.00 soles ( $\sin$ IGV).

- Políticas de cobranzas: Los lugares donde será vendido el producto directamente serán los Supermercados, quienes trabajan a concesión, esto significa que sólo pagan por los productos vendidos por ellos y no por el total de los productos que se les entrega, para el caso de aquellos productos que no se vendan antes de la fecha de vencimiento, tendrán que ser cubiertos por el proveedor y reemplazados en el menor tiempo posible. Los supermercados tienen como política de pago a proveedores entre 60 y 90 días luego de haberse expuesto la mercadería en los anaqueles. El producto será distribuido también a tiendas minoristas y bodegas, donde el pago es inmediato y, según el informe de Ipsos, es donde mayormente compran las personas de los NSE C y D. 
- Políticas de servicio y garantía: El producto contará con una línea gratuita postventa para quejas o sugerencias. Además, la política de garantía establece que en el caso de que el producto no satisfaga las expectativas del cliente, se realizará el reemplazo correspondiente o devolución del dinero siempre y cuanto la queja esté debidamente sustentada.

- Políticas de distribución: La política de distribución que se empleará será la distribución indirecta, ya que se trabajará con intermediarios. Dentro de este canal existen dos tipos: El canal corto y el canal largo tal como se muestra en la figura 2.10 .

Figura 2. 10

Cadena de distribución indirecta

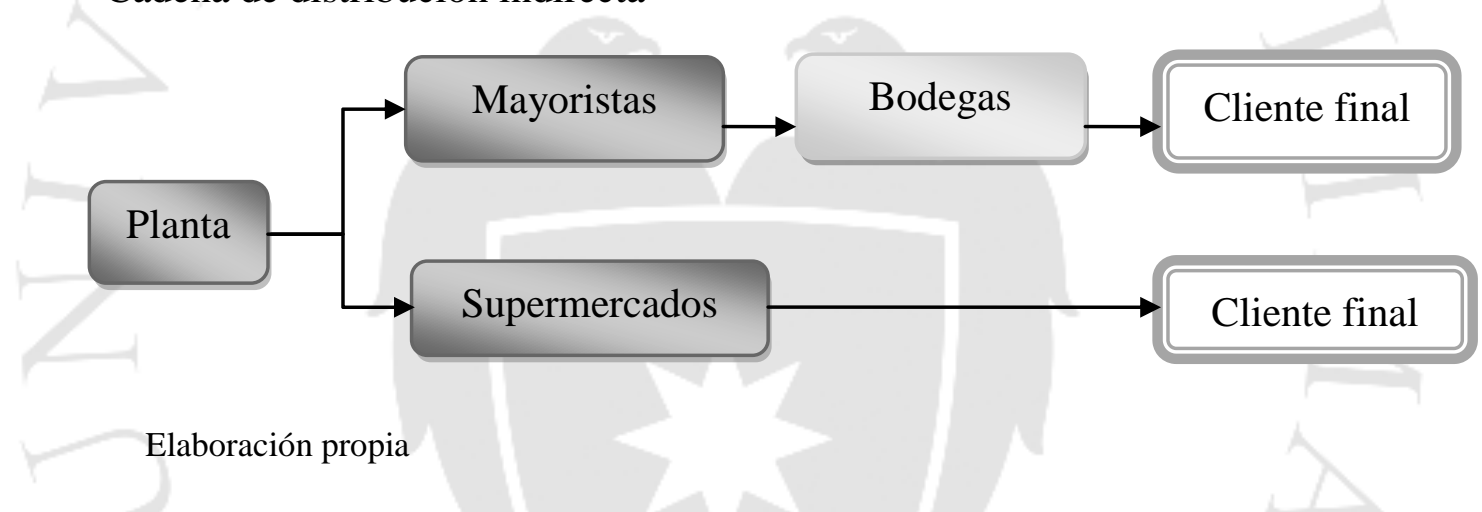

Considerando que los lugares donde existe mayor frecuencia de consumo de betún para calzado son las bodegas y supermercados, se utilizarán ambos tipos de canales.

\subsubsection{Publicidad y promoción}

Se realizarán campañas publicitarias a través de diferentes medios de comunicación, cuyo objetivo será dar a conocer las ventajas y beneficios del producto en comparación a los que se ofrecen actualmente en el mercado. Se colocará información en paneles publicitarios, se realizarán propagandas a través de la radio, se contará con una página web donde los consumidores podrán observar las cualidades y propiedades del producto; también se crearán perfiles en las redes sociales donde se publicarán anuncios y novedades acerca del producto. No promoveremos el producto tanto como uno de limpieza, sino como el único 
betún que no contamina al medio ambiente, no es tóxico y no pone en riesgo la salud de las personas y animales.

La marca se promoverá mediante diferentes estrategias de publicidad. Para esto se utilizará una clasificación con términos de mercadotecnia que se muestran a continuación:

- BTL (below the line): Publicidad no masiva de comunicación dirigida a segmentos de mercado objetivo; en nuestro caso son, la población de los NSE B, C y D que estudian o trabajan. Así mismo, se promoverá el producto en páginas de internet, principalmente en redes sociales como "Facebook". En la tabla 2.18 se muestra el porcentaje de la población de Lima Metropolitana por NSE que consumió internet en un mes cualquiera del 2015.

\section{Tabla 2. 18}

Consumo del servicio de internet $(\%)$

\begin{tabular}{|c|c|c|c|c|c|c|c|}
\cline { 2 - 7 } & NSE A & NSE B & NSE C & NSE C1 & NSE C2 & NSE D & NSE E \\
\hline $\begin{array}{c}\text { Consumo del servicio } \\
\text { de internet }\end{array}$ & 87.5 & 75.4 & 57.6 & 62.1 & 49.7 & 43.0 & 37.0 \\
\hline
\end{tabular}

Fuente: APEIM, (2015)

Podemos observar que no toda la población de Lima consume el servicio de internet, por lo cual, además de este tipo de publicidad debemos utilizar otras.

- ATL (Above the line): El producto en estudio también será promocionado en programas de TV. Además, se elaborará un comercial mostrando sus beneficios y aporte con el medio ambiente. En la tabla 2.19 se muestra el porcentaje de hogares que cuentan con TV a colores y con cable.

Tabla 2. 19

Hogares con TV a color y cable (\% Lima Metropolitana)

\begin{tabular}{|c|c|c|c|c|c|c|c|}
\cline { 2 - 8 } \multicolumn{1}{c|}{} & NSE A & NSE B & NSE C & NSE C1 & NSE C2 & NSE D & NSE E \\
\hline TV a color & 100.0 & 99.6 & 97.8 & 98.4 & 97.0 & 92.1 & 72.8 \\
\hline TV cable & 91.2 & 78.6 & 57.6 & 61.9 & 51.0 & 35.2 & 10.3 \\
\hline
\end{tabular}

Fuente: APEIM, (2015) 
Se puede concluir que, por medio de la TV, la publicidad llegará a la mayoría de hogares; incluso podremos promocionar el betún para calzado en canales de cable.

- Trade Marketing (Publicidad en el punto de venta): También se invertirá en promoción mediante afiches, colgantes, exhibidores del producto en estudio dentro de los puntos de venta como bodegas y supermercados.

\subsubsection{Análisis de precios}

\subsubsection{Tendencia histórica de los precios}

Se tomó como referencia los precios promedios de las importaciones y exportaciones de betún para calzado que se realizaron entre los años 2009 y 2015. En la figura 211 se observa el evolutivo.

Figura 2. 11

Precios históricos de importaciones y exportaciones (US\$ / kg)

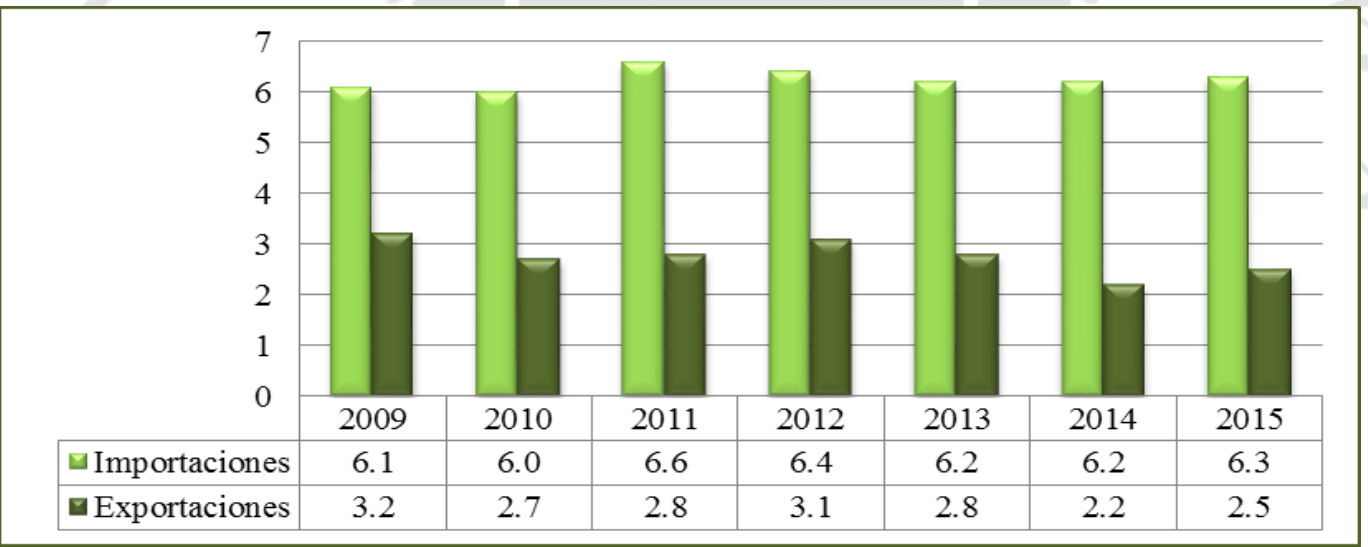

Fuente: Veritrade, (2016)

Elaboración propia

Como se puede observar en la tabla mostrada, los precios de importaciones y exportaciones del betún para calzado no tienen variaciones significantes entre los años mostrados. 


\subsubsection{Precios actuales}

En la tabla 2.20 podemos observar los precios actuales del betún para calzado en las diferentes presentaciones y marcas que se ofrecen actualmente en el mercado:

Tabla 2. 20

Precios actuales del betún en pasta para calzado (S/. / Presentación)

\begin{tabular}{|c|c|c|}
\hline Presentación & Marca & $\begin{array}{c}\text { Precio } \\
(\mathbf{S} / \text {. })\end{array}$ \\
\hline Negro en pasta (88ml) & Kiwi & 4.1 \\
\hline Negro en pasta (42ml) & Kiwi & 2.1 \\
\hline Negro en pasta (42gr) & Sapolio & 1.7 \\
\hline Negro en pasta (65ml) & Nugget & 4.9 \\
\hline Marrón en pasta (30gr) & Nugget & 2.7 \\
\hline
\end{tabular}

Fuente: Plaza Vea, (2016)

Elaboración propia

Considerando que los precios del betún medianos oscilan entre S/. 1.7 y 2.7, se considerará como precio del producto en estudio S/. 2.00.

\subsection{Análisis de los insumos principales}

\subsubsection{Características principales de la materia prima}

En el proyecto se utilizará como materia prima principal la cáscara de plátano que actualmente se desecha o utiliza como alimento balanceado para animales; esta, pasará por un control de calidad previo para luego ser procesada y obtener como producto final un betún en pasta para calzado.

Las principales características de la cáscara de plátano son:

- Representa aproximadamente el $30 \%$ del fruto.

- Cuenta con vitamina B.

- La compone compuestos fenólicos que varían entre 0.9 a 3g/ 100g en base seca, así como galocatequina $160 \mathrm{mg} / 100 \mathrm{~g}$ en base seca, siendo este último compuesto el que se relaciona con la capacidad antioxidante de la cáscara.

- Fibra dietética $(50 \mathrm{~g} / 100 \mathrm{~g})$.

- Cuenta con aminoácidos esenciales como la leucina, valina, fenilalanina y treonina. 
- Cuenta con ácidos grasos poliinsaturados, que forman de 2.2 a $10.9 \%$ del contenido lipídico total, y ácidos grasos esenciales como el ácido linoleico y ácido alinolénico (Medegrephic, 2014).

Los principales beneficios de la cáscara de plátano son:

- Es fuente potencial de sustancias antioxidantes y antimicrobianas.

- La presencia de ceras permite dar lustre al cuero, limpiar las hojas de las plantase incluso pulir cubiertos de plata.

\subsubsection{Disponibilidad de la materia prima}

El cultivo del banano y plátano en el Perú tiene gran importancia social y económica por ser uno de los productos fundamentales en la dieta alimenticia principalmente en la Amazonía peruana y en las zonas tropicales del norte del Perú.

La gran diferencia entre el banano y el plátano es su contenido de humedad; el plátano contiene un promedio de $65 \%$ y el banano $74 \%$.

Figura 2. 12

Ejemplo de plátano y banano respectivamente

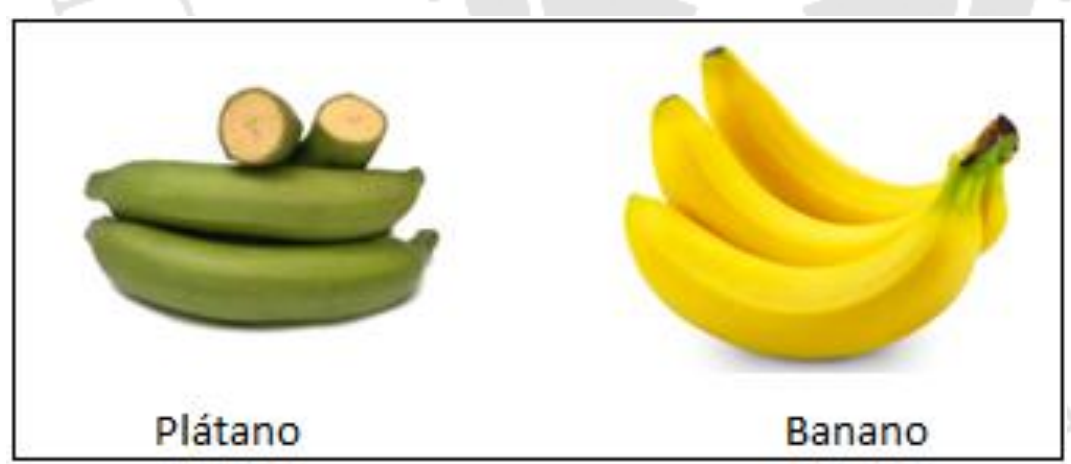

Fuente: Natursan, (2016)

En las figuras 2.13 y 2.14 se muestran la producción nacional del banano y el plátano respectivamente. 
Figura 2. 13

Producción nacional del banano (miles de toneladas)

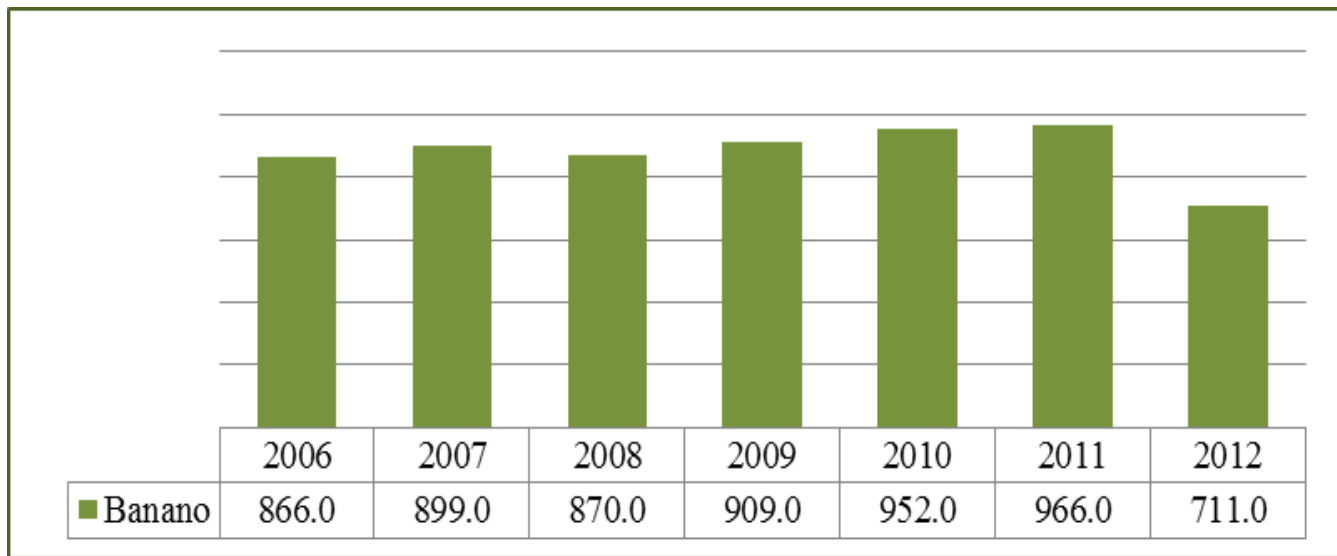

Fuente: Ministerio de agricultura y riego, (2014)

Elaboración propia

Figura 2. 14

Producción nacional del plátano (miles de toneladas)

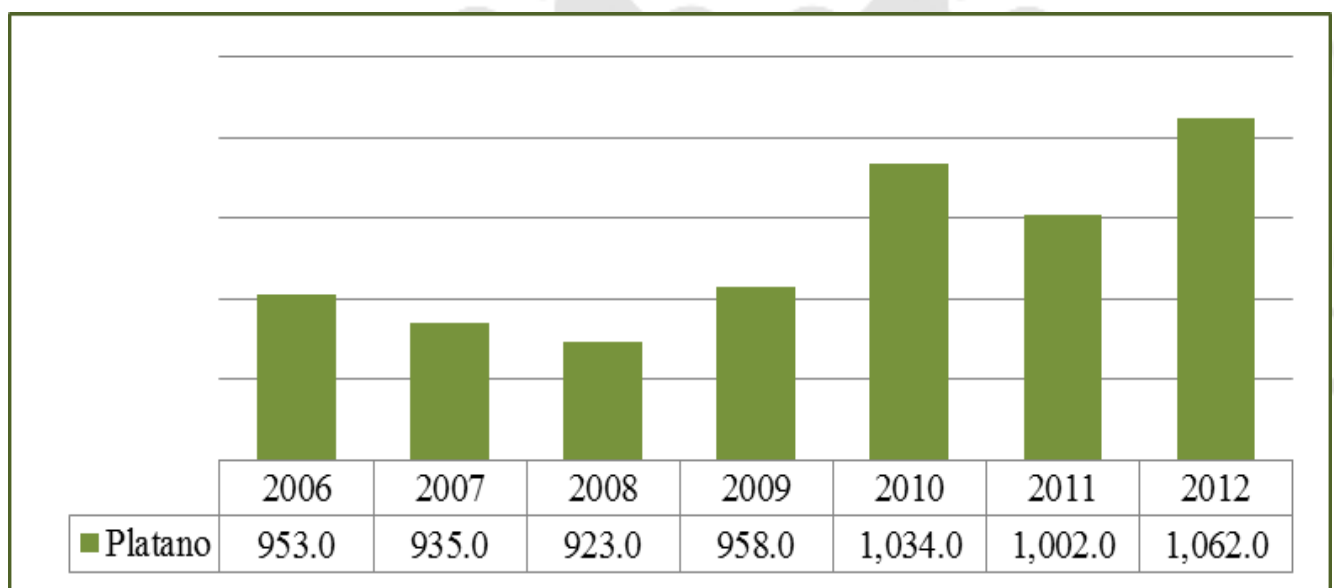

Fuente: Ministerio de agricultura y riego, (2014)

Elaboración propia

Del total de la producción de plátano y banano a nivel nacional, la selva participa con aproximadamente el $85 \%$ (60\% de plátano y $40 \%$ de banano). Otras de las principales regiones productoras es la costa norte donde se produce básicamente banano.

En la última década, el 99.7\% del comercio (exportaciones e importaciones) ha sido de banano, y solo el $0.03 \%$ de plátano. En la figura 2.15 se muestra el consumo nacional de banano y se considera que el consumo nacional del plátano es similar a la cantidad que se produce (figura 2.14). 
Figura 2. 15

Consumo nacional del banano (miles de toneladas)

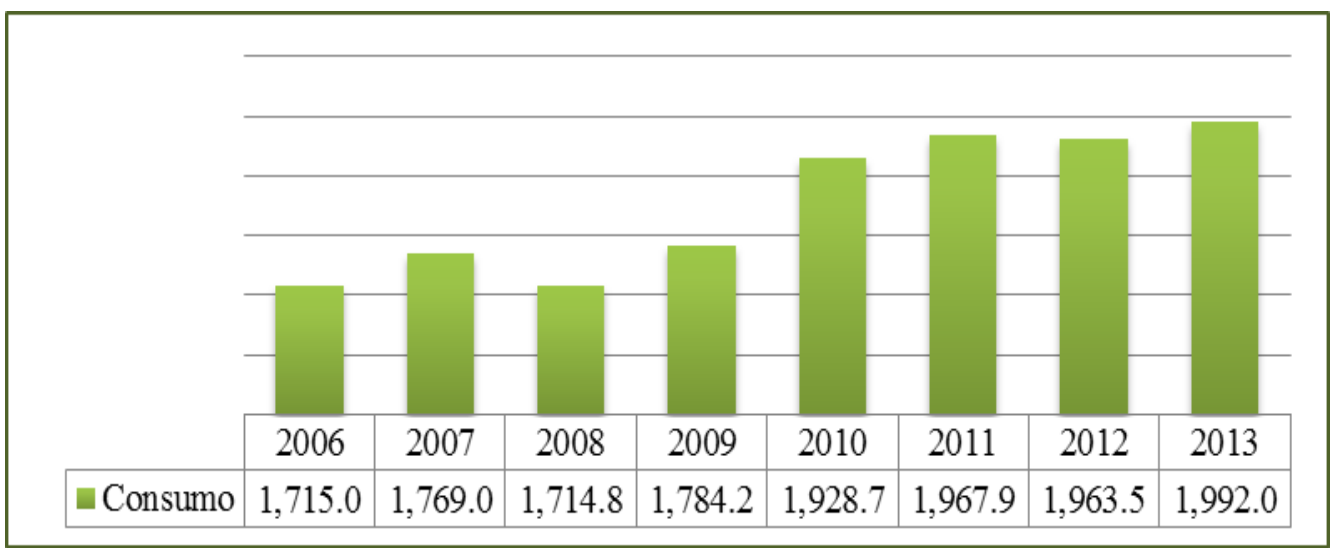

Fuente: Ministerio de agricultura y riego, (2014)

Elaboración propia

La forma de consumo del plátano y banano en la selva es $74 \%$ cocinado y frito, el $21 \%$ como fruta y el $5 \%$ como harina; en las ciudades costeras, el consumo de plátano como fruto es de $48 \%$, el $25 \%$ frito, el $10 \%$ lo consume como producto procesado y el $1 \%$ como harina; además en base a la información mostrada en la figura 2.15, el consumo de plátano y banano en Lima Metropolitana ha incrementado en promedio $20 \%$ con respecto a años anteriores. El consumo de plátano y banano nos permite tener materia prima disponible para la elaboración del presente producto.

\subsubsection{Costos de la materia prima}

La manera factible de obtener cáscara de plátano no contaminada es a través de productores o proveedores de productos a base de pulpa de plátano.

No contamos con precios históricos ni del mercado actual de la cáscara ya que ésta no se comercializa; sin embargo, para determinar los precios de la cáscara se contactó con varios proveedores de productos a base de cáscara de plátano (chifles y harinas en especial) de la costa Norte y Selva del Perú, quienes nos brindaron precios estimados por tonelada de cáscara y costos de flete con IGV, los cuales dependen de tres factores:

- Cantidad de producción de productos a base de plátano.

- El tamaño de mercado en Lima.

- La distancia de la zona productora a Lima. 
En la tabla 2.21, se muestra el promedio de los precios de la cáscara que nos brindaron los diferentes productores de productos a base de pulpa de plátano.

\section{Tabla 2. 21}

Precio de la cáscara de plátano incluyendo flete terrestre (S/. / kg)

\begin{tabular}{|c|c|c|c|c|}
\cline { 2 - 5 } \multicolumn{1}{c|}{} & \multicolumn{2}{c|}{ Selva } & \multicolumn{2}{c|}{ Costa Norte } \\
\cline { 2 - 5 } \multicolumn{1}{c|}{} & Fresca & Deshidratada & Fresca & Deshidratada \\
\hline Precio de cáscara & 0.35 & 0.60 & 2.00 & 5.00 \\
\hline Costo de Flete (terrestre) & 0.25 & 0.40 & 1.00 & 1.00 \\
\hline
\end{tabular}

Nota: Se tomó información brindada por 10 empresas de la Selva y 10 de la Costa Norte.

Elaboración propia

En base a estudios realizados, al secar la cáscara de plátano, esta pierde alrededor del $70 \%$ de su peso, es por ello que se investigaron los precios de cáscara deshidratada. Como se puede apreciar en la tabla 2.21, los productores de productos de plátano procesado nos pueden abastecer tanto de cáscara fresca como de cáscara seca; para el presente estudio se considerará la compra de cáscara fresca ya que los precios de la cáscara seca se elevan casi el $50 \%$ con la posible tendencia de incrementar, además los proveedores demorarían más en abastecernos ya que el secado se realiza al sol y demora entre 3 y 7 días dependiendo de las condiciones climatológicas. 


\section{CAPÍTULO III: LOCALIZACIÓN DE PLANTA}

\subsection{Identificación y análisis detallado de los factores de localización}

A continuación, se presentan los factores que tomaremos en cuenta para determinar la localización de planta:

- Proximidad de materia prima: Uno de los factores más importante para la localización de planta es a proximidad de la materia prima ya que la distancia o la cercanía de los proveedores pueden incrementar o disminuir nuestros costos, así como el tiempo de entrega y reposición. La materia prima principal que se requiere es la cáscara de plátano la cual inicialmente obtendremos de empresas que producen productos derivados de la pulpa de plátano; estas empresas se encuentran mayormente en la Selva y Costa norte del Perú.

- Cercanía al mercado: El mercado objetivo al que va a ir dirigido el producto en estudio es Lima, ya que ahí se concentra la mayor población a nivel nacional. La cercanía al mercado es un factor muy importante ya que la lejanía incrementaría notablemente los costos de distribución del producto terminado. Por tal motivo, la planta deberá ser ubicada en Lima o alguna de sus provincias.

- Disponibilidad de mano de obra: Se debe realizar un análisis de disponibilidad de mano de obra que hay en cada sector en estudio; así como el nivel de educación, preparación y experiencia que requiere la empresa y la fabricación del producto.

- Costo del suministro de energía eléctrica: El consumo de energía eléctrica se realizará tanto en el área de producción para el funcionamiento de maquinarias y equipos, como en las oficinas, comedor, baños y toda el área administrativa.

- Costo del suministro de agua potable: Se requiera agua potable para la limpieza de la materia prima, así como para el uso de los trabajadores de planta, oficina.

- Costo del servicio de transporte: Las vías de acceso a la posible ubicación deben 
estar en buenas condiciones para que el transporte de materia prima y producto terminado se realice eficientemente y a tiempo.

- Costo del terreno: Se debe tomar en cuenta los costos y la disponibilidad de terrenos en cada una de las zonas que vamos analizar para determinar la ubicación de la planta.

\subsection{Identificación y descripción de las alternativas de localización}

- Proximidad de la materia prima: La mayoría de las empresas de productos derivados de la cáscara de plátano se encuentran en la costa norte del Perú (Piura y Chiclayo), y en la selva (Iquitos y Pucallpa). En la tabla 3.1 se muestra la distancia entre los lugares donde se establecen nuestros proveedores de cáscara de plátano hasta las provincias de Lima donde podría estar ubicada la planta: Lima, Cañete y Huara. Estas provincias se han tomado considerando que son las que tienen mayor población en el departamento del Lima. En la tabla 3.1 se muestran las distancias de cada una de las provincias en estudio hacia la zona donde se ubican los proveedores.

\section{Tabla 3. 1}

Distancia de las provincias en estudio hacia los proveedores

\begin{tabular}{|c|c|c|}
\hline Desde & Hasta & Km \\
\hline \multirow{4}{*}{ Piura } & Lima & 984.0 \\
\cline { 2 - 3 } & Cañete & $1,166.0$ \\
\cline { 2 - 3 } & Huaura & 850.0 \\
\hline \multirow{4}{*}{ Chiclayo } & Lima & 765.7 \\
\cline { 2 - 3 } & Cañete & 947.7 \\
\cline { 2 - 3 } & Huaura & 670.1 \\
\hline \multirow{4}{*}{ Pucallpa } & Lima & 740.1 \\
\cline { 2 - 3 } & Cañete & 922.1 \\
\cline { 2 - 3 } & Huaura & 627.1 \\
\hline \multirow{4}{*}{ Iquitos } & Lima & $1,011.0$ \\
\cline { 2 - 3 } & Cañete & $1,093.0$ \\
\cline { 2 - 3 } & Huaura & 944.0 \\
\hline
\end{tabular}

Fuente: Google Maps, (2016)

Elaboración propia 
Como se puede observar, la mayor distancia está entre los proveedores y la provincia de Cañete.

- Cercanía al mercado: El presente proyecto tendrá como mercado objetivo Lima Metropolitana, considerando que en el futuro puede abarcar un mercado más grande. El análisis del factor cercanía de mercado es muy importante ya que está relacionado con los costos de distribución y envío del producto final; para su análisis se tomarán las distancias entre las provincias en estudio y Lima, las cuales se observan en la tabla 3.2.

Tabla 3.2

Distancia de las provincias hacia el mercado

\begin{tabular}{|c|c|}
\hline Provincias & $\mathbf{K m}$ \\
\hline Lima & 0 \\
\hline Cañete & 150.0 \\
\hline Huaura & 127.5 \\
\hline
\end{tabular}

Fuente: Google Maps, (2016)

Elaboración propia

Podemos observar que la provincia más cercana al mercado meta es Lima.

- Disponibilidad de mano de obra: La disponibilidad de mano de obra es un factor muy importante ya que a pesar de que es abundante en el país, hay que considerar que para no ocasionar conflictos sociales y tener buena rentabilidad es preferible contratar a trabajadores de la misma ciudad en la que viven; adema, los costos de trasladar a un trabajador y a su familia son altos. En la tabla 3.3 se puede observar la población en edad de trabajar que se encuentra desocupada en cada una de las provincias en estudio.

Tabla 3.3

Población desocupada: Mano de obra por provincia

\begin{tabular}{|c|c|r|c|c|}
\hline Provincias & Población en edad de trabajar & \multicolumn{1}{c|}{ PEA } & PEA ocupada & PEA desocupada \\
\hline Lima & $7,707,476$ & $5,231,070$ & $4,962,679$ & 268,391 \\
\hline Cañete & 282,527 & 85,048 & 82,088 & 2,960 \\
\hline Huaura & 290,341 & 80,663 & 77,322 & 3,341 \\
\hline
\end{tabular}

Fuente: INEI, (2015)

Elaboración propia 
Podemos observar que el mayor número de personas desocupadas en edad de trabajar se encuentra en la provincia de Lima.

- Costo del suministro de energía eléctrica: Este factor es muy importante ya que es fundamental que la planta cuente con fuentes de energía para su funcionamiento. El factor que se analizará es la tarifa BT5B (no residencial), la cual es para suministro de energía eléctrica de baja tensión mayor a 1.000 kwh, esta tarifa es la que se usa habitualmente plantas.

En la tabla 3.4 se muestran los cargos por energía activa en cada una de las provincias en estudio.

Tabla 3.4

Tarifa BT5B (no residencial) por zona (sin igv)

\begin{tabular}{|c|c|c|}
\hline \multirow{2}{*}{ Provincias } & \multicolumn{2}{|c|}{ Tarifas } \\
\cline { 2 - 3 } & Cargo fijo (S/./ mes) & $\begin{array}{c}\text { Cargo por energía activa (ctm. } \\
\text { S/./ kwh) }\end{array}$ \\
\hline Lima Metropolitana (Norte) & 2.49 & 47.70 \\
\hline Lima Metropolitana (Sur) & 2.49 & 46.42 \\
\hline Cañete & 3.09 & 50.72 \\
\hline Huaura & 5.35 & 180.76 \\
\hline
\end{tabular}

Fuente: OSINERGMIN, (2016)

- Costo de suministro de agua potable: Perú cuenta con tres vertientes hidrográficas: Vertiente de Atlántico (98.2\% de los recursos hídricos), vertiente del Pacífico (1.5\%) y vertiente del Titicaca (0.3\%) (INEI, 2015). Actualmente la población peruana está ubicada en su mayoría en la vertiente del Pacífico.

En el Perú existen 51 entidades prestadoras de servicio (EPS) de agua potable de las cuales 5 de ellas están ubicadas en el departamento de Lima. En la tabla 3.5 se muestra la cobertura en las provincias en estudio. 
Tabla 3.5

Nivel de cobertura de las EPS (2014)

\begin{tabular}{|c|c|c|}
\hline EPS & Provincia & Cobertura (\%) \\
\hline SEDAPAL S.A & Lima & 97.0 \\
\hline EMAPA CAÑETE S.A & Cañete & 72.8 \\
\hline EMAPA HUACHO S.A & Huaura & 94.5 \\
\hline
\end{tabular}

Fuente: SUNASS, (2016)

Además de la cobertura, para un completo análisis de este factor, de deben considerar los costos de suministro de agua potable que se muestran en la tabla 3.6.

Tabla 3.6

Estructura tarifaria para el suministro de agua potable

\begin{tabular}{|c|c|c|c|c|c|}
\hline \multirow[t]{2}{*}{ Empresa de agua } & \multirow[t]{2}{*}{ Categoría } & \multirow{2}{*}{$\begin{array}{l}\text { Rangos } \\
\left(\mathrm{m}^{3} / \mathrm{mes}\right)\end{array}$} & \multicolumn{2}{|c|}{$\begin{array}{c}\text { Tarifa variable }(\mathrm{S} / . / \\
\left.\mathrm{m}^{3}\right)\end{array}$} & \multirow{2}{*}{$\begin{array}{l}\text { Cargo fijo } \\
\text { (S/. / mes) }\end{array}$} \\
\hline & & & Agua & Alcantarillado & \\
\hline \multirow{2}{*}{ SEDAPAL S.A } & \multirow{2}{*}{ Industrial } & 0 a 1000 & 4.85 & 2.19 & \multirow{2}{*}{4.88} \\
\hline & & 1000 a mas & 5.21 & 2.35 & \\
\hline \multirow{2}{*}{ EMAPA CAÑETE S.A } & \multirow{2}{*}{ Industrial } & 0 a 70 & 1.02 & 0.53 & \multirow{2}{*}{1.45} \\
\hline & & 70 a mas & 2.17 & 1.13 & \\
\hline \multirow{2}{*}{ EMAPA HUACHO S.A } & \multirow{2}{*}{ Industrial } & 0 a 60 & 1.85 & 0.82 & \multirow{2}{*}{2.65} \\
\hline & & 60 a mas & 3.93 & 1.75 & \\
\hline
\end{tabular}

Fuente: SUNASS, (2016)

Se puede observar que los costos fijos de agua potable son mayores en Lima comparándolo con las otras provincias en estudio.

- Servicio de transporte: El factor de servicio de transporte es muy importante ya que influye en los costos de traslado de materia prima y distribución de productos terminados; el costo varía de acuerdo a las condiciones de la vía y a las distancias recorridas.

El transporte de carga dominante es el carretero, con una participación del $73.8 \%$ y un costo promedio de 0.043 US\$/ton-km en el 2009 (Ministerio de Comercio Exterior y Turismo, 2009); además, el transporte de carga por carretera es el más utilizado por su rapidez, costo competitivo, flexibilidad de rutas, alta disponibilidad y buena cobertura geográfica. 
Para el presente proyecto, se empleará el servicio de transporte para los insumos secundarios y la entrega de productos terminados a distintos distribuidores. Para el caso del transporte de la cáscara de plátano, lo realizará el mismo proveedor, quien aprovechará de sus volúmenes de producción y venta al mercado de Lima.

Para el transporte local del producto terminado, se debe tener en cuenta las restricciones respecto a las dimensiones de los vehículos que pueden acceder a las zonas urbanas donde están ubicados los almacenes de los Supermercados y bodegas.

- Terreno: Para la elección del terreno donde se implementará la planta se debe considerar que pertenezca a una zona industrial y realizar una serie de trámites en diversas instituciones públicas y municipales.

Los precios de los terrenos en los parques industriales de Lima oscilan entre US\$ 300 y $700 \mathrm{x} \mathrm{m}^{2}$. En la figura 3.1 se muestra el mapa de parques industriales en Lima.

Figura 3. 1

Parques industriales en Lima

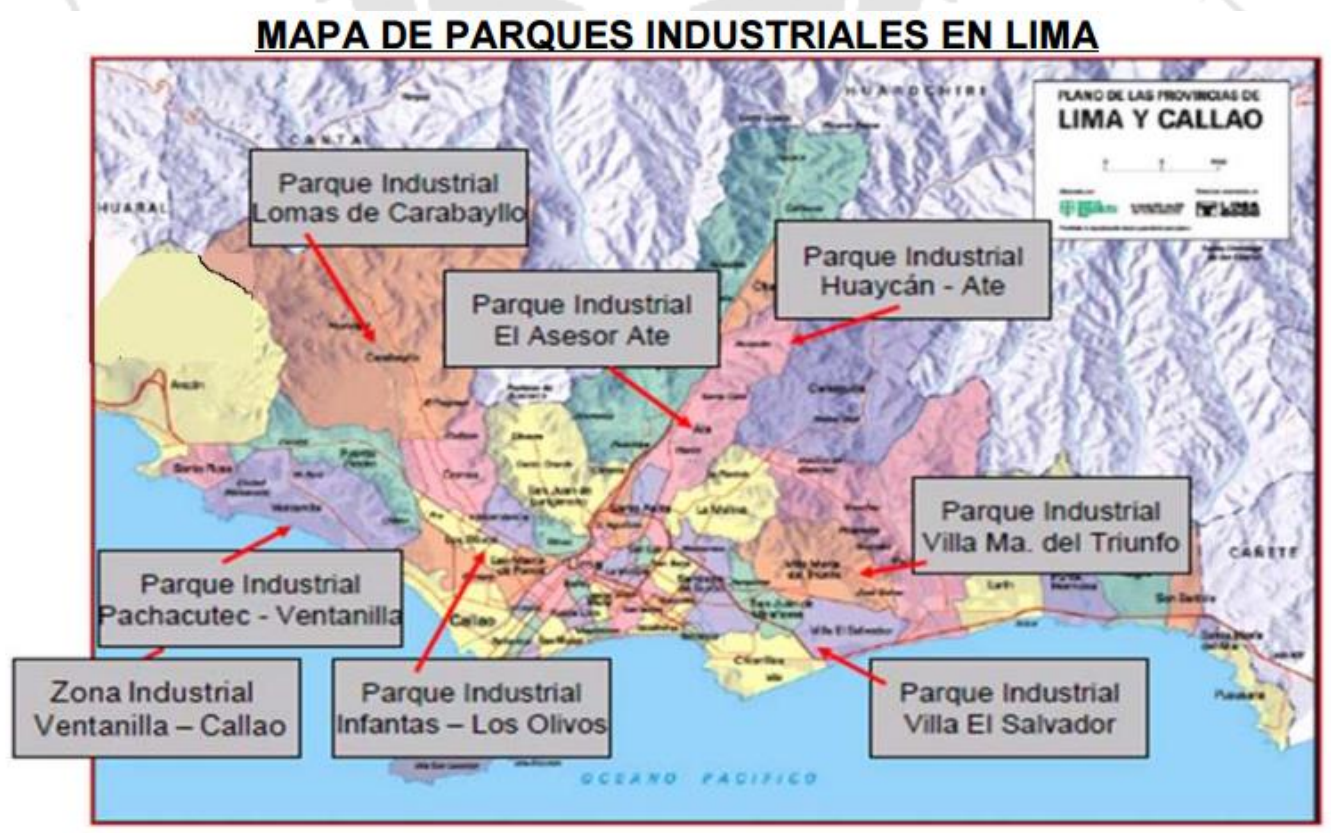

Fuente: Ministerio de Producción, (2015) 
Con respecto a la provincia de Cañete, en el año 2015 se empezó la construcción del primer parque industrial con cumplimiento de todas las normas ambientales; contará con alrededor de 100 lotes de $10,000 \mathrm{~m}^{2}$ con un costo aproximado de US\$ $100 \mathrm{x} \mathrm{m}^{2}$ (Asia Sur, 2015).

Por otro lado, Huacho, capital de Huaura, es el centro industrial de los distritos de la parte alta y media de la provincia; las zonas declaradas industriales son "Carquín” y "El Chururo" que albergan varias fábricas y plantas industriales en la periferia de la ciudad. El precio aproximado de un terreno en Huaura es de US\$ $50 \times \mathrm{m}^{2}$.

\subsection{Evaluación y selección de localización}

Tomando como referencia las tres provincias planteadas y cada uno de los factores mencionados y analizados en el punto anterior, se evaluará y determinará la ubicación ideal para la implementación de la planta en estudio.

\subsubsection{Evaluación y selección de la macro localización}

Para realizar la evaluación y elección de la provincia en la que se ubicará la planta en estudio, se utilizará el método Ranking de Factores. En la tabla 3.7 se muestran las letras con las que identificaremos cada uno de los factores de macro localización analizados anteriormente.

Tabla 3.7

Factores para el análisis de macro localización

\begin{tabular}{|c|c|}
\hline \multicolumn{2}{|c|}{ Factores de macro localización } \\
\hline A & Proximidad de materia prima \\
\hline B & Cercanía al mercado \\
\hline C & Disponibilidad de mano de obra \\
\hline D & Abastecimiento de energía eléctrica \\
\hline E & Abastecimiento de agua \\
\hline F & Servicio de transporte \\
\hline G & Terreno \\
\hline
\end{tabular}

Elaboración propia 
En la tabla 3.8 se muestra la matriz de enfrentamiento, donde se asigna el valor "1" a aquel factor igual de importante o más importante que el factor con el cual es comparado y el valor "0" si el factor analizado es menos importante que el factor con el cual es comparado; además, en la columna del extremo derecho se contabilizan los puntos para cada factor con lo cual se evalúa el porcentaje obtenido.

\section{Tabla 3.8}

Matriz de enfrentamiento de los factores de macro localización

\begin{tabular}{|c|c|c|c|c|c|c|c|c|c|}
\hline Factor & A & B & C & D & E & F & G & Total & Ponderación \% \\
\hline A & & 0 & 1 & 1 & 1 & 1 & 1 & 5 & 19.2 \\
\hline B & 1 & & 1 & 1 & 1 & 1 & 1 & 6 & 23.1 \\
\hline C & 0 & 1 & & 1 & 1 & 1 & 1 & 5 & 19.2 \\
\hline D & 1 & 0 & 1 & & 1 & 1 & 1 & 5 & 19.2 \\
\hline E & 0 & 0 & 0 & 1 & & 1 & 1 & 3 & 11.5 \\
\hline F & 0 & 0 & 0 & 0 & 0 & & 1 & 1 & 3.8 \\
\hline G & 0 & 0 & 0 & 0 & 0 & 1 & & 1 & 3.8 \\
\hline
\end{tabular}

Elaboración propia

Con la ponderación obtenida en la matriz de enfrentamiento mostrada en el Tabla 3.8, se realizará una matriz de evaluación, donde por cada factor se colocará una calificación conforme se muestra en la tabla 3.9. Con esta información se obtiene el puntaje final por cada una de las provincias en estudio. En la tabla 3.10 se muestran los resultados de la matriz de evaluación de localidades de macro localización.

Tabla 3.9

Escala de evaluación

\begin{tabular}{|c|c|}
\hline Estado & Calificación \\
\hline Muy Bueno & 8 \\
\hline Bueno & 6 \\
\hline Regular & 4 \\
\hline Malo & 2 \\
\hline
\end{tabular}

Elaboración propia 
Tabla 3. 10

Matriz de evaluación de localidades de macro localización

\begin{tabular}{|c|c|c|c|c|c|c|c|}
\hline \multirow{2}{*}{ Factor } & \multirow{2}{*}{ Ponderación } & \multicolumn{3}{|c|}{ Lima } & \multicolumn{2}{c|}{ Cañete } & \multicolumn{2}{c|}{ Huaura } \\
\cline { 3 - 9 } & & Calificación & Puntaje & Calificación & Puntaje & Calificación & Puntaje \\
\hline A & 19.2 & 4 & 76.9 & 2 & 38.4 & 6 & 115.3 \\
\hline B & 23.0 & 8 & 184.6 & 2 & 46.1 & 4 & 92.3 \\
\hline C & 19.2 & 8 & 153.8 & 4 & 76.9 & 4 & 76.9 \\
\hline D & 19.2 & 8 & 153.8 & 6 & 115.3 & 4 & 76.9 \\
\hline E & 11.5 & 6 & 69.2 & 4 & 46.1 & 6 & 69.2 \\
\hline F & 3.8 & 8 & 30.7 & 4 & 15.3 & 4 & 15.3 \\
\hline G & 3.8 & 4 & 15.3 & 4 & 15.3 & 8 & 30.7 \\
\hline \multicolumn{2}{|c|}{684.62} & \multicolumn{7}{c|}{353.85} & 476.92 \\
\hline
\end{tabular}

Elaboración propia

La provincia donde se ubicará la planta en estudio será Lima, ya que es la que obtuvo mayor puntaje en la matriz de evaluación de localidades.

\subsubsection{Evaluación y selección de la micro localización}

Luego de haber determinado que la provincia en la que se ubicará la planta será Lima, se realizará un análisis de micro localización en el que se evaluará el distrito más conveniente para la localización de planta.

Uno de los factores importantes que se debe tomar en cuenta para determinar el distrito, es la ubicación de los parques industriales; en la figura 3.1 se puede observar que los distritos Carabayllo, Ate, Ventanilla, Los Olivos, Villa el Salvador y Villa María del Triunfo cuentan con parques industriales; de estos distritos, se tomarán los 3 con mayor población de los NSE B, C y D; estos son: Los Olivos, Ate y Villa María del Triunfo.

Como se muestra en la figura 3.2, los distritos escogidos para el estudio se encuentran localizados en diferentes zonas de lima. 
Figura 3. 2

Distritos en estudio para la localización de planta: Los Olivos, Ate y Villa María del Triunfo

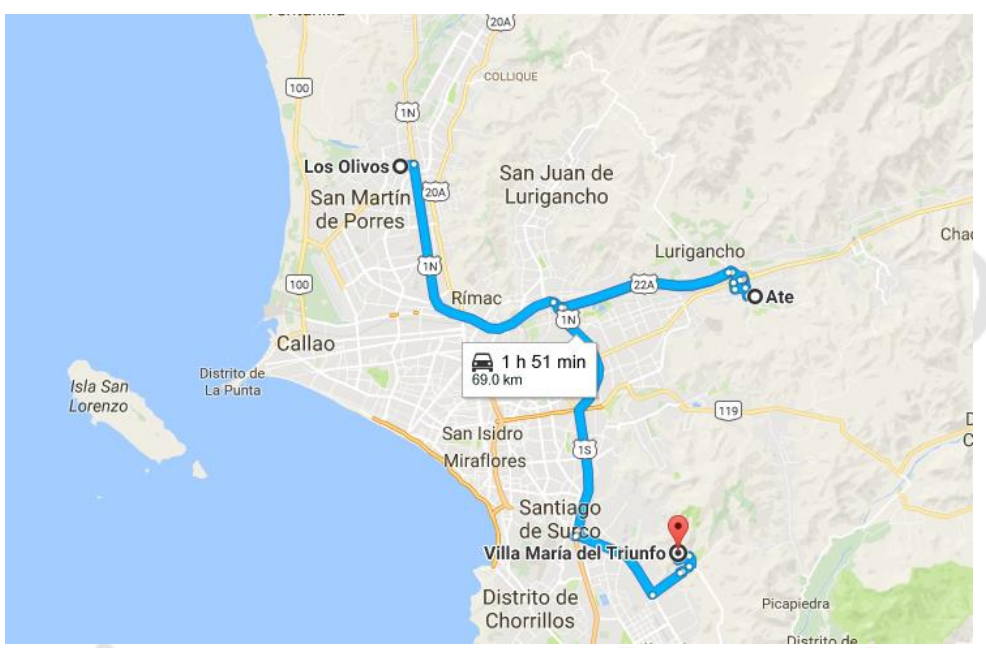

Fuente: Google Maps, (2016)

Para realizar el análisis de micro localización se considerarán los factores mostrados en la tabla 3.11, los cuales se relacionaron con una letra.

\section{Tabla 3. 11}

Factores para el análisis de micro localización

\section{Factores de micro localización}

\begin{tabular}{|c|c|}
\hline A & Costo del terreno \\
\hline B & Seguridad ciudadana \\
\hline C & Facilidades municipales \\
\hline D & Disponibilidad de terreno \\
\hline
\end{tabular}

Elaboración propia

A continuación, se analizará cada uno de ellos:

- Costo del terreno: La industria peruana no solo afronta un déficit de terrenos para sus actividades industriales, sino también el problema de que los precios son muy elevados, incluso cinco veces más que los de otras capitales de Sur América.

En la tabla 3.12 se muestra en promedio, los precios de terrenos por metro cuadrado en cada uno de los distritos en estudio. 
Tabla 3.12

Precio de $\mathrm{m}^{2}$ de terreno por distrito

\begin{tabular}{|c|c|}
\hline Distrito & Precio $\mathbf{x} \mathbf{~ m}^{2}$ (US\$) \\
\hline Villa María del Triunfo & 624.8 \\
\hline Ate & 907.7 \\
\hline Los Olivos & 945.0 \\
\hline
\end{tabular}

Nota: Se tomaron promedios de 5 terrenos de cada distrito

Elaboración propia

Podemos observar que los precios de terrenos en el distrito de Villa María del Triunfo son menores que los de Ate y los Olivos.

\section{- Seguridad Ciudadana:}

Se considera como un factor muy importante la seguridad ciudadana, ya que tenemos la función de asegurar la convivencia pacífica, la erradicación de la violencia, la utilización pacífica y ordenada de vías y espacios públicos, así como evitar la comisión de delitos y faltas contra las empresas, las personas y sus bienes.

Un indicador importante para aproximarse a la situación de inseguridad en el país es la cantidad de denuncias por delitos que se ha realizado.

\section{Tabla 3. 13}

Cantidad de denuncias por delitos (2014)

\begin{tabular}{|c|c|}
\hline Distrito & Denuncias de delitos \\
\hline Villa María del Triunfo & 3,346 \\
\hline Ate & 7,259 \\
\hline Los Olivos & 6,322 \\
\hline
\end{tabular}

Fuente: Seguridad Ciudadana, (2015)

\section{- Facilidades municipales:}

En el 2007, el Instituto Nacional de Defensa del Consumidor y de la Protección a la Propiedad Intelectual (INDECOPI) elaboró un informe denominado "Índice de Acceso al Mercado" (IAM) el cual mide el nivel de adecuación de las municipalidades al marco legal y nos indica las facilidades que las municipalidades de las provincias de Lima y Callao ofrecen. 
Para el estudio se tomaron las leyes requeridas para tramitar licencias de funcionamiento tanto provisionales como definitivas, autorización de trabajos en la vía pública, así como implementación de anuncios publicitarios y la aprobación y publicación de los Textos Únicos de Procesamientos Administrativos (TUPA) de cada distrito. El documento IAM indica que el nivel máximo de Índice de Acceso al Mercado lo tiene en primer lugar la Municipalidad del Callao, en segundo lugar, Ate, en tercer lugar, el Agustino, el cuarto lugar Lima y en quinto lugar San Isidro. El distrito Villa María del Triunfo se encuentra en el puesto 18 y los Olivos en el 42 (Indecopi, 2008).

\section{- Disponibilidad de terreno:}

Considerando que los distritos en estudio se encuentran ubicados en el Norte, Sur y Centro de Lima, se tomará en cuenta la oferta de propiedades industriales y almacenes existentes en cada zona mencionada. En la figura 3.3 se muestra dicha distribución.

Figura 3.3

Oferta existente de propiedades industriales (2011)

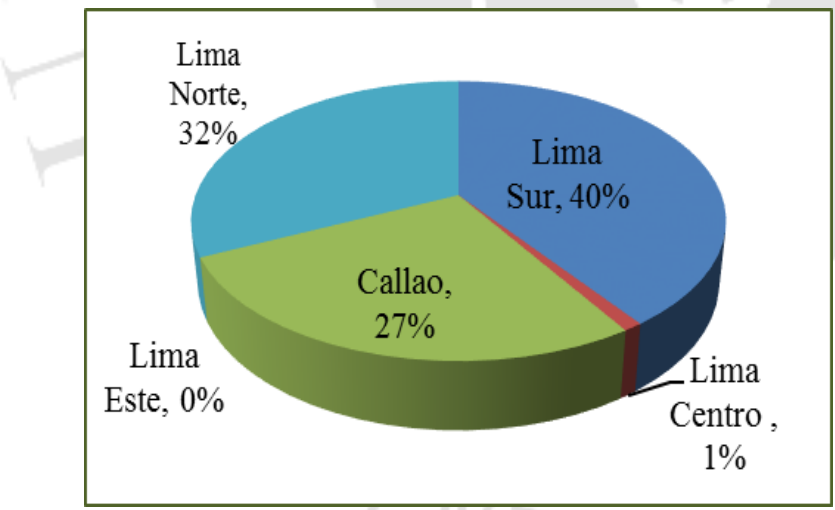

Fuente: MarketView, (2011)

Luego de analizar cada uno de los factores de la micro localización, se hallará la ponderación de cada uno de ellos realizando la matriz de enfrentamiento de factores que se muestra en la tabla 3.14 . 
Tabla 3.14

Matriz de enfrentamiento de factores

\begin{tabular}{|c|c|c|c|c|c|c|}
\hline Factor & A & B & C & D & Total & Ponderación \% \\
\hline A & & 0 & 1 & 0 & 1 & 14.3 \\
\hline B & 1 & & 1 & 1 & 3 & 42.8 \\
\hline C & 0 & 0 & & 1 & 1 & 14.3 \\
\hline D & 1 & 0 & 1 & & 2 & 28.6 \\
\hline
\end{tabular}

Elaboración propia

Con los datos de ponderación hallados y la escala de evaluación que se muestra en la tabla 3.9, realizaremos la matriz de localidades de micro localización, donde se halla el puntaje final por cada distrito en estudio (tabla 3.15).

Tabla 3.15

Matriz de localidades de micro localización

\begin{tabular}{|c|c|c|c|c|c|c|c|}
\hline \multirow{2}{*}{ Factor } & \multirow{2}{*}{ Ponderación } & \multicolumn{2}{|c|}{ Villa María del Triunfo } & \multicolumn{2}{c|}{ Ate } & \multicolumn{2}{c|}{ Los Olivos } \\
\cline { 3 - 9 } & & Calificación & Puntaje & Calificación & Puntaje & Calificación & Puntaje \\
\hline A & 14.3 & 6 & 85.7 & 2 & 28.6 & 2 & 28.6 \\
\hline B & 42.8 & 6 & 257.1 & 4 & 171.4 & 2 & 85.7 \\
\hline C & 14.3 & 4 & 57.1 & 8 & 114.3 & 2 & 28.6 \\
\hline D & 28.6 & 6 & 171.4 & 2 & 57.1 & 4 & 114.3 \\
\hline \multicolumn{2}{|c|}{ TOTAL } & \multicolumn{2}{|c|}{571.4} & \multicolumn{2}{|c|}{371.4} & \multicolumn{2}{|c|}{257.1} \\
\hline
\end{tabular}

Elaboración propia

Luego de haber realizado el análisis de macro y micro localización determinamos que la plata se ubicará en el distrito de Villa María del Triunfo perteneciente a la provincia de Lima. 


\section{CAPÍTULO IV: TAMAÑO DE PLANTA}

Para determinar la medida de la unidad del producto que elaboraremos, en la encuesta realizada en el capítulo de estudio de mercado se hizo la pregunta ¿Qué tamaño de betún para calzado consume con mayor frecuencia? El resultado se muestra en la figura 4.1.

Figura 4. 1

Resultado de la encuesta: ¿Qué tamaño de betún para calzado consume con mayor frecuencia?

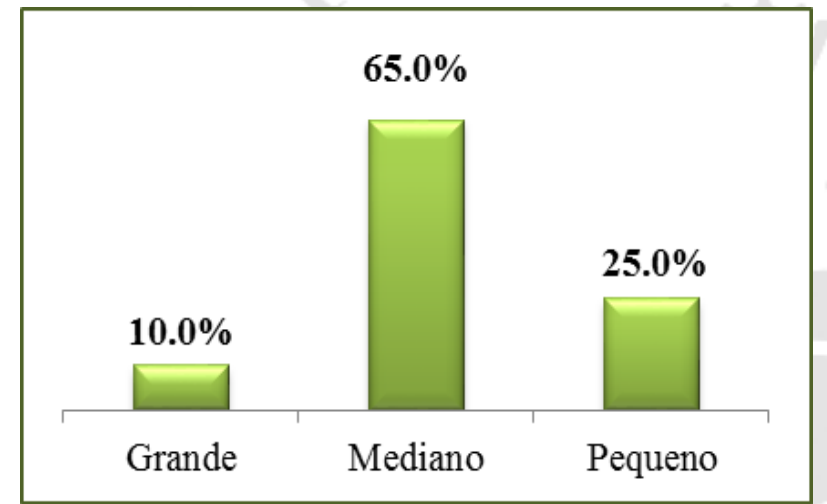

Elaboración propia

Como se puede observar en los resultados a la pregunta de la encuesta, el $65 \%$ prefiere tamaño mediano; por ello se tomará como unidad envases de $50 \mathrm{gr}$ de betún para calzado.

\subsection{Relación tamaña - mercado}

En este punto, se determinará la cantidad de unidades de producto final que se debe producir para satisfacer la demanda del proyecto. En la tabla 4.1 se muestra la demanda en unidades de producto para el presente proyecto. 
Tabla 4. 1

Demanda del mercado en unidades de producto final

\begin{tabular}{|c|c|c|}
\hline Año & $\begin{array}{c}\text { Demanda del } \\
\text { Proyecto }(\mathrm{Kg})\end{array}$ & $\begin{array}{c}\text { Unidades } \\
\text { de 50gr }\end{array}$ \\
\hline 2016 & $55,881.5$ & $1,117,629.7$ \\
\hline 2017 & $60,496.5$ & $1,209,929.5$ \\
\hline 2018 & $65,111.5$ & $1,302,229.4$ \\
\hline 2019 & $69,726.5$ & $1,394,529.2$ \\
\hline 2020 & $74,341.5$ & $1,486,829.1$ \\
\hline 2021 & $78,956.4$ & $1,579,128.9$ \\
\hline 2022 & $83,571.4$ & $1,671,428.8$ \\
\hline
\end{tabular}

Elaboración propia

En el último año de operación se requerirá una capacidad productiva máxima de $1,671,428.8$ unidades de producto final.

\subsection{Relación tamaña - recursos productivos}

Se realizará el análisis tamaño-recurso productivo para determinar la cantidad de recursos necesarios para cubrir la demanda del proyecto.

Los recursos productivos a utilizar en el presente proyecto son:

- Insumos: Cáscara de plátano o banano, glicerina, benzoato de sodio, borato de sodio y anilina (colorante orgánico).

- Materiales: Envases y etiquetas.

- Servicio: Energía eléctrica y servicio de agua potable.

- Mano de obra.

Se evaluará principalmente la disponibilidad de cáscara de plátano y banano en el mercado ya que es el insumo principal del producto y su escasez puede limitar el tamaño de planta.

En la tabla 4.2 se muestra el consumo total de plátano y banano en el 2012, así como su equivalente en cáscara: 
Tabla 4. 2

Consumo de plátano y banano equivalente en cáscara 2012 (miles de toneladas)

\begin{tabular}{|c|c|c|}
\cline { 2 - 3 } \multicolumn{1}{c|}{} & Consumo de plátano y banano & Cantidad de cáscara \\
\hline Banano & $1,963.5$ & 589.1 \\
\hline Plátano & $1,062.0$ & 318.6 \\
\hline Total & $3,025.5$ & 907.7 \\
\hline
\end{tabular}

Fuente: Ministerio de Agricultura y Riego, (2014)

Elaboración propia

Para determinar si la cáscara de plátano es limitante o no, se hallarán los kg de cáscara necesarios para cubrir la demanda del 2022.

En la tabla 4.3 se muestra el porcentaje de utilización de la cáscara de plátano disponible del 2012 para cubrir la demanda del último año del proyecto.

Tabla 4.3

Cantidad de cáscara a utilizar en el último año del proyecto

\begin{tabular}{|c|c|c|c|c|c|}
\cline { 2 - 6 } & $\begin{array}{c}\text { Cantidad de cáscara } \\
\text { disponible en el 2012 } \\
\text { (miles de toneladas) }\end{array}$ & $\begin{array}{c}\text { Demanda del } \\
\text { proyecto } 2022 \\
(\mathrm{~kg})\end{array}$ & $\begin{array}{c}\mathrm{kg} \text { de } \\
\text { cáscara para } \\
1 \mathrm{~kg} \text { de } \\
\text { betún }\end{array}$ & $\begin{array}{c}\text { kg de cáscara } \\
\text { necesarios para la } \\
\text { producción del 2022 }\end{array}$ & $\begin{array}{c}\text { Utilización de } \\
\text { cáscara de } \\
\text { plátano }(\%)\end{array}$ \\
\hline Total & $3,025.5$ & $83,571.4$ & 1.6 & $376,071.5$ & 0.012 \\
\hline
\end{tabular}

Elaboración propia

Como se observa, el porcentaje de utilización de la cáscara de plátano disponible en el 2012 para la producción de betún en el 2022 no llega ni al 1\% del total disponible. Podemos concluir que el recurso materia prima no es limitante.

\subsection{Relación tamaño - tecnología}

El factor tecnológico es fundamental ya que puede limitar el tamaño de planta. Se consideran máquinas y equipos que faciliten el proceso productivo, minimizando las demoras y los tiempos de ocio, esto permitirá una producción en gran volumen que respete los estándares de calidad. En la tabla 4.4 se puede observar el tiempo estándar por cada máquina. 
Para el cálculo de las capacidades en kg de la caldera mezcladora y envasadora, se consideró la densidad del producto terminado hallada en las pruebas experimentales de laboratorio: $0.94 \mathrm{gr} / \mathrm{ml}$.

Tabla 4.4

Tiempo estándar de producción

\begin{tabular}{|c|c|c|c|}
\hline Máquinas & Capacidad & Capacidad en kg & Unidades por hora \\
\hline Lavadero & $200 \mathrm{~kg} / \mathrm{hora}$ & $200 \mathrm{~kg} / \mathrm{hora}$ & 1,778 \\
\hline Deshidratador & $300 \mathrm{~kg} / \mathrm{hora}$ & $300 \mathrm{~kg} / \mathrm{hora}$ & 1,333 \\
\hline Moledor & $200 \mathrm{~kg} / \mathrm{hora}$ & $200 \mathrm{~kg} / \mathrm{hora}$ & 9,560 \\
\hline Tamiz & $1000 \mathrm{Lt} / \mathrm{hora}$ & $581 \mathrm{~kg} / \mathrm{hora}$ & 27,772 \\
\hline Caldera mezcladora & $500 \mathrm{Lt} / \mathrm{hora}$ & $471 \mathrm{~kg} / \mathrm{h}$ & 9,420 \\
\hline Envasadora & 3600 envases/ hora & $180 \mathrm{~kg} / \mathrm{hora}$ & 3,600 \\
\hline Etiquetadora & 3600 envases/hora & 3600 envases/hora & 3,600 \\
\hline
\end{tabular}

Elaboración propia

El factor limitante de la operación será el cuello de botella; el cual, como se muestra en la tabla 4.4, es el proceso de secado o deshidratado con una capacidad de 1,333 unidades por hora.

Para el cálculo de tamaño de planta por tecnología, además del tiempo estándar de producción, se considerará que la planta trabajará 5 días a la semana, 1 turno de 8 hora diario; además, se descontará un tiempo de reparación aleatorio acumulativo de 1 hora diaria, el cual se utilizará para atención de calibración y buen funcionamiento de las máquinas a pesar de contar con un programa de mantenimiento preventivo. En la tabla 4.5 se muestra el tamaño de planta por tecnología.

Tabla 4.5

Tamaño de planta por tecnología

\begin{tabular}{|l|c|c|c|c|c|}
\hline Operación & $\begin{array}{c}\text { Producción/hora } \\
\text { (unidades) }\end{array}$ & $\begin{array}{c}\text { Horas } \\
\text { reales/turno }\end{array}$ & $\begin{array}{c}\text { Turnos / } \\
\text { día }\end{array}$ & Días/año & $\begin{array}{c}\text { Unidades de envases de } \\
\text { betún (50gr) al año }\end{array}$ \\
\hline Deshidratar & 1,333 & 7 & 1 & 260 & $2,426,060$ \\
\hline
\end{tabular}

Elaboración propia 
Se puede observar que la tecnología no limita el tamaño de planta, ya que la operación cuello de botella me da una producción mayor a la demanda en el último año de estudio.

\subsection{Relación tamaño - inversión}

La inversión total del proyecto está conformada por la inversión tangible, intangible y el capital de trabajo.

La inversión fija tangible para el presente proyecto está conformado por la adquisición del terreno, maquinarias y equipos de oficina, edificaciones, vehículos, muebles e imprevistos; lo cual nos da un total de S/. 1, 532,485.0.

La inversión fija intangible incluye los gastos de reclutamiento de personal, gastos financieros y administrativos pre operarios, gastos de puesta en marcha, gastos de prefactibilidad, software, supervisión y capacitaciones; lo cual no da un total de S/. 14,776.0.

El capital de trabajo como se explicará al detalle más adelante, está conformado por los gastos que se generan antes de que la empresa perciba ingresos de dinero por ventas; para este proyecto se estima S/. 401,929.8.

En la tabla 4.6 se observa el total de la inversión para el presente proyecto.

Tabla 4. 6

Inversión total para la implementación del proyecto

\begin{tabular}{|c|c|}
\cline { 2 - 2 } \multicolumn{1}{c|}{} & Inversión (S/.) \\
\hline Inversión fija tangible & $1,532,485.0$ \\
\hline Inversión fija intangible & $14,776.0$ \\
\hline Capital de trabajo & $401,929.8$ \\
\hline Total & $\mathbf{1 , 9 4 9 , 1 9 0 . 8}$ \\
\hline
\end{tabular}

Elaboración propia

La cuantificación de los recursos monetarios suficientes para implementar y poner en marca el presente proyecto se analizará al detalle el en capítulo 7. 


\subsection{Relación tamaño - punto de equilibrio}

El punto de equilibrio es el estado de equilibrio entre ingresos y egresos de la empresa, es decir, es el nivel del negocio en el cual los ingresos igualan a los egresos; por lo tanto, no hay ganancia ni pérdida.

Para hallar el punto de equilibrio se deben considerar los costos fijos y variables unitarios de la empresa, los cuales se analizarán con más detalle y exactitud en el capítulo 7 del presente estudio, y el precio de venta (PV) del producto final, el cual, después del análisis de precios se ha definido que será S/. 2.00 sin IGV por cada unidad de 50 gr. En las tablas 4.7 y 4.8 se muestran los costos variables unitarios y los costos fijos considerados.

Tabla 4.7

Costos variables unitarios considerados por cada envase de $50 \mathrm{gr}$

\begin{tabular}{|c|c|}
\hline Suministros & S/./ Unidad \\
\hline Luz & 0.002 \\
\hline Agua & 0.005 \\
\hline $\begin{array}{c}\text { Materia prima e } \\
\text { insumos }\end{array}$ & 1.114 \\
\hline Total & $\mathbf{1 . 1 2 0}$ \\
\hline
\end{tabular}

Elaboración propia

Tabla 4.8

Costos fijos anuales considerados (S/)

\begin{tabular}{|c|c|}
\hline Costos fijos & Año \\
\hline Mano de obra directa & $76,510.7$ \\
\hline Depreciación fabril & $26,408.5$ \\
\hline $\begin{array}{c}\text { Gasto total de } \\
\text { administración }\end{array}$ & $408,404.0$ \\
\hline Gastos de ventas & $48,000.0$ \\
\hline $\begin{array}{c}\text { Amortización de } \\
\text { intangibles }\end{array}$ & $1,377.6$ \\
\hline $\begin{array}{c}\text { Depreciación no } \\
\text { fabril }\end{array}$ & $6,250.0$ \\
\hline Total & $\mathbf{5 6 6 , 9 5 0 . 8}$ \\
\hline
\end{tabular}

Elaboración propia

Para hallar el punto de equilibrio, tenemos la siguiente fórmula:

$$
\text { Punto de equilibrio }=\frac{\text { Costo fijo }}{P v u-C v u}
$$

Reemplazando tenemos: Punto de equilibrio $=644,262$ unidades. 


\subsection{Selección del tamaño de planta}

En la tabla 4.9 se muestra el tamaño de planta determinado por cada factor analizado.

Tabla 4.9

Selección del tamaño de planta

\begin{tabular}{|c|r|}
\hline Factor limitante & Envases (50gr) \\
\hline Tamaño mercado & $1,671,429.0$ \\
\hline Tamaño - recursos productivos & No es limitante \\
\hline Tamaño - tecnología & $2,426,060.0$ \\
\hline Tamaño inversión & $1,949,190.8$ \\
\hline Tamaño - punto de equilibrio & $644,262.0$ \\
\hline
\end{tabular}

Elaboración propia

Como se observa, ninguno de los factores analizados en limitante para el tamaño de planta; por ello, para cumplir con el mercado meta tomaremos como tamaño máximo de planta el mercado. 


\section{CAPÍTULO V: INGENIERÍA DEL PROYECTO}

\subsection{Definición técnica del producto}

\subsubsection{Especificaciones técnicas del producto}

El producto en estudio tiene como materia prima principal la cáscara de plátano, lo cual lo convierte en un producto ecológico y sostenible con el cuidado del medio ambiente; además tiene como principal función dar lustre, mejorar la apariencia y aumentar la vida útil del calzado. En la cutícula de la cáscara de plátano encontramos ceras epicuticulares que ayudan a mejorar la repelencia al agua y crean una propiedad de auto - limpieza, este es el compuesto activo que le permite al producto en estudio brindar al calzado buena resistencia, insolubilidad e impenetrabilidad de humedad y agentes externos; además, al ser untado al calzado, origina una capa protectora que al ser frotada da lustrosidad.

El producto final tendrá las siguientes características:

- Características físicas: El producto final será una pasta de color negro, ya que, en base a la encuesta realizada previamente, el $94 \%$ de clientes consumen betún de color negro; sin embargo, se realizarán próximos estudios para la elaboración de betún de otros colores.

- Composición química: Los componentes principales son cáscara de plátano, glicerina, benzoato de Sodio, borato de Sodio, glicerina, y colorante orgánico de color negro.

- Forma de presentación: El producto final se presentará en envases de plástico reciclado de 50gr con tapa abre fácil y etiqueta con la información del producto.

- Usos: La función principal del producto en estudio es limpiar y proteger el calzado de cuero o similares, para lo cual se recomienda retirar el polvo del calzado, luego, untar el producto y lustrar hasta que brille y no quede algún residuo. 
En el proceso de elaboración del betún orgánico se considerará un sistema que permita controlar la composición y la dosificación de cada uno de los insumos para cumplir con los estándares y obtener un producto de calidad.

\subsubsection{Composición del producto}

En la tabla 5.1 se muestra la composición por cada $50 \mathrm{gr}$ del producto final, considerando que esta será la cantidad de betún ecológico por cada envase.

\section{Tabla 5. 1}

Composición del betún ecológico por envase de 50gr

\begin{tabular}{|c|c|}
\hline Composición del betún ecológico & $\%$ \\
\hline Cáscara de plátano pulverizada & 42.0 \\
\hline Glicerina & 56.0 \\
\hline Benzoato de Sodio & 0.8 \\
\hline Borato de Sodio & 0.8 \\
\hline Colorante orgánico & 0.8 \\
\hline
\end{tabular}

Elaboración propia

Se puede observar que los insumos que presentan mayor porcentaje del producto final son cáscara de plátano pulverizada y glicerina.

\subsubsection{Diseño gráfico del producto}

El diseño del envase del producto en estudio debe mostrar principalmente que se trata de un betún orgánico que tiene las propiedades de limpiar, dar brillo y proteger el calzado de cuero o similares tan bien como las pastas que actualmente se comercializan. Además, se tendrán en cuenta los detalles principales tales como el color y cantidad, así mismo se mostrará indirectamente que el producto proviene de la cascara de plátano. 
Figura 5. 1

Diseño del envase del betún ecológico de 50gr.

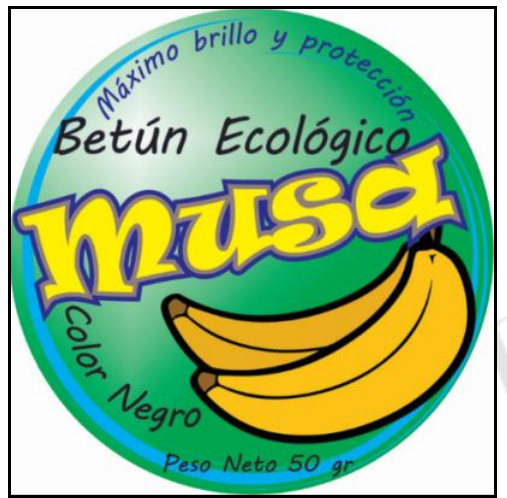

Elaboración propia

\subsubsection{Regulaciones técnicas del producto}

Propiedades físicas y químicas del betún industrial (Protokimica):

- Color: Negro

- Densidad: $0.83 \mathrm{gr} / \mathrm{ml}$

- Kilo/Galón: 3.18

- $\%$ de sólido: 36.4

- Olor: Característico.

Características técnicas del betún en estudio:

- Color: Negro

- Humedad: $29.6 \%$

- Densidad: $0.94 \mathrm{gr} / \mathrm{ml}$

- $\quad \mathrm{Ph}: 7.5$

Instrucciones de uso del betún en general:

1) Limpiar y secar superficie a proteger.

2) Aplicar betún uniformemente y dejarlo secar.

3) Remover con cepillo hasta obtener brillo. 


\subsection{Tecnologías existentes y proceso de producción}

Para la elaboración del betún ecológico a base de cáscara de plátano, se requiere máquinas industriales con las que actualmente contamos tanto en el mercado nacional como el internacional. Estas son: Deshidratador, moledor o molino, malla o tamiz, tanque mezclador con chaqueta, dosificador, envasadora y etiquetadora.

\subsubsection{Naturaleza de la tecnología requerida}

\subsubsection{Descripción de la tecnología existente}

El proceso de elaboración del betún ecológico a base de cáscara de plátano es nuevo en la industria; sin embargo, como se indicó anteriormente, la tecnología y maquinaria existen tanto en el mercado peruano como en el internacional.

A continuación, detalla la tecnología existente para cada una de las etapas del proceso productivo:

A. Secado: El proceso inicial al cual está sometida la cáscara de plátano fresca es el secado, el cual consiste en la eliminación del agua en forma progresiva. Existen varios métodos y máquinas de secado, las cuales se presentan a continuación:

- Secado Solar: En este método se utiliza como fuente de energía los rayos solares; para realizarlo, se debe esparcir la materia prima en una superficie limpia y dejarla secar durante un periodo de 3 a 7 días dependiendo de la temperatura y de la estación (invierno o verano). La cantidad a secar depende del área disponible que está expuesta al sol y se debe considerar que, por el tiempo de demora del secado al aire libre, la cáscara puede sufrir algún tipo de deterioro.

- Secador rotatorio a vapor de agua: Este equipo consta de un cilindro hueco que gira sobre su eje con una ligera inclinación que permitir el desliz de los sólidos a secar hacia la boca de salida, por donde se alimenta el gas caliente que habrá de secar a contracorriente el sólido deslizado. El calentamiento se realiza por contacto directo a través del cilindro que se caliente por el paso de los gases. 
- Secador de bandejas: El secador de bandejas o secador de anaqueles, consiste en un gabinete donde se alojan los materiales a secar. En el gabinete del secador, corre gran cantidad de aire calentado por vapor, de modo que puede arrastrar suficiente agua para conseguir un secado eficiente de sólidos.

- Secador continuo de túnel: Este tipo de secador está formado por un túnel, por donde pasan bandejas o carretillas con el material a secar; dentro del túnel, se hace fluir, generalmente a contracorriente, aire caliente que finalmente seca los sólidos.

B. Molienda: El material secado deber ser molido hasta obtener partículas de pequeño diámetro $(0.25 \mathrm{~mm})$. La tecnología existente para la molienda es: Por compresión (reducción grosera de sólidos duros), por impacto (martillo), por roce o desgaste (adecuado para materiales blandos), por corte (tijeras o cuchillas) y por desgarramiento (adecuado para materiales blandos).

Los tipos de molinos que existen con las tecnologías mencionadas son:

- Molino de Martillo: Este equipo, tiene una velocidad de giro de 10,000 rpm la cual permite la salida del producto pulverizado con tamaño de partícula entre $20-50 \mu \mathrm{m}$ $(0.02-0.05 \mathrm{~mm})$.

- Molino de bolas: Este tipo de molino no lo consideramos ya que el molido se realiza por rose o desgaste, y tal como se mencionó anteriormente, no es adecuado para materiales sólidos duros.

- Molino de rodillo: La velocidad de este equipo oscila entre 50 y 300 rpm; se considera como un sistema de reducción intermedia ya que el producto final mide alrededor de $75 \mu \mathrm{m}(0.075 \mathrm{~mm})$.

- Molino de hélices o cuchillas: Este equipo cuenta con cuchillas fijas que funcionan a una velocidad de 200 a $900 \mathrm{rpm}$. Uno de los factores que afectan el tamaño del material final es la coincidencia en la distancia de separación entre cuchillas móviles y fijas. El tamaño final obtenido es aproximadamente mayor a $100 \mu \mathrm{m}(0.1$ $\mathrm{mm})$. 
C. Tamizado: Luego de la etapa de molienda, es necesario homogeneizar el tamaño de partículas. Se requiere que el tamaño final de las partículas sea menos a 0.25 $\mathrm{mm}$.

D. Mezclado: La cáscara pulverizada se mezcla con glicerina, benzoato de Sodio, borato de Sodio y trementina a una temperatura de $100^{\circ} \mathrm{C}$ por 30 minutos. Para lo cual disponemos de tanques mezcladores con chaqueta con una temperatura mínima de $100^{\circ} \mathrm{C}$.

E. Envasado: Luego de mezclar los componentes, se procede a envasar la mezcla en envases redondos de plástico reciclado; en este proceso, se debe revisar que la cantidad ingresada a cada envase sea la correcta. En el mercado se encuentran varios modelos de máquinas envasadora para este tipo de envases, en las cuales se puede calibrar la cantidad se producto final que se requiera. Para la elección del equipo, se considerará principalmente la capacidad, el nivel de eficiencia y costo, tomando en cuenta que para el presente producto no es necesario envasar al vacío.

F. Etiquetado: Luego del envasado y tapado del producto, se coloca la etiqueta encima de la tapa; para ello, en el mercado contamos con las siguientes tecnologías de etiquetadora:

- Etiquetadora de doble cara de alta velocidad: Diseñada para etiquetar superficies de objetos cuadrados, planos o redondos en industrias químicas, alimenticias o farmacéuticos. Tiene la capacidad de colocar etiquetas simples o dobles al mismo tiempo.

- Etiquetadoras horizontales automáticas: Son principalmente usadas para el etiquetado automático e impresión de códigos para las botellas con diámetro pequeño como botellas de ampollas, y envases de vía oral en la industria farmacéutica. 
- Etiquetadora vertical automática: Este tipo de etiquetadoras es usada principalmente para etiquetar contenedores cilíndricos, cuadrados o cónicos para productos medicinales, artículos de uso diario o alimentos.

G. El material del envase que se eligió para el producto final es plástico reciclado; ya que, el plástico es un material que tarda mucho en degradarse y actualmente, luego de desecharse se amontona en los océanos, mares o en cualquier otro lugar, provocando la contaminación en agua, tierra y atmosfera.

Los tipos de plástico y el producto que se obtiene luego de su reciclado se presenten a continuación:

- Polietileno tereftalato (PET): Este tipo de plástico se utiliza principalmente en la producción de botellas para bebidas. A través de su reciclado se puede obtener fibras para relleno de bolsas de dormir, alfombras y almohadas.

- Polietileno de alta densidad (HDPE): El tipo de plástico se utiliza en envases contenedores de leche, detergente o aceite para motor. Con el producto que se obtiene luego de su reciclaje se puede elaborar macetas, contenedores de basura y botellas de detergente.

- Cloruro de polivinilo (PVC): El PVC es utilizado en botellas contenedoras de shampoo, envases de aceite de cocina, artículos de servicio de comida rápida, etc. Del reciclaje de este material se puede obtener tubos de drenaje e irrigación.

- Polietileno de baja densidad (LDPE): Este tipo de plástico se encuentra en bolsas de supermercado, de pan y plástico para envolver alimentos. Tras su reciclado se puede obtener bolsas de supermercado nuevamente y contenedores.

- Polipropileno (PP): El polipropileno se utiliza en los recipientes contenedores de yogurt, sorbetes, tapas de botella, etc. Con este plástico reciclado se puede obtener viguetas de plástico, peldaños para registros de drenaje y cajas de baterías para autos. 
- Polietireno (PS): El PS se encuentra en tazas desechables de bebidas calientes y bandejas de carne. Este plástico puede reciclarse como viguetas de plástico, cajas de cintas para casetes y macetas

\subsubsection{Selección de la tecnología}

Considerando cada una de las tecnologías explicadas en el punto anterior; por cada etapa del proceso de producción del producto en estudio se toma la más conveniente en base al alcance y precios en el mercado. En la tabla 5.2 se muestra cada una de las etapas con la tecnología seleccionada.

Tabla 5.2

Selección de la tecnología por etapa del proceso

\begin{tabular}{|c|c|}
\hline Etapa & Tecnología \\
\hline Secado & Secador de bandejas \\
\hline Molienda & Molino de martillos \\
\hline Tamizado & Tamizador automático \\
\hline Mezclado & Tanque mezclador con chaqueta \\
\hline Envasado & Envasadora con pistón (llenado automático) \\
\hline Etiquetado & Etiquetadora horizontal automática \\
\hline
\end{tabular}

Elaboración propia

Además, el material del envase contenedor del betún ecológico será de polipropileno reciclado, ya que es el que nos dará un tipo de plástico adecuado para el envasado del producto.

\subsubsection{Proceso de producción}

\subsubsection{Descripción del proceso}

El proceso de producción del betún ecológico en estudio consta de varias etapas, las cuales se describen a continuación:

- Recepción: La cáscara de plátano será enviada por el proveedor directamente a nuestro almacén de materia prima; luego, unos operarios la pesarán para controlar el peso de la cáscara recibida, después de ello, pasará por un control de calidad 
manual en el que se desechará cualquier material que no sea cáscara de plátano. En esta etapa, podremos recepcionar tanto cáscara de plátano como de banano, ya que en los siguientes procesos esta se combinará y no afectará la composición del producto final.

- Lavado y escurrido: Luego de la recepción y clasificación de la cáscara de plátano, esta es lavada con agua potable con el fin de retirar el polvo y otras impurezas que pueden afectar las propiedades del producto final. Antes del pasar al proceso de secado, la cáscara se deja escurrir para que pierda la cantidad de agua que obtuvo en el lavado.

- Pesado: La cáscara limpia es pesada nuevamente para determinar la cantidad de cáscara que pasará por el proceso de secado.

- Secado: La cáscara limpia será colocada de manera homogénea en las bandejas de un secador eléctrico con el que aseguramos la continuidad de la energía. Se dejará secar a una temperatura de $60^{\circ} \mathrm{C}$ por un tiempo de 1 hora y media aproximadamente hasta que quede totalmente deshidratada, con esto la cáscara perderá el $75 \%$ de su peso (humedad).

- Molienda: La cáscara totalmente deshidratada, pasara por un molino de martillos hasta que quede pulverizada.

- Tamizado: Para la obtención de partículas homogéneas y asegurarnos de que estas tengan el tamaño adecuado para realizar la pasta, es necesario pasar el material molido por un tamiz menos a $250 \mu \mathrm{m}(0.25 \mathrm{~mm})$.

- Mezclado al calor: La cáscara pulverizada y homogénea, se mezcla con glicerina en un tanque mezclador, luego se incorpora debidamente dosificado benzoato de Sodio, borato de Sodio y colorante orgánico. El mezclado debe realizarse a $100^{\circ} \mathrm{C}$.

- Envasado: Luego del proceso de mezclado, el producto final debe pasar lo antes posible a la etapa de envasado para evitar que se enfríe y solidifique. 
Antes de envasar el producto, los envases de plástico deben haber pasado previamente por un proceso de control de calidad para evitar la presencia de elementos que contaminen o cambien las propiedades del betún.

El producto envasado se debe dejar enfriar por un tiempo aproximado de 30 $\min$.

- Etiquetado: En este proceso se colocarán las etiquetas en la tapa del envase en donde se encuentra la información de la composición del betún para calzado y se detalla el nombre del producto, marca y logo de la empresa, contenido neto, nombre y domicilio fiscal, ciudad de origen, identificación del lote, fecha de caducidad y contra indicaciones.

- Embalado: El producto final envasado y etiquetado debidamente, se empacará manualmente en grupos de 12 unidades en pequeñas cajas de cartón.

- Almacenamiento: Cada caja de 12 unidades de betún envasado y etiquetado se colocará en el almacén de productos terminados, considerando que no deben permanecer por más de 48 horas, ya que se incurriría en un costo mayor de almacenamiento. 


\subsubsection{Diagrama de proceso: DOP}

Figura 5. 2

Diagrama de operaciones del proceso de producción de betún ecológico a base de cáscara de plátano

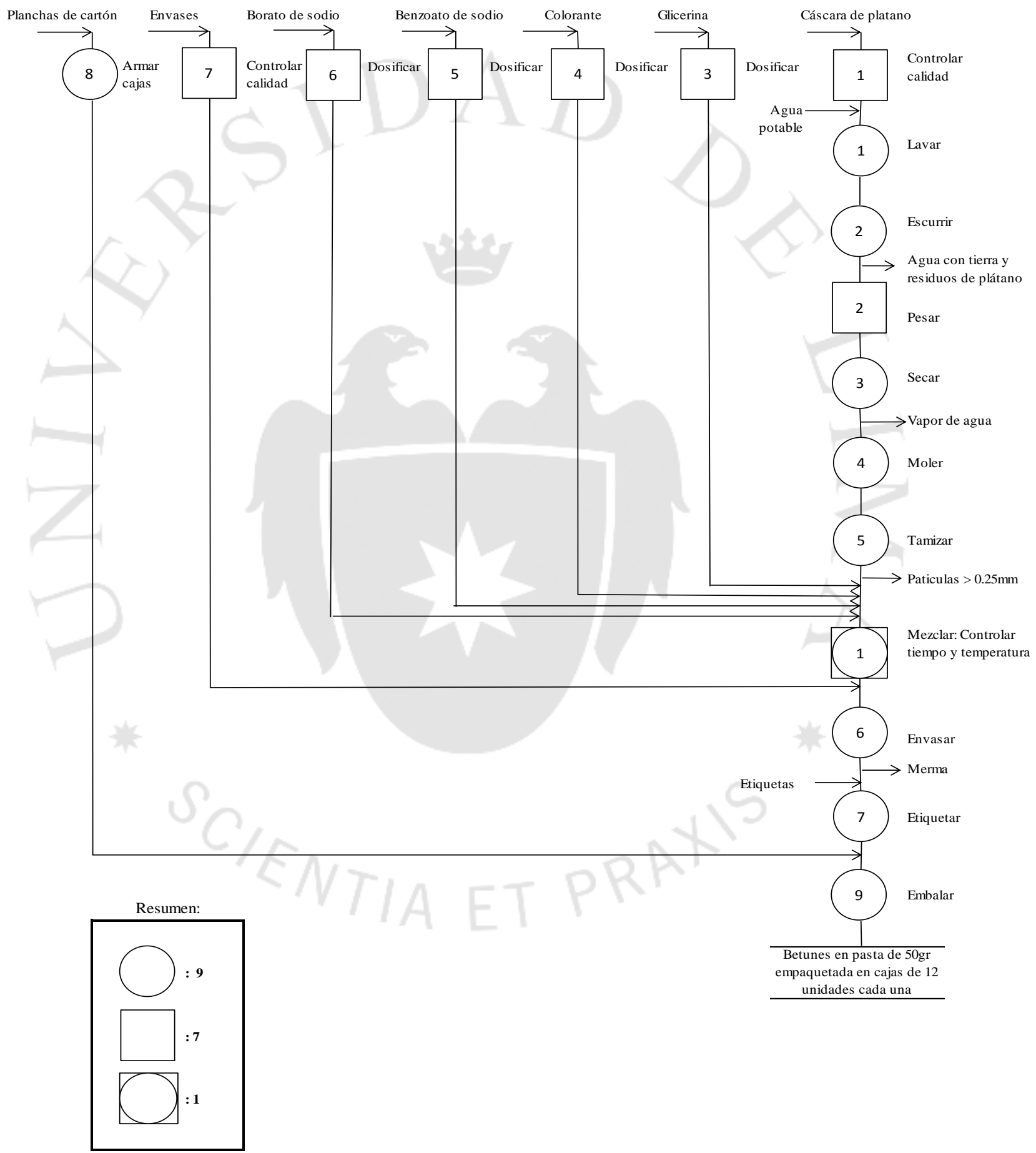

Elaboración propia 


\subsubsection{Balance de materia y energía}

Para realizar el balance de materia en $\mathrm{kg}$, se consideró la densidad de la glicerina $\left(1.26 \mathrm{~g} / \mathrm{cm}^{3}\right)$.

\section{Figura 5.3}

Diagrama de bloques para la producción de betún ecológico a base de cáscara de plátano

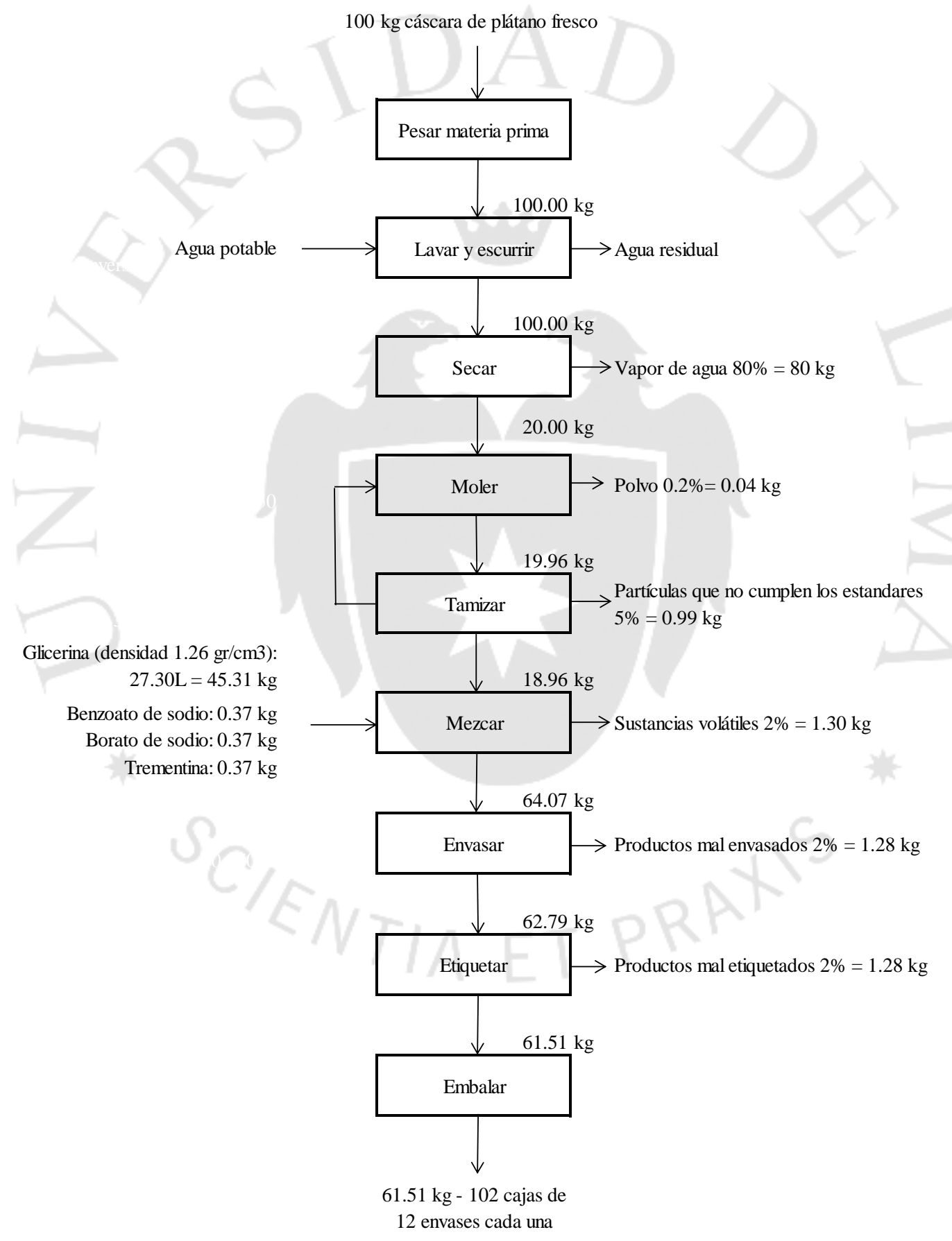

Elaboración propia 


\subsection{Características de las instalaciones y equipos}

\subsubsection{Selección de la maquinaria y equipos}

Para la selección de la maquinaria, se consideraron diferentes criterios tales como los costos de adquisición y operación, la eficiencia, el grado de dificultad para operar, el espacio físico ocupado, facilidades para reparación, entre otros.

El criterio principal que consideramos es el costo de la maquinaria, ya que por ser un proyecto nuevo es necesario contar con la mayor liquidez posible durante los primeros años del proyecto.

\subsubsection{Especificaciones de la maquinaria}

En este capítulo, se detallará cada una de las máquinas a utilizar en las etapas del proceso de producción de betún ecológico a base de cáscara de plátano. En la ficha técnica de cada una se muestran las características generales más importantes, tales como capacidad, potencia, dimensiones, entre otras.

Tabla 5.3

Balanza

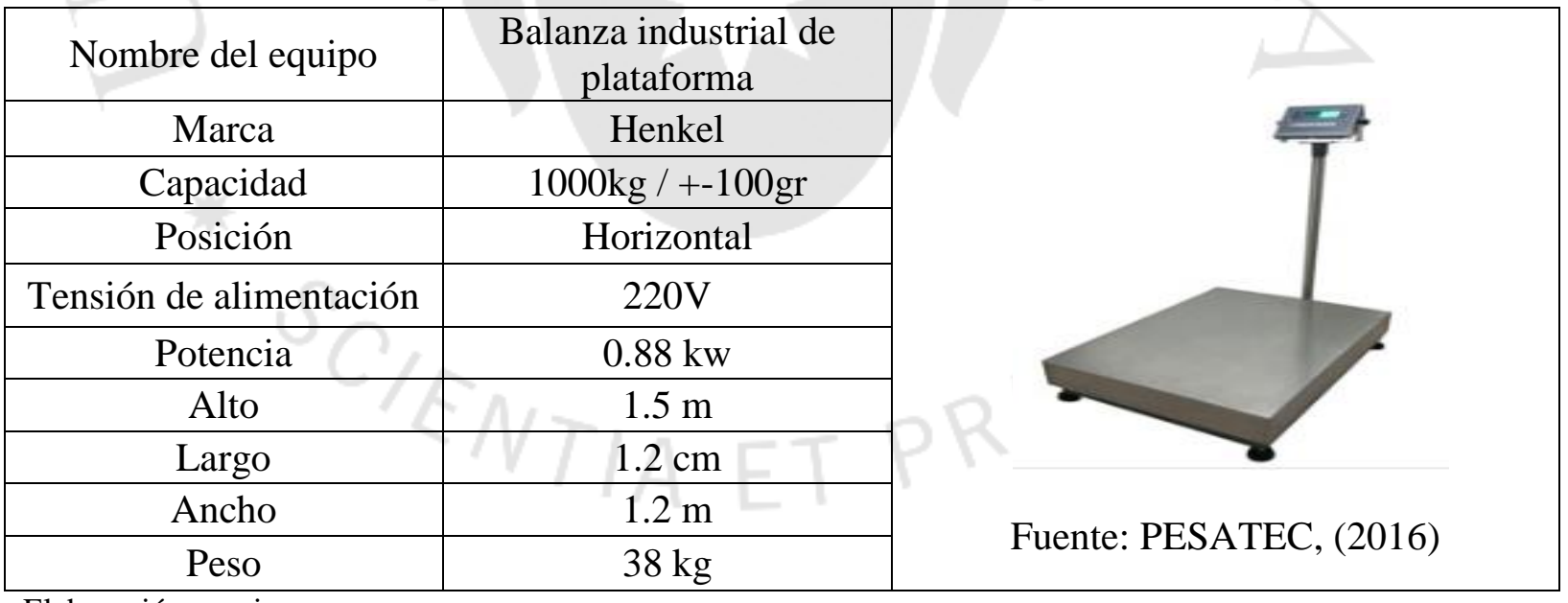

Elaboración propia 
Tabla 5.4

Lavadero

\begin{tabular}{|c|c|c|}
\hline Nombre del equipo & Lavadero de acero inox. & \\
\hline Proveedor & A\&A METALICOS & \\
\hline Capacidad & $100 \mathrm{~kg}$ & \\
\hline Posición & Horizontal & \\
\hline Tensión de alimentación & - & \\
\hline Potencia & - & \\
\hline Alto & $0.5 \mathrm{~m}$ & \\
\hline Largo & $0.5 \mathrm{~m}$ & \\
\hline Ancho & $0.5 \mathrm{~m}$ & \\
\hline Peso & $200 \mathrm{~kg}$ & Fuente: METALICOS, (2016) \\
\hline
\end{tabular}

Elaboración propia

Tabla 5. 5

Deshidratador

\begin{tabular}{|c|c|c|}
\hline Nombre del equipo & Deshidratador & - \\
\hline Proveedor & Ktperu & 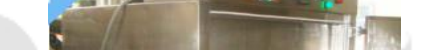 \\
\hline Capacidad & $300 \mathrm{~kg} / \mathrm{h}$ ora & \\
\hline Posición & Vertical & \\
\hline Tensión de alimentación & $220 \mathrm{~V} / 380 \mathrm{~V}$ & \\
\hline Potencia & $5 \mathrm{kw}$ & \\
\hline Alto & $2 \mathrm{~m}$ & \\
\hline Largo & $2.3 \mathrm{~m}$ & \multirow{3}{*}{ Fuente: KTPERU, (2016) } \\
\hline Ancho & $1.2 \mathrm{~m}$ & \\
\hline Peso & $1580 \mathrm{~kg}$ & \\
\hline
\end{tabular}

Elaboración propia

Tabla 5. 6

Moledor

\begin{tabular}{|c|c|}
\hline Nombre del equipo & Molino \\
\hline Proveedor & ZZ Lance \\
\hline Capacidad & $200 \mathrm{~kg} /$ hora \\
\hline Posición & Vertical \\
\hline Tensión de alimentación & $380 \mathrm{~V}$ \\
\hline Potencia & $3.5 \mathrm{kw}$ \\
\hline Alto & $1.4 \mathrm{~m}$ \\
\hline Largo & $1.2 \mathrm{~m}$ \\
\hline Ancho & $0.9 \mathrm{~m}$ \\
\hline Peso & $300 \mathrm{~kg}$ \\
\hline
\end{tabular}

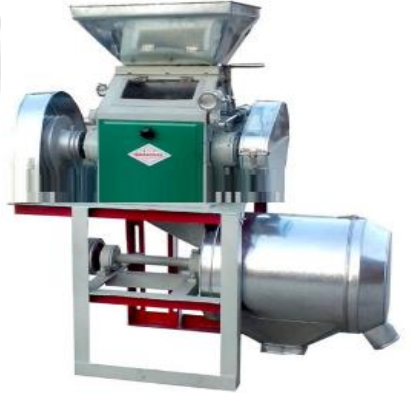

Fuente: ETDISA, (2016)

Elaboración propia 
Tabla 5.7

Tamiz

\begin{tabular}{|c|c|c|}
\hline Nombre del equipo & Tamiz vibrador & \\
\hline Proveedor & G\&G Industrial & \\
\hline Capacidad & 1000 Lt / hora & \\
\hline Posición & Vertical & \\
\hline Tensión de alimentación & $380 \mathrm{~V} / 220 \mathrm{~V}$ & \\
\hline Potencia & $2.2 \mathrm{kw}$ & \\
\hline Alto & $1.1 \mathrm{~m}$ & \\
\hline Largo & $0.9 \mathrm{~m}$ & \\
\hline Ancho & $1.1 \mathrm{~m}$ & YGIND \\
\hline Peso & $350 \mathrm{~kg}$ & \\
\hline
\end{tabular}

Elaboración propia

Tabla 5.8

Tanque mezclador

\begin{tabular}{|c|c|c|}
\hline Nombre del equipo & Tanque chaqueta con agitador & \\
\hline Marca & Drafpack & \\
\hline Capacidad & $500 \mathrm{Lt} /$ hora & \\
\hline Posición & Vertical & \\
\hline Tensión de alimentación & $220 \mathrm{~V} / 380 \mathrm{~V}$ & \\
\hline Potencia & $4 \mathrm{kw}$ & \\
\hline Alto & $2.7 \mathrm{~m}$ & \\
\hline Largo & $0.84 \mathrm{~m}$ & \\
\hline Ancho & $1 \mathrm{~m}$ & Fuente: DRAFPACK, (2016) \\
\hline Peso & $550 \mathrm{~kg}$ & \\
\hline
\end{tabular}

Elaboración propia

Tabla 5. 9

Dosificador

\begin{tabular}{|c|c|}
\hline Nombre del equipo & Dosificador de polvo \\
\hline Proveedor & Drafpack \\
\hline Capacidad & 30 dosis / min \\
\hline Posición & Vertical \\
\hline Tensión de alimentación & $220 \mathrm{~V}$ \\
\hline Potencia & $0.5 \mathrm{kw}$ \\
\hline Alto & $0.6 \mathrm{~m}$ \\
\hline Largo & $0.8 \mathrm{~m}$ \\
\hline Ancho & $0.5 \mathrm{~m}$ \\
\hline Peso & $140 \mathrm{~kg}$ \\
\hline
\end{tabular}

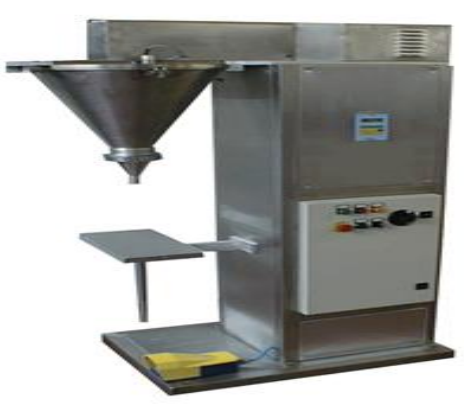

Fuente: DRAFPACK, (2016)

Elaboración propia 
Tabla 5. 10

Envasadora

\begin{tabular}{|c|c|c|}
\hline Nombre del equipo & $\begin{array}{c}\text { Envasadora tapadora con } \\
\text { pistón }\end{array}$ & \\
\hline Proveedor & Drafpack & \\
\hline Capacidad & 3600 envases / hora & \\
\hline Posición & Horizontal & \\
\hline Tensión de alimentación & $220 \mathrm{~V}, 50 \mathrm{hz}$ & \\
\hline Potencia & $1.5 \mathrm{kw}$ & \\
\hline Alto & $0.9 \mathrm{~m}$ & \\
\hline Largo & $1.3 \mathrm{~m}$ & \\
\hline Ancho & $0.5 \mathrm{~m}$ & Fuente: DRAFPACK, (2016) \\
\hline Peso & $45 \mathrm{~kg}$ & \\
\hline
\end{tabular}

Elaboración propia

Tabla 5. 11

Etiquetadora

\begin{tabular}{|c|c|c|}
\hline Nombre del equipo & Etiquetadora automática & 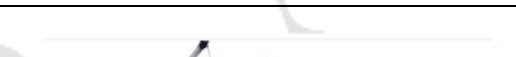 \\
\hline Proveedor & Drafpack & \\
\hline Capacidad & 3600 envases $\mathrm{x}$ hora & \\
\hline Posición & Horizontal & 0.9 \\
\hline Tensión alimentación & $220 \mathrm{~V}$ & \\
\hline Potencia & $1.5 \mathrm{kw}$ & \\
\hline Alto & $1.0 \mathrm{~m}$ & \\
\hline Largo & $2.1 \mathrm{~m}$ & \\
\hline Ancho & $0.7 \mathrm{~m}$ & Fuente: DRAFPACK, (2016) \\
\hline Peso & $300 \mathrm{~kg}$ & \\
\hline
\end{tabular}

Elaboración propia

\subsection{Capacidad instalada}

\subsubsection{Cálculo de la capacidad instalada}

La capacidad instalada es el mayor nivel de producción que se puede generar del proceso en base a la capacidad de la maquinaria, uso de los equipos y eficiencia de los operarios.

Considerando un turno de 8 horas y un tiempo de paro de maquinaria por limpieza y mantenimiento de 1 hora por turno hallamos el factor de utilización "u”, el cual mostramos en la tabla 5.12. 
Tabla 5. 12

Cálculo del factor de utilización

\begin{tabular}{|c|c|c|c|}
\hline Minutos totales & $\begin{array}{c}\text { Minutos de } \\
\text { paro }\end{array}$ & $\begin{array}{c}\text { Tiempo } \\
\text { efectivo/turno }\end{array}$ & Factor (u) \\
\hline 480 & 60 & 420 & 0.88 \\
\hline
\end{tabular}

Elaboración propia

Además, se considerará un factor de eficiencia de 0.85 ya que las etapas de pesado, lavado y embalado son manuales y las demás automáticas.

Dado que la capacidad de algunas de las máquinas está dada en volumen, se utilizó la densidad de la cáscara molida y la del producto final.

- Cáscara deshidratada y molida: $0.581 \mathrm{gr} / \mathrm{cm}^{3}$

- Producto final: $0.940 \mathrm{gr} / \mathrm{cm}^{3}$

En la tabla 5.13 se muestra el cálculo de la capacidad de planta en base al balance de materia en a cada una de las etapas del proceso y el factor de conversión que nos permite mostrar la equivalencia entre la masa de los insumos que ingresan a cada etapa del proceso y el producto final. 
Tabla 5. 13

Cálculo de la capacidad de planta con balance de materia

\begin{tabular}{|c|c|c|c|c|c|c|c|c|c|c|c|}
\hline Operación & $\begin{array}{l}\text { Cantidad } \\
\text { entrante } \\
(\mathbf{k g})\end{array}$ & $\begin{array}{l}\text { Prod./ } \\
\text { hora } \\
\text { (kg) }\end{array}$ & $\begin{array}{c}\text { N. } \\
\text { máquinas } \\
\mathbf{u} \\
\text { operarios }\end{array}$ & $\begin{array}{l}\text { Horas } \\
\text { reales } \\
\text { /turno }\end{array}$ & $\begin{array}{l}\text { Días } \\
/ \\
\text { año }\end{array}$ & $(\mathbf{U})$ & $(\mathbf{E})$ & $\begin{array}{c}\text { Capacidad de } \\
\text { procesamiento } \\
\text { según balance } \\
(\mathrm{kg})\end{array}$ & $\begin{array}{l}\text { Factor de } \\
\text { conversión }\end{array}$ & $\begin{array}{l}\text { Capacidad } \\
\text { de } \\
\text { producción } \\
\text { prod. } \\
\text { Terminado } \\
\quad(\mathrm{kg})\end{array}$ & $\begin{array}{l}\text { Unidades } \\
\text { de } \\
\text { producto } \\
\text { terminado } \\
(50 \mathrm{gr})\end{array}$ \\
\hline $\begin{array}{l}\text { Lavar y } \\
\text { escurrir }\end{array}$ & 100.0 & 200 & 1 & 7 & 260 & - & 0.85 & $309,400.0$ & 0.6 & $190,311.9$ & $3,806,238.8$ \\
\hline Deshidratar & 100.0 & 300 & 1 & 7 & 260 & 0.88 & 0.85 & $408,408.0$ & 0.6 & $251,211.8$ & $5,024,235.2$ \\
\hline Moler & 20.0 & 200 & 1 & 7 & 260 & 0.88 & 0.85 & $272,272.0$ & 3.1 & $837,372.5$ & $16,747,450.7$ \\
\hline Tamizar & 20.0 & 581 & 1 & 7 & 260 & 0.88 & 0.85 & $790,950.2$ & 3.1 & $2,437,442.1$ & $48,748,842.0$ \\
\hline $\begin{array}{l}\text { Mezclar y } \\
\text { hervir }\end{array}$ & 19.0 & 471 & 1 & 7 & 260 & 0.88 & 0.85 & $641,200.6$ & 3.2 & $2,080,181.8$ & $41,603,635.5$ \\
\hline Envasar & 64.1 & 180 & 1 & 7 & 260 & 0.88 & 0.85 & $245,044.8$ & 1.0 & $235,253.7$ & $4,705,074.3$ \\
\hline Etiquetar & 62.8 & 180 & 1 & 7 & 260 & 0.88 & 0.85 & $245,044.8$ & 1.0 & $240,049.5$ & $4,800,989.2$ \\
\hline Embalar & 61.5 & 43 & 2 & 7 & 260 & - & 0.85 & $133,660.8$ & 1.0 & $133,660.8$ & $2,673,216.0$ \\
\hline $\begin{array}{c}\text { Producto } \\
\text { terminado } \\
(\mathrm{kg})\end{array}$ & 61.5 & & & & & & & & & & \\
\hline
\end{tabular}

Elaboración propia

La capacidad instalada, o la cantidad máxima de unidades de producto terminado que se puede obtener en el proceso productivo del presente proyecto es de 2, 673,216.0 unidades de 50gr cada una. 


\subsubsection{Cálculo detallado del número de máquinas requeridas}

Para hallar el número de máquinas necesarias en cada etapa del proceso, y cumplir con la demanda del proyecto, se utilizó la siguiente fórmula:

$$
N^{`} \text { de máquinas }=\frac{\text { Tiempo de operación } * \text { Demanda anual }}{\text { Numero total de horas disponibles al año }}
$$

Donde se considerará como "Demanda anual", la demanda del último año en estudio: $83,571.4 \mathrm{~kg}$ de betún. Además, como se indicó en el punto anterior, la planta funcionará un turno de 7 horas disponibles de lunes a viernes, y por ser un proceso semi automático se tendrán en cuenta los factores de eficiencia (E) y utilización (U). En la tabla 5.14 se observa el cálculo de número de máquinas.

Tabla 5.14

Cálculo del número de máquinas requeridas

\begin{tabular}{|c|c|c|c|c|c|c|c|}
\hline Máquina & $\begin{array}{c}\text { Demanda } \\
\text { (kg/año) }\end{array}$ & $\begin{array}{c}\text { Tiempo } \\
\text { estándar } \\
\text { (horas/kg) }\end{array}$ & $(\mathrm{U})$ & $(\mathrm{E})$ & $\begin{array}{c}\text { Horas } \\
\text { disponibles } \\
\text { (horas/año) }\end{array}$ & $\begin{array}{c}\mathbf{N}^{0} \text { de } \\
\text { máquinas }\end{array}$ & $\begin{array}{c}\mathbf{N}^{0} \text { de } \\
\text { máquinas }\end{array}$ \\
\hline Secadora & $83,571.4$ & 0.003 & 0.88 & 0.85 & 1,820 & 0.153 & 1 \\
\hline Molino & $83,571.4$ & 0.005 & 0.88 & 0.85 & 1,820 & 0.230 & 1 \\
\hline Tamiz & $83,571.4$ & 0.002 & 0.88 & 0.85 & 1,820 & 0.079 & 1 \\
\hline Mezcladora & $83,571.4$ & 0.002 & 0.88 & 0.85 & 1,820 & 0.097 & 1 \\
\hline Envasadora & $83,571.4$ & 0.006 & 0.88 & 0.85 & 1,820 & 0.255 & 1 \\
\hline Etiquetadora & $83,571.4$ & 0.006 & 0.88 & 0.85 & 1,820 & 0.255 & 1 \\
\hline
\end{tabular}

Elaboración propia

Para cumplir con la demanda del último año de estudio, se requiere una máquina por cada etapa automática del proceso.

En la tabla 5.15 se muestran las máquinas y equipos adicionales que requerimos para el proceso de producción. 
Tabla 5. 15

Número de máquinas y equipos adicionales

\begin{tabular}{|c|c|}
\hline Máquina/Equipo & $\mathbf{N}^{0}$ \\
\hline Balanza & 1 \\
\hline Dosificador & 3 \\
\hline Lavadero & 1 lavadero con 2 pozas \\
\hline Traspaleta manual & 2 \\
\hline Apilador eléctrico & 1 \\
\hline
\end{tabular}

Elaboración propia

Los equipos y máquinas adicionales mostradas no limitan la producción en la planta en estudio.

\subsection{Resguardo de la calidad y/o inocuidad en el producto}

Para brindarle al cliente final un producto de calidad que satisfaga sus necesidades y expectativa, el producto en estudio debe pasar por un control de calidad en cada una de las etapas del proceso; además, se debe contar con un sistema que nos permita asegurar la calidad de los proveedores, recepción de materias primas, almacenamiento y producto terminado.

\subsubsection{Calidad de la materia prima, de los insumos, del proceso y del producto}

La calidad dentro de una organización es un factor muy importante que generar satisfacción tanto a los trabajadores como a los clientes finales. Hoy en día es necesario cumplir con los estándares de calidad para lograr entrar a competir a un mercado cada vez más exigente. A continuación, se detalla el plan de calidad:

- Control de materia prima e insumos: El control de calidad por el que debe pasar los insumos y materia prima constará de la siguiente fase:

Verificación del cumplimiento de las características técnicas requeridas de la materia prima, las cuales se deben de haber acordado previamente con los proveedores. Para realizar el control se contará con un manual paso a paso y una "ficha técnica de calidad" por cada insumo, donde se establecerán los puntos más importantes a verificar antes de aceptar los productos. 
- Control de las condiciones de almacenaje y conservación.

- Análisis de muestras de los componentes químicos en el laboratorio. Previo a la descarga de materia prima, se evaluará la humedad, aspecto, color, olor, textura y presencia de cuerpos extraños. Se utilizarán solo cuando hayan sido clasificados como aptos; de no ser así, se coordinará el cambio con los proveedores.

- Establecimiento y seguimiento de normas de limpieza diaria, periódica y semestral de almacenes.

- Control del proceso de producción: Este plan de control se llevará a cabo durante el proceso de producción y se basa en las características de calidad que el producto debe tener a medida que pasa por las etapas del proceso tales como la fabricación del producto y desempeño de los operarios en sus funciones.

- Control del producto terminado: En la tabla 5.16 se detallan los puntos a considerar por cada grupo de características del producto final.

Tabla 5. 16

Características de calidad

\begin{tabular}{|c|c|}
\hline Grupo de características & Características de calidad \\
\hline Características & 1. Color \\
organolépticas & 2. Forma \\
& 3. Olor \\
4. Consistencia
\end{tabular}

Elaboración propia

Para este producto, se puede considerar que las características organolépticas son las más importantes, ya que son las primeras que los consumidores perciben al adquirir y usar el producto. Otra de las características importantes es el grupo "valor de empleo", ya 
que por ser un producto que se puede terminar de consumir en un periodo de tiempo largo, es indispensable que tenga buena capacidad de conservación.

\subsubsection{Estrategias de mejora}

Para el presente proyecto se buscará la mejora continua mediante la utilización de diferentes técnicas de medición, planeamiento de recursos de acción e implementación de nuevas alternativas, con el fin de automatizar procesos, mejorar los tiempos de producción, incrementar la productividad y disminuir costos.

\subsection{Estudio de impacto ambiental}

El estudio de impacto ambiental nos ayuda a identificar, prevenir e interpretar los impactos ambientales que producirá el proyecto en su entorno. Se establecerán controles que minimicen o eliminen los aspectos ambientales asociados a impactos significativos y se aplicará una adecuada gestión del sistema ambiental. A continuación, se describe el impacto ambiental que pueden generar las etapas de construcción de la planta y el proceso productivo:

- Etapa de construcción: La construcción de la planta en estudio no afectará la flora y fauna ya que se realizará en una zona industrial autorizada en el distrito de Villa María del Triunfo. Sin embargo, se deben controlar los impactos negativos por levantamiento de polvo o tierra que puede causar problemas respiratorios u oculares a los pobladores y transeúntes; también se debe asegurar el desecho de residuos sólidos en lugares adecuados para evitar la contaminación de suelos y agua.

- Etapa de operación: En la tabla 5.17 se muestran los impactos ambientales y las medidas correctivas que se tomarán en esta etapa. 
Tabla 5. 17

Matriz de caracterización de aspectos e impactos ambientales

\begin{tabular}{|c|c|c|c|}
\hline Proceso & Aspecto & Impacto & Medidas correctivas \\
\hline $\begin{array}{l}\text { Selección de } \\
\text { materia } \\
\text { prima }\end{array}$ & $\begin{array}{c}\text { Generación de residuos } \\
\text { principalmente } \\
\text { orgánicos no } \\
\text { contaminantes }\end{array}$ & $\begin{array}{l}\text { Contaminación de } \\
\text { suelo }\end{array}$ & $\begin{array}{l}\text { Manejo adecuado y colocación de } \\
\text { desechos en vertederos orgánicos }\end{array}$ \\
\hline Lavado & $\begin{array}{c}\text { Generación de residuos } \\
\text { principalmente } \\
\text { orgánicos no } \\
\text { contaminantes }\end{array}$ & $\begin{array}{c}\text { Contaminación de agua } \\
\text { y suelos }\end{array}$ & Proceso de recuperación de agua \\
\hline Secado & $\begin{array}{c}\text { Generación de vapor de } \\
\text { agua liberado al } \\
\text { ambiente }\end{array}$ & $\begin{array}{l}\text { Contaminación del aire } \\
\text { y agua }\end{array}$ & Uso racional de energía \\
\hline Molido & $\begin{array}{l}\text { Generación de ruidos y } \\
\text { uso excesivo de energía }\end{array}$ & $\begin{array}{l}\text { Contaminación sonora } \\
\text { y riesgo de accidente al } \\
\text { introducir el material a } \\
\text { moler }\end{array}$ & $\begin{array}{c}\text { Uso de tapones para los oídos; } \\
\text { implementación de fichas de seguridad } \\
\text { y uso de equipo así como } \\
\text { implementación de un sistema de } \\
\text { seguridad antes, después y durante el } \\
\text { proceso de molido }\end{array}$ \\
\hline Tamizado & $\begin{array}{l}\text { Generación de residuos } \\
\text { sólidos orgánicos }\end{array}$ & $\begin{array}{l}\text { Contaminación del } \\
\text { suelo }\end{array}$ & $\begin{array}{c}\text { Colocación de desechos en vertederos } \\
\text { orgánicos }\end{array}$ \\
\hline $\begin{array}{l}\text { Mezclado al } \\
\text { calor }\end{array}$ & $\begin{array}{l}\text { Generación de derrames } \\
\text { de componentes }\end{array}$ & $\begin{array}{l}\text { Contaminación del } \\
\text { suelo y aire }\end{array}$ & $\begin{array}{l}\text { Manejo controlado de insumos durante } \\
\text { el proceso }\end{array}$ \\
\hline $\begin{array}{l}\text { Envasado, } \\
\text { etiquetado y } \\
\text { embalado }\end{array}$ & $\begin{array}{l}\text { Generación de desechos } \\
\text { sólidos como envases de } \\
\text { plástico, etiquetas o } \\
\text { cajas de cartón }\end{array}$ & $\begin{array}{l}\text { Contaminación del } \\
\text { suelo }\end{array}$ & $\begin{array}{l}\text { Clasificación por tipo de material para } \\
\text { su posterior reciclado o reutilización }\end{array}$ \\
\hline
\end{tabular}

Elaboración propia

Cada una de las medidas correctivas mostradas se pondrá en práctica antes, durante y después de cada etapa del proceso de producción.

\subsection{Seguridad y salud ocupacional}

Durante la implementación y puesta en marcha de la planta productora de betún para calzado a base de cascar de plátano se debe considerar la seguridad, salud, protección y atención de los empleado durante el desempeño de sus labores ocupacionales; para lo cual, se implementarán los equipos de seguridad personal necesario como guantes, mandil, tapones u orejeras, cascos, botas, lentes y mascarilla; además, para evitar accidentes 
durante el manejo de las máquinas y equipos, se incluirán manuales y capacitaciones presenciales o virtuales y se realizarán evaluaciones de conocimiento técnico de maquinarias previo al uso de estas.

Se cumplirá adecuadamente con la Ley de Seguridad y Salud en el Trabajo (Ley N 29783) (Normas Legales, 2011), en la que se indica que el empleador debe garantizar el establecimiento de los medios y condiciones que protejan la vida, salud y bienestar de los trabajadores, así como 9 principios que se cumplirán rigurosamente.

Además, según la Organización Internacional de trabajo (OIT) existen diversos factores laborales que afectan las condiciones del trabajo, tales como:

- Ruido: El ruido presente en el entorno laboral puede causar alteraciones temporales como fatigas auditivas o permanentes como hipoacusia o sordera; además, puede producir una sensación de desagrado o disgusto en los trabajadores. El ruido superior a 66 decibeles requiere un esfuerzo potencialmente peligroso para las cuerdas vocales. Otro punto resaltante es que puede aumentar el riesgo de accidentes de trabajo al enmascarar las alarmas y voces. Un trabajador puede estar expuesto como máximo 8 horas a un ruido de 85 decibeles.

El problema del ruido puede ser atacado con controles de ingeniería, implementación de los equipos ruidosos en lugares cerrados o apartados y utilización de equipos de protección personal.

- Temperatura: Las condiciones climáticas no aptas para los trabajadores pueden degradar el medio ambiente del trabajo, afectando el rendimiento físico y mental de los trabajadores y provocando posibles riesgos de accidentes. Se implementarán sistemas de control de temperatura para mantenerla constante entre 24 y $26^{\circ} \mathrm{C}$.

- Humedad: Para garantizar un ambiente de trabajo agradable, es importante asegurarse de que la humedad no sea menor al 40\%. Ya que el riesgo de enfermedades aumenta, estas enfermedades pueden ser: Sequedad en la piel, dolores de cabeza, sinusitis, aumento de la susceptibilidad a las infecciones y sensación de falta de aire. La humedad se controlará periódicamente. 
- Iluminación: El grado de seguridad con el que se ejecuta una tarea depende en gran parte de la calidad de iluminación. La visibilidad de un objeto puede ser alterada por el contraste de luminarias debido a factores como sombras. La luminancia del área de trabajo influye en la facilidad de realizar una tarea o ver un objeto; por ello, es de suma importancia analizar minuciosamente el área donde se realizarán las tareas y sus alrededores. Para proporcionar las condiciones necesarias para el confort visual se debe implementar: Iluminación uniforme y óptima, ausencia de brillos deslumbrantes, condiciones de contraste adecuadas y colores correctos.

Además de los factores laborales mencionados, en las diferentes zonas de la planta puede producirse incendios de clase $\mathrm{A}$ en las oficinas producido por materiales sólidos como papeles, plásticos y maderas o incendios de clase $\mathrm{C}$ producidos por los riesgos eléctricos que existen en el área de producción. Por ello como medida de resguardo de la seguridad se deberá implementar extintores de polvo $\mathrm{ABC}$.

Debemos considerar también que en cada una de las etapas del proceso existen riesgos potenciales, los cuales analizaremos en la tabla 5.18. Además, en el anexo se muestran las señales de equipos contra incendios, prohibición, advertencia, obligación y evacuación que se implementará. 
Tabla 5. 18

Evaluación de riesgos

\begin{tabular}{|c|c|c|c|c|c|}
\hline $\begin{array}{l}\text { Etapas del } \\
\text { proceso }\end{array}$ & $\begin{array}{l}\text { Actividad } \\
\text { rutinaria- } \\
\text { no } \\
\text { rutinaria }\end{array}$ & Peligro & $\begin{array}{l}\text { Peligro } \\
\text { significativo }\end{array}$ & Riesgo & Medida de control \\
\hline $\begin{array}{c}\text { Recepción y } \\
\text { pesado }\end{array}$ & Rutinaria & $\begin{array}{c}\text { Manejo manual } \\
\text { de carga }\end{array}$ & $\mathrm{Si}$ & $\begin{array}{c}\text { Dolor y } \\
\text { enfermedades de } \\
\text { columna }\end{array}$ & $\begin{array}{l}\text { Supervisión de uso de } \\
\text { EPS's, así como tiempo } \\
\text { de descanso adecuado. }\end{array}$ \\
\hline Lavado & Rutinaria & $\begin{array}{l}\text { Manejo manual } \\
\text { de carga, } \\
\text { exposición a } \\
\text { tierra y/o } \\
\text { elementos } \\
\text { extraños en la } \\
\text { cáscara } \\
\end{array}$ & $\mathrm{Si}$ & $\begin{array}{l}\text { Infección en las } \\
\text { manos, dolor y } \\
\text { enfermedades de } \\
\text { la columna }\end{array}$ & $\begin{array}{l}\text { Supervisión de uso de } \\
\text { EPS's, así como tiempo } \\
\text { de descanso adecuado. }\end{array}$ \\
\hline $\mathrm{Sec}$ & Rutinaria & $\begin{array}{l}\text { Exposición al } \\
\text { calor }\end{array}$ & $\mathrm{Si}$ & $\begin{array}{l}\text { Quemaduras en } \\
\text { las manos y } \\
\text { cuerpo }\end{array}$ & $\begin{array}{l}\text { Implementación de } \\
\text { EPS's, señales de } \\
\text { advertencia de calor y } \\
\text { capacitación constante. }\end{array}$ \\
\hline Molido & Rutinaria & $\begin{array}{l}\text { Exposición al } \\
\text { ruido y al polvo }\end{array}$ & $\mathrm{Si}$ & $\begin{array}{l}\text { Enfermedades } \\
\text { auditivas y de } \\
\text { respiración }\end{array}$ & $\begin{array}{l}\text { Uso de tapones para los } \\
\text { oídos y mascarillas; } \\
\text { implementación de } \\
\text { fichas de seguridad y } \\
\text { capacitación constante } \\
\text { de uso adecuado de } \\
\text { equipos. }\end{array}$ \\
\hline Tamizado & Rutinaria & $\begin{array}{l}\text { Manejo manual } \\
\text { de carga, } \\
\text { exposición al } \\
\text { polvo }\end{array}$ & $\mathrm{Si}$ & $\begin{array}{l}\text { Dolor y } \\
\text { enfermedades de } \\
\text { la columna así } \\
\text { como de } \\
\text { respiración } \\
\end{array}$ & $\begin{array}{l}\text { Supervisión de uso de } \\
\text { EPS's, así como tiempo } \\
\text { de descanso adecuado. }\end{array}$ \\
\hline $\begin{array}{l}\text { Mezclado al } \\
\text { calor }\end{array}$ & Rutinaria & $\begin{array}{c}\text { Exposición a } \\
\text { agentes químicos } \\
\text { y al calor }\end{array}$ & $\mathrm{Si}$ & $\begin{array}{l}\text { Dolor de cabeza, } \\
\text { mareos y } \\
\text { quemaduras }\end{array}$ & $\begin{array}{l}\text { Supervisión de uso de } \\
\text { EPS's, capacitación } \\
\text { constante de uso } \\
\text { adecuado de } \\
\text { maquinaria }\end{array}$ \\
\hline $\begin{array}{l}\text { Envasado, } \\
\text { etiquetado }\end{array}$ & Rutinaria & $\begin{array}{l}\text { Rocío de } \\
\text { producto caliente }\end{array}$ & $\mathrm{Si}$ & $\begin{array}{c}\text { Quemaduras en } \\
\text { las manos y } \\
\text { cuerpo }\end{array}$ & $\begin{array}{l}\text { Supervisión de uso de } \\
\text { EPS's, capacitación } \\
\text { constante de uso } \\
\text { adecuado de } \\
\text { maquinaria. }\end{array}$ \\
\hline Embalado & Rutinaria & $\begin{array}{l}\text { Movimiento } \\
\text { repetitivo, } \\
\text { manejo manual } \\
\text { de carga }\end{array}$ & $\mathrm{Si}$ & $\begin{array}{c}\text { Dolor y } \\
\text { enfermedades de } \\
\text { la columna }\end{array}$ & $\begin{array}{l}\text { Supervisión de uso de } \\
\text { EPS's, así como tiempo } \\
\text { de descanso adecuado. }\end{array}$ \\
\hline Almacenamiento & Rutinaria & Trabajo en altura & $\mathrm{Si}$ & $\begin{array}{l}\text { Caída de objetos } \\
\text { pesados y golpes }\end{array}$ & $\begin{array}{c}\text { Capacitación y } \\
\text { certificación de manejo } \\
\text { de equipos logísticos y } \\
\text { uso correcto de arnés, } \\
\text { casco y conos de } \\
\text { señalización. }\end{array}$ \\
\hline
\end{tabular}

Elaboración propia 


\subsection{Sistema de mantenimiento}

Las operaciones de mantenimiento dentro de una empresa permiten tener una alta disponibilidad de cada una de las máquinas a utilizar y poder cumplir con el programa de producción eliminando paradas imprevistas que extienden el tiempo del proceso.

Para el presente proyecto se implementará un programa de mantenimiento preventivo a las máquinas y equipos. Contar con un departamento de mantenimiento independiente dentro de la planta, incurriría en costos altos; por ello, en este programa participarán los operarios de la empresa quienes deberán ser capacitados constantemente; para los equipos que requieran mantenimiento más exhaustivo como calibraciones y ajustes, se dispondrá de personal profesional externo. Al ser los mismos operarios los que más conocen sobre el funcionamiento de las máquinas, podrán reconocer cualquier inconveniente que se presente, y realizar la reparación inmediata; se debe considerar también que a pesar de cumplir rigurosamente con el programa de mantenimiento preventivo, habrán situaciones en las que será necesario realizar mantenimiento reactivo, y contar con una logística eficiente y rápida que nos ayude a conseguir repuestos y personal experto para evitar los costos de no producción. En las tablas 5.19 y 5.20 se muestran los cronogramas de implementación de mantenimiento preventivo.

Tabla 5. 19

Cronograma de mantenimiento preventivo de equipos

\begin{tabular}{|c|c|c|c|}
\hline Máquinas / Equipos & Actividad a realizar & $\begin{array}{c}\text { Tipo de } \\
\text { mantenimiento }\end{array}$ & Frecuencia \\
\hline Traspaleta manual & Revisión de barra de tracción y ruedas & Preventivo & Semestral \\
\hline \multirow{3}{*}{ Apilador eléctrico } & Limpieza interna & Inspección & Mensual \\
\hline & Mantenimiento del dispositivo eléctrico & Preventivo & Semestral \\
\hline & $\begin{array}{c}\text { Revisión de los electrolitos, terminales, } \\
\text { cables, batería y cadena }\end{array}$ & Inspección & Diario \\
\hline
\end{tabular}

Elaboración propia 
Tabla 5. 20

Cronograma de mantenimiento preventivo de máquinas

\begin{tabular}{|c|c|c|c|}
\hline $\begin{array}{l}\text { Máquinas / } \\
\text { Equipos }\end{array}$ & Actividad a realizar & $\begin{array}{l}\text { Tipo de } \\
\text { mantenimiento }\end{array}$ & Frecuencia \\
\hline \multirow{2}{*}{ Balanza } & Limpieza de platillo y pantalla & Inspección & Diaria \\
\hline & Calibración & Inspección & Mensual \\
\hline \multirow{2}{*}{ Horno } & Limpieza de bandejas & Preventivo & Diaria \\
\hline & Revisión general & Preventivo & Anual \\
\hline \multirow{2}{*}{ Moledor } & Limpieza interna & Inspección & Diaria \\
\hline & Mantenimiento del motor & Preventivo & Anual \\
\hline \multirow{2}{*}{ Tamiz } & Limpieza interna & Inspección & Diaria \\
\hline & Mantenimiento del motor & Preventivo & Anual \\
\hline \multirow{2}{*}{$\begin{array}{l}\text { Tanque de } \\
\text { mezcla }\end{array}$} & Limpieza interna & Inspección & Diaria \\
\hline & Mantenimiento del motor y del sistema de seguridad & Preventivo & Anual \\
\hline \multirow{2}{*}{ Dosificador } & Limpieza interna & Inspección & Mensual \\
\hline & Revisión general & Preventivo & Anual \\
\hline \multirow{3}{*}{ Envasadora } & $\begin{array}{l}\text { Revisión de botones y pantalla en el sector de mandos y } \\
\text { dispositivos de seguridad }\end{array}$ & Preventivo & Semestral \\
\hline & Limpieza de boquillas & Inspección & Semanal \\
\hline & Revisión de bandas transportadoras & Preventivo & Semestral \\
\hline \multirow{3}{*}{ Etiquetadora } & $\begin{array}{c}\text { Revisión de botones y pantalla en el sector de mandos y } \\
\text { dispositivos de seguridad }\end{array}$ & Preventivo & Semestral \\
\hline & Revisión de rodillos o ejes & Preventivo & Semestral \\
\hline & Revisión de bandas transportadoras & Preventivo & Semestral \\
\hline
\end{tabular}

Elaboración propia

\subsection{Programa de producción}

\subsubsection{Factores para la programación de la producción}

Para determinar la vida útil de este proyecto se tomará en cuenta los factores que influyen en la implementación del mismo:

- Calidad de los equipos y máquinas

- Mantenimiento

- Combustible

El proyecto en estudio ha sido planteado considerando una vida útil de 6 años (2017-2022) a partir de la implementación de la planta. El análisis y evaluación de 
resultados del proyecto se realizará desde que la planta empieza a producir y finalizará cuando termine la vida útil del proyecto.

\subsubsection{Programa de producción}

Es necesario cumplir con la programación, abastecimiento de materiales, mano de obra, instalaciones y todos los elementos necesarios para cumplir con el programa de producción.

En la tabla 5.21, se puede observar el porcentaje de utilización de la planta considerando la demanda del proyecto hasta el año 2022, la capacidad de planta representada por el cuello de botella y un stock de seguridad del $1 \%$ de la demanda. Además, en la tabla 5.22 se muestra el programa de producción anual, mensual y diario en unidades.

Tabla 5. 21

Porcentaje de utilización de planta

\begin{tabular}{|c|c|c|c|c|c|}
\hline Año & $\begin{array}{c}\text { Demanda } \\
\text { (unidades } \\
\mathbf{5 0 g r )}\end{array}$ & $\begin{array}{c}\text { Stock de } \\
\text { seguridad } \\
(\mathbf{1 \%})\end{array}$ & $\begin{array}{c}\text { Producción } \\
\text { (unidades 50gr) }\end{array}$ & $\begin{array}{c}\text { Capacidad } \\
\text { de planta } \\
\text { (unidades } \\
\mathbf{5 0 g r}\end{array}$ & $\begin{array}{c}\text { Utilización } \\
\text { de planta } \\
\text { (\%) }\end{array}$ \\
\hline 2016 & $1,117,630$ & 11,176 & $1,128,806$ & $2,673,216$ & 42.2 \\
\hline 2017 & $1,209,930$ & 12,099 & $1,222,029$ & $2,673,216$ & 45.7 \\
\hline 2018 & $1,302,230$ & 13,022 & $1,315,252$ & $2,673,216$ & 49.2 \\
\hline 2019 & $1,394,529$ & 13,945 & $1,408,475$ & $2,673,216$ & 52.7 \\
\hline 2020 & $1,486,829$ & 14,868 & $1,501,697$ & $2,673,216$ & 56.2 \\
\hline 2021 & $1,579,129$ & 15,791 & $1,594,920$ & $2,673,216$ & 59.7 \\
\hline 2022 & $1,671,429$ & 16,714 & $1,688,143$ & $2,673,216$ & 63.2 \\
\hline
\end{tabular}

Elaboración propia

Podemos observar que el porcentaje de utilización de planta incrementa año tras año, sin embargo, no llegamos a utilizar el $100 \%$ en los 6 años de estudio. 
Tabla 5. 22

Programación de producción

\begin{tabular}{|c|c|c|c|c|}
\hline Año & $\begin{array}{c}\text { Producción } \\
\text { (unidades/año) }\end{array}$ & $\begin{array}{c}\text { Producción } \\
\text { (unidades/mes) }\end{array}$ & $\begin{array}{c}\text { Producción } \\
\text { (unidades/semana) }\end{array}$ & $\begin{array}{c}\text { Producción } \\
\text { (unidades/día) }\end{array}$ \\
\hline 2016 & $1,128,806$ & 94,067 & 21,708 & 4,342 \\
\hline 2017 & $1,222,029$ & 101,836 & 23,501 & 4,700 \\
\hline 2018 & $1,315,252$ & 109,604 & 25,293 & 5,059 \\
\hline 2019 & $1,408,475$ & 117,373 & 27,086 & 5,417 \\
\hline 2020 & $1,501,697$ & 125,141 & 28,879 & 5,776 \\
\hline 2021 & $1,594,920$ & 132,910 & 30,672 & 6,134 \\
\hline 2022 & $1,688,143$ & 140,679 & 32,464 & 6,493 \\
\hline
\end{tabular}

Elaboración propia

\subsection{Requerimiento de insumos, servicios y personal}

\subsubsection{Materia prima, insumos y otros materiales}

Para determinar la cantidad de materia prima, insumos y otros materiales se consideró la información mostrada en el balance de materia expuesto anteriormente.

En la tabla 5.23 se muestra el requerimiento de $\mathrm{kg}$ de cada uno de los insumos y materiales necesarios para cumplir con el programa de producción en unidades de $50 \mathrm{gr}$ cada una. 
Tabla 5.23

Requerimiento de materia prima, insumos y otros materiales durante los 6 años de estudio

\begin{tabular}{|c|c|c|c|c|c|c|c|c|}
\hline $\begin{array}{l}\text { Insumos/ } \\
\text { Materiales }\end{array}$ & $\begin{array}{c}\text { Cantidad (Kg) } \\
\text { requerida para } \\
\text { una unidad } \\
(50 \mathrm{gr})\end{array}$ & 2016 & 2017 & 2018 & 2019 & 2020 & 2021 & 2022 \\
\hline $\begin{array}{c}\text { Cáscara de } \\
\text { plátano }\end{array}$ & 0.08129 & $91,757.9$ & $99,335.8$ & $106,913.6$ & $114,491.5$ & $122,069.4$ & $129,647.2$ & $137,225.1$ \\
\hline Glicerina & 0.03683 & $41,575.5$ & $45,009.0$ & $48,442.6$ & $51,876.1$ & $55,309.6$ & $58,743.2$ & $62,176.7$ \\
\hline $\begin{array}{c}\text { Benzoato de } \\
\text { Sodio } \\
\end{array}$ & 0.00030 & 339.5 & 367.5 & 395.6 & 423.6 & 451.7 & 479.7 & 507.7 \\
\hline $\begin{array}{c}\text { Borato de } \\
\text { Sodio }\end{array}$ & 0.00030 & 339.5 & 367.5 & 395.6 & 423.6 & 451.7 & 479.7 & 507.7 \\
\hline $\begin{array}{l}\text { Colorante } \\
\text { Orgánico }\end{array}$ & 0.00030 & 339.5 & 367.5 & 395.6 & 423.6 & 451.7 & 479.7 & 507.7 \\
\hline Envases & 1.00000 & $1,128,806.0$ & $1,222,028.8$ & $1,315,251.7$ & $1,408,474.5$ & $1,501,697.4$ & $1,594,920.2$ & $1,688,143.1$ \\
\hline Etiquetas & 1.00000 & $1,128,806.0$ & $1,222,028.8$ & $1,315,251.7$ & $1,408,474.5$ & $1,501,697.4$ & $1,594,920.2$ & $1,688,143.1$ \\
\hline
\end{tabular}

Elaboración propia

Se puede observar que, para cumplir con el requerimiento de la demanda de los próximos años de estudio, el insumo principal es la cáscara de plátano. 


\subsubsection{Servicios: Energía eléctrica, agua, vapor, combustible, etc.}

Para asegurar el funcionamiento correcto de la planta, es necesario contar con los servicios de agua potable y energía eléctrica.

- Servicio de agua potable: Para el cálculo de la cantidad de agua potable que se requiere, es necesario saber la producción final y la cantidad inicial de cáscara, ya que el proceso de lavado de materia prima principal es el que tiene mayor consumo de agua. Además, se debe considerar la cantidad de agua que se requiere para otras actividades; tales como, servicios higiénicos, limpieza de área de trabajo y área administrativa, para lo cual se está tomando el mismo valor para los 6 años del proyecto.

En la tabla 5.24 se muestra el requerimiento de agua durante el primer año de estudio.

Tabla 5. 24

Requerimiento de agua durante el primer año de estudio $\left(\mathrm{m}^{3}\right)$

\begin{tabular}{|c|c|c|c|}
\cline { 2 - 4 } \multicolumn{1}{c|}{} & $\mathbf{2 0 1 7}$ & $\mathrm{S} / . / \mathrm{m}^{3}$ & Total \\
\hline Producción & 5,400 & 5.21 & 28,145 \\
\hline Oficina & 2,000 & 5.21 & 10,424 \\
\hline Total & 7,400 & 5.21 & 38,568 \\
\hline
\end{tabular}

Elaboración propia

El consumo de agua en el primer año de implementación será 38,568 nuevos soles.

- Energía eléctrica: Para realizar el cálculo de consumo anual de energía eléctrica, se considerarán los kWh de cada máquina empleada en las etapas del proceso de producción y el tiempo de funcionamiento para la producción requerida anualmente; además se deberá considerar el consumo de energía eléctrica del área administrativa. Se considera la opción tarifaria BT5B (no residencial por zona). 
Tabla 5. 25

Consumo de energía eléctrica durante el año 2017 (kWh)

\begin{tabular}{|c|c|c|c|c|c|c|}
\hline & $\begin{array}{l}\text { Cantidad de } \\
\text { máquinas }\end{array}$ & $\begin{array}{l}\text { Requerimiento de } \\
\text { máquinas (horas/año) }\end{array}$ & $\begin{array}{l}\text { Potencia } \\
(\mathbf{K w})\end{array}$ & Total de $\mathbf{k W h}$ & $\begin{array}{l}\text { S/./ } \\
\mathbf{k W h}\end{array}$ & Total \\
\hline \multicolumn{7}{|l|}{ Área de producción } \\
\hline Deshidratador & 1.00 & 204.90 & 5.0 & $1,024.49$ & 0.47 & 481.5 \\
\hline Moledor & 1.00 & 307.35 & 3.5 & $1,075.72$ & 0.47 & 505.6 \\
\hline Tamiz & 1.00 & 105.80 & 2.2 & 232.76 & 0.47 & 109.4 \\
\hline Caldera mezcladora & 1.00 & 130.51 & 4.0 & 522.04 & 0.47 & 245.4 \\
\hline Dosificador de polvo & 3.00 & 260.00 & 0.5 & 130.00 & 0.47 & 61.1 \\
\hline Envasadora & 1.00 & 341.50 & 1.5 & 512.25 & 0.47 & 240.8 \\
\hline Etiquetadora & 1.00 & 341.50 & 1.5 & 512.25 & 0.47 & 240.8 \\
\hline Balanza & 1.00 & 260.00 & 0.9 & 228.80 & 0.47 & 107.5 \\
\hline & & & \multicolumn{3}{|c|}{ Total planta } & $1,992.0$ \\
\hline \multicolumn{7}{|l|}{ Área administrativa } \\
\hline Computadoras & 6.00 & $1,820.00$ & 0.3 & $3,276.00$ & 0.47 & $1,539.7$ \\
\hline Impresoras & 3.00 & $1,820.00$ & 0.5 & $2,457.00$ & 0.47 & $1,154.8$ \\
\hline Iluminación total & & & & $5,733.00$ & 0.47 & $2,694.5$ \\
\hline & & & \multicolumn{3}{|c|}{ Total oficina } & $5,389.0$ \\
\hline
\end{tabular}

Elaboración propia

En base a lo observado el consumo de energía en el primer año de implementación será de S/. 7, 381.0.

\subsubsection{Determinación del número de operarios y trabajadores indirectos}

Durante el proceso de producción de betún ecológico, solo las etapas de lavado de cáscara de plátano y embalado de producto final son manuales; sin embargo, también se contará con un operario en cada una de las otras etapas del proceso. Además, para una adecuada administración de insumos, producto, comercialización y distribución del producto en estudio se contará con mano de otra indirecta en las oficinas. En las tablas 5.26 y 5.27 se muestra la cantidad de mano de obra directa e indirecta. 
Tabla 5. 26

Personal directo

\begin{tabular}{|c|c|}
\hline Puesto de trabajo & $\begin{array}{c}\mathbf{N}^{0} \text { de } \\
\text { trabajadores }\end{array}$ \\
\hline Ope. de limpieza de cáscara & 1 \\
\hline Ope. del área de secado & 1 \\
\hline Ope. del área de molienda & 1 \\
\hline Ope. del área de tamizado & 1 \\
\hline Ope. del área de mezclado & 1 \\
\hline Ope. del área de envasado & 1 \\
\hline Ope. del área de etiquetado & 1 \\
\hline Ope. de embalaje de producto final & 2 \\
\hline Ope. de almacén & 1 \\
\hline Total & 10 \\
\hline
\end{tabular}

Elaboración propia

Tabla 5. 27

Personal indirecto

\begin{tabular}{|c|c|}
\hline Puesto de trabajo & $\begin{array}{c}\mathbf{N}^{0} \text { de } \\
\text { trabajadores }\end{array}$ \\
\hline Gerente General & 1 \\
\hline Jefe de operaciones y producción & 1 \\
\hline Jefe de almacén & 1 \\
\hline Jefe de mantenimiento & 1 \\
\hline Jefe de finanzas & 1 \\
\hline Jefe de marketing & 1 \\
\hline Vendedores & 1 \\
\hline Secretaria & 10 \\
\hline Total & \\
\hline
\end{tabular}

Elaboración propia

Contaremos con 10 personas que apoyarán directamente en todo el proceso de producción y 10 que apoyarán indirectamente.

\subsubsection{Servicio de terceros}

Para un adecuado sistema de limpieza y seguridad en la planta y eficiencia en los costos, requeriremos los servicios de terceros como LIMPIUM y SILSA para limpieza, 
PROSEGUR para seguridad y otros para el área de transporte. Sin perjuicio a ello, se cumplirá con las condiciones generales para la contratación de servicios de terceros.

\subsection{Disposición de planta}

\subsubsection{Características físicas del proyecto}

- Factor edificio: La planta en estudio debe contar con instalaciones apropiadas tanto en el área de operación como en el área administrativa. Para ello se debe considerar el terreno, pisos, techos, paredes y cableado.

Como se determinó en el capítulo 3, el terreno se ubicará en la zona industrial de Villa María del Triunfo, con lo cual aseguramos la estabilidad del suelo para la construcción de una planta. El tamaño del terreno debe ser adecuado para implementar un área de producción con máquinas industriales y un área administrativa con oficinas y servicios higiénicos.

El piso del área de producción debe ser llano, sin escalones que posibiliten caídas o accidente de los trabajadores; además debe ser de material no resbaladizo. El piso de las oficinas administrativas debe ser cubierto con mayólicas de alto tránsito de color claro para no afectar la iluminación.

En el área de producción se debe considerar una altura de techo suficiente para fácil manipulación de maquinaria y mercadería, además debe contar con paredes de concreto, ventilación adecuada, espacio despejado, señalización y disponibilidad de EPS's. El área administrativa será aproximadamente el $20 \%$ del terreno, ya que no cuanta con equipos grandes ni almacenes, esta área deberá tener acceso al área de producción con un diseño adecuado para mitigar los ruidos y vapores. Además, se contará con equipos de oficina como computadoras, impresoras y escritorios; deberá contar también con buena iluminación al igual que el área de producción (tubos fluorescentes de aproximadamente 32W). Se deberá contar con instalaciones eléctricas protegidas y debidamente señalizadas tanto en el área de producción como en las oficinas. 
- Factor servicio: El área administrativa estará conformada por una oficina para cada jefe y gerente, vendedor y secretaria; cada oficina contará con una computadora, impresora, un escritorio y 3 asientos, además de una adecuada ventilación y acceso a la puerta de salida. El área de cada oficina será aproximadamente de $9 \mathrm{~m}^{2}$.

Se implementará un servicio higiénico con la división de "DamasCaballeros" en el área de producción y otro en las oficinas administrativas. Para cada uno se colocará una puerta de $0.90 \mathrm{~cm}$ para facilitar posible ingreso de sillas de rueda. Cada baño contará con un inodoro, un lavatorio y un vestuario; se estima que la medida de cada uno será de $4 \mathrm{~m}^{2}$.

El comedor se encontrará fuera del área de producción y en el primer piso; tendrá la capacidad de atender a todos los trabajadores tanto de planta como de oficina al mismo tiempo para lo cual contará con 4 mesas grandes para 6 personas cada un considerando al personal tercero. El área mínima por persona que se requiere es de 1.58; para mayor holgura se considerara 24 personas como máximo.

Con relación a los almacenes, se contará con uno a baja temperatura (< $13^{\circ} \mathrm{C}$ ) para la conservación de la cáscara de plátano, otro para los demás insumos (glicerina, borato de sodio, benzoato de sodio y colorante) y uno para productos terminados. Se considerará que los almacenes de materia prima se encuentren cerca del área de producción e incluso de la máquina con la que empieza el proceso; el almacén de productos terminados debe ubicarse en un lugar estratégico cerca al área de producción y al área de salida para que sea rápidamente distribuido. El cálculo del área de almacenes se detalla a continuación:

- Almacén de cáscara de plátano: La cáscara de plátano se transportará y llegará a la planta en bolsas oscuras fabricadas a partir de fibra sintética suficientemente resistente para evitar el colapso bajo cualquier condición de manipulación que se presente, con suficiente ingreso de ventilación para evitar la acumulación de calor proveniente de la respiración del insumo, además tienen como ventaja ser livianas, re-usables, el proveedor las puede fabricar localmente y a bajo costo, además 
protege la materia prima durante el transporte y uniformiza el número de unidades o peso del insumo por envase (inicialmente de $50 \mathrm{~kg}$ ) de modo que todos los proveedores manejen cantidades estandarizadas.

La cáscara de plátano se recepcionará semanalmente de diferentes proveedores y se apilará en pallets de 5 sacos por pallet ya que la resistencia de la cáscara no permite cargar mayor peso.

Para determinar el área del almacén, tomamos como referencia los kg que requerimos mensual y semanalmente para abastecer la demanda del proyecto. En la tabla 5.28 se muestra el requerimiento de pallets para cumplir con la demanda de una semana:

Tabla 5. 28

$\mathrm{N}^{\circ}$ pallets requeridos para almacenaje de cáscara de plátano

\begin{tabular}{|c|c|c|c|c|c|}
\hline $\begin{array}{c}\text { Kg requeridos } \\
\text { por mes }\end{array}$ & $\begin{array}{c}\text { Kg requeridos por } \\
\text { semana }\end{array}$ & $\begin{array}{c}\text { Kg / } \\
\text { saco }\end{array}$ & $\begin{array}{c}\text { Sacos/ } \\
\text { pallet }\end{array}$ & $\begin{array}{c}\text { N de sacos } \\
\text { requeridos }\end{array}$ & $\begin{array}{c}\text { N Pallets requeridos } \\
\text { semanalmente }\end{array}$ \\
\hline 11,435 & 2,639 & 50 & 5 & 53 & 11 \\
\hline
\end{tabular}

Elaboración propia

Considerando que la medida de un pallet es alrededor de $1.20 \mathrm{~m}^{2}$, que se contará con 1 rack de 3 niveles y un pasadizo de transito; el área de almacén deberá ser aproximadamente $4.8 \mathrm{~m}$ de ancho y $4 \mathrm{~m}$ de profundidad, lo que resulta $19.2 \mathrm{~m}^{2}$.

- Almacén de insumos: La recepción de los demás insumos se realizará mensualmente, en la tabla 5.29 se detalla la cantidad de pallets requeridos para cumplir con la demanda de un mes. 
Tabla 5. 29

$\mathrm{N}^{\mathrm{o}}$ pallets requeridos para almacenaje de insumos

\begin{tabular}{|c|c|c|c|c|c|}
\hline Insumo/Material & Req. mensual & $\begin{array}{c}\text { Cantidad de } \\
\text { insumo } \mathbf{x} \text { envase }\end{array}$ & $\begin{array}{c}\mathbf{N}^{\prime} \text { envases } \\
\text { requeridos }\end{array}$ & $\begin{array}{c}\mathbf{N}^{\prime} \text { envases } \mathbf{x} \\
\text { pallet }\end{array}$ & $\begin{array}{c}\text { N Pallets } \\
\text { requeridos }\end{array}$ \\
\hline Glicerina (Kg) & $5,181.4$ & 315 & 16 & 4 & 4.1 \\
\hline Benzoato de Sodio (Kg) & 42.3 & 25 & 2 & 6 & 0.3 \\
\hline Borato de Sodio (Kg) & 42.3 & 25 & 2 & 6 & 0.3 \\
\hline Colorante Orgánico (Kg) & 42.3 & 25 & 2 & 6 & 0.3 \\
\hline Envases (unid.) & $140,678.6$ & 1400 & 100 & 1 & 100.5 \\
\hline Etiquetas (unid.) & $140,678.6$ & 10000 & 14 & 1 & 14.1 \\
\hline Cajas de cartón (unid.) & $11,723.2$ & 500 & 23 & 1 & 23.4 \\
\hline
\end{tabular}

Elaboración propia

Se requerirá un almacén de insumos para 143 pallets, para lo cual se considerarán 3 racks de 4 niveles cada uno, el área de los racks será de aproximadamente $43 \mathrm{~m}^{2}$, además se considerará un pasillo de $20 \%$ para facilidad tránsito y uso de equipos logísticos. El área total de almacén de insumos será de $51.6 \mathrm{~m}^{2}$.

- Almacén de productos terminados: Considerando que la mercadería se distribuye semanalmente, el cálculo del área de almacén debe ser para 32, 465 unidades que equivalen a 2, 506 cajas de 12 unidades cada una; considerando que en cada pallet le colocarán 120 cajas, se requerirá un almacenamiento de 23 pallets semanalmente. El almacén contará con un rack de 3 pisos con dimensiones de $9.2 \mathrm{~m}^{2}$ más un $20 \%$ como espacio de tránsito y manipulación de equipos logísticos. El área total de almacén de productos terminados es de $11 \mathrm{~m}^{2}$.

Con relación al patio de recepción de materia prima y despacho de mercadería, el tamaño deberá permitir el ingreso de 3 camiones a la vez y realizar maniobras de carga y descarga por parte de los operarios, tomando en cuenta que un camión mide aproximadamente $27.2 \mathrm{~m}^{2}$, y un espacio de manipulación de materiales de $50 \mathrm{~m}^{2}$, el área total del patio deberá ser 132 m²; además se contará con un área de estacionamiento para uso del personal principalmente de oficina y clientes. 
Se contará también con un tópico de $8 \mathrm{~m}^{2}$ en el que se podrá atender todo el personal de la empresa en caso se requiera.

\subsubsection{Determinación de las zonas físicas requeridas}

Las zonas físicas requeridas en la planta son:

- Almacén de materia prima

- Almacén de insumos

- Área de producción

- Área de EPS's

- Servicios higiénicos de damas

- Servicios higiénicos de caballeros

- Oficina del Gerente General

- Oficina de los Jefes de área

- Zonas de seguridad

- Comedor

- Tópico

- Estacionamiento

- Patio de maniobras

\subsubsection{Cálculo de áreas para cada zona}

Para determinar el área mínima requerida por el área de producción se utilizó el método de Guerchet. En las tablas 5.30 y 5.31 se detallan las medidas y resultados de los elementos estáticos y móviles; además en la tabla 5.32 se detalla el cálculo del valor de k "Coefíciente de evolución" con el que se realizó el cálculo de la superficie de evolución. 
Tabla 5. 30

Análisis de Guerchet para elementos estáticos

\begin{tabular}{|c|c|c|c|c|c|c|c|c|c|c|c|}
\hline Elementos fijos & $\mathbf{L}$ & $\mathbf{A}$ & $\mathbf{h}$ & $\mathbf{N}$ & $\mathbf{n}$ & $\mathbf{S s}$ & $\mathbf{S g}$ & $\mathbf{S e}$ & $\mathbf{S T}$ & Ss x n & Ss x $\mathbf{n} \mathbf{x} \mathbf{h}$ \\
\hline Balanza & 1.2 & 1.2 & 1.5 & 3.0 & 1.0 & 1.4 & 4.3 & 3.2 & 9.0 & 1.4 & 2.2 \\
\hline Lavadero & 1.2 & 1.2 & 0.5 & 1.0 & 1.0 & 1.4 & 1.4 & 1.6 & 4.5 & 1.4 & 0.7 \\
\hline Deshidratador & 2.3 & 1.2 & 2.0 & 1.0 & 1.0 & 2.8 & 2.8 & 3.1 & 8.6 & 2.8 & 5.5 \\
\hline Moledor & 1.2 & 0.9 & 1.4 & 3.0 & 1.0 & 1.1 & 3.2 & 2.4 & 6.8 & 1.1 & 1.5 \\
\hline Tamiz & 0.9 & 1.1 & 1.1 & 2.0 & 1.0 & 1.0 & 1.9 & 1.6 & 4.5 & 1.0 & 1.0 \\
\hline Tanque mezclador & 0.8 & 1.0 & 2.7 & 3.0 & 1.0 & 0.8 & 2.3 & 1.8 & 4.9 & 0.8 & 2.1 \\
\hline Dosificador & 1.4 & 0.7 & 2.7 & 3.0 & 3.0 & 1.0 & 2.9 & 2.2 & 18.4 & 2.9 & 7.9 \\
\hline Envasadora & 1.3 & 0.5 & 0.9 & 3.0 & 1.0 & 0.7 & 2.0 & 1.5 & 4.1 & 0.7 & 0.6 \\
\hline Etiquetadora & 2.1 & 0.7 & 1.0 & 3.0 & 1.0 & 1.5 & 4.4 & 3.3 & 9.2 & 1.5 & 1.5 \\
\hline Pariguelas & 1.2 & 1.0 & 1.5 & $\mathrm{X}$ & 6.0 & 1.2 & $\mathrm{X}$ & 0.7 & 11.3 & 7.2 & 10.4 \\
\hline Mesa de trabajo & 0.5 & 1.5 & 1.5 & 3.0 & 1.0 & 0.8 & 2.3 & 1.7 & 2.4 & 0.8 & 1.1 \\
\hline
\end{tabular}

Elaboración propia

Tabla 5. 31

Análisis de Guerchet para elementos móviles

\begin{tabular}{|c|c|c|c|c|c|c|c|c|c|c|c|}
\hline Elementos móviles & $\mathbf{L}$ & $\mathbf{A}$ & $\mathbf{h}$ & $\mathbf{N}$ & $\mathbf{n}$ & $\mathbf{S s}$ & $\mathbf{S g}$ & $\mathbf{S e}$ & $\mathbf{S T}$ & Ss x n & Ss x $\mathbf{n} \mathbf{x} \mathbf{h}$ \\
\hline Apilador eléctrico & 2.5 & 1.8 & 2.1 & $\mathrm{X}$ & 1 & 4.5 & $\mathrm{X}$ & $\mathrm{X}$ & $\mathrm{X}$ & 4.5 & 9.8 \\
\hline Traspaleta manual & 1.3 & 0.5 & 1.2 & $\mathrm{X}$ & 2 & 0.7 & $\mathrm{X}$ & $\mathrm{X}$ & $\mathrm{X}$ & 1.4 & 1.7 \\
\hline Operarios & $\mathrm{X}$ & $\mathrm{X}$ & 1.65 & $\mathrm{X}$ & 10 & 0.5 & $\mathrm{X}$ & $\mathrm{X}$ & $\mathrm{X}$ & 5.0 & 8.3 \\
\hline
\end{tabular}

Elaboración propia

Tabla 5. 32

Cálculo del coeficiente de evolución (k)

\begin{tabular}{|c|c|}
\hline Altura de los elementos móviles (hEM) & 1.81 \\
\hline Altura de los elementos estáticos (hEE) & 1.61 \\
\hline Coeficiente de evolución $(\mathrm{k})$ & 0.56 \\
\hline
\end{tabular}

Elaboración propia

En base al estudio realizado se determinó que el área mínima requerida en el área de producción es de $83.5 \mathrm{~m}^{2}$. 


\subsubsection{Dispositivos de seguridad industrial y señalización}

En todas las áreas de la planta debe haber señales de seguridad expuestos a la vista de todo el personal. Se deben considerar los colores establecidos en la Norma Técnica Peruana 390.010-2004. Esta Norma se aplica a las señales de seguridad que se deben utilizar en todas las plantas industriales con la finalidad de orientar, prevenir y reducir accidentes, riesgos a la salud y facilitar el control de las emergencias a través de colores, formas, símbolos y dimensiones.

Tomando en cuenta la norma, los significados de los colores son:

- Rojo: Prohibición, material de prevención y lucha contra incendios.

- Azul: Obligación

- Azul (circular): Seguridad

- Amarillo: Riesgo de peligro

- Verde: Información de emergencia.

Además, se contará con 3 extintores distribuidos correctamente en la planta para evitar la propagación de posibles incendios, el tipo de extintor que se colocará será el 2A 10BC, ya que están compuestos por halotron, que es un agente limpio.

En el anexo 2 se muestran las señales de seguridad y símbolos que colocaremos para la seguridad de la planta.

\subsubsection{Disposición general}

Para realizar la distribución general de la planta, es necesario hacer un análisis de las actividades que se llevan a cabo en cada zona de trabajo. Con esto se podrá realizar la mejor distribución de los espacios considerando los flujos de materiales, la cercanía entre las tareas y los flujos de productos terminados. El análisis de disposición de planta se realizará utilizando la herramienta "Tabla relacional"; para lo cual se manejará la escala de valores que se muestra en la tabla 5.33 y los códigos de motivos definidos de la tabla 5.34. 
Tabla 5. 33

Escala de valores

\begin{tabular}{|c|c|}
\hline Código & Valor de proximidad \\
\hline $\mathrm{A}$ & Absolutamente necesario \\
\hline $\mathrm{E}$ & Especialmente necesario \\
\hline $\mathrm{I}$ & Importante \\
\hline $\mathrm{O}$ & Normal u ordinario \\
\hline $\mathrm{U}$ & Sin importancia \\
\hline $\mathrm{X}$ & No recomendable \\
\hline
\end{tabular}

Elaboración propia

Tabla 5. 34

Código de motivos

\begin{tabular}{|c|c|}
\hline Código & Motivos \\
\hline 1 & Por las tuberías de agua y desagüe \\
\hline 2 & No es necesario \\
\hline 3 & Comodidad del personal \\
\hline 4 & Facilidad de control e inventario en el almacén \\
\hline 5 & Fácil traslado \\
\hline 6 & Inspección y seguridad \\
\hline 7 & Polvo, olor o ruido \\
\hline 8 & Peligro de contaminación \\
\hline 9 & Seguridad del trabajador \\
\hline
\end{tabular}

Elaboración propia

En base a los códigos de valor de proximidad, los códigos de motivos y los colores y símbolos de proximidad a utilizar, se elaboró la tabla relacional de actividades que se muestra en la figura 5.4. 
Figura 5.4

Tabla relacional de actividades

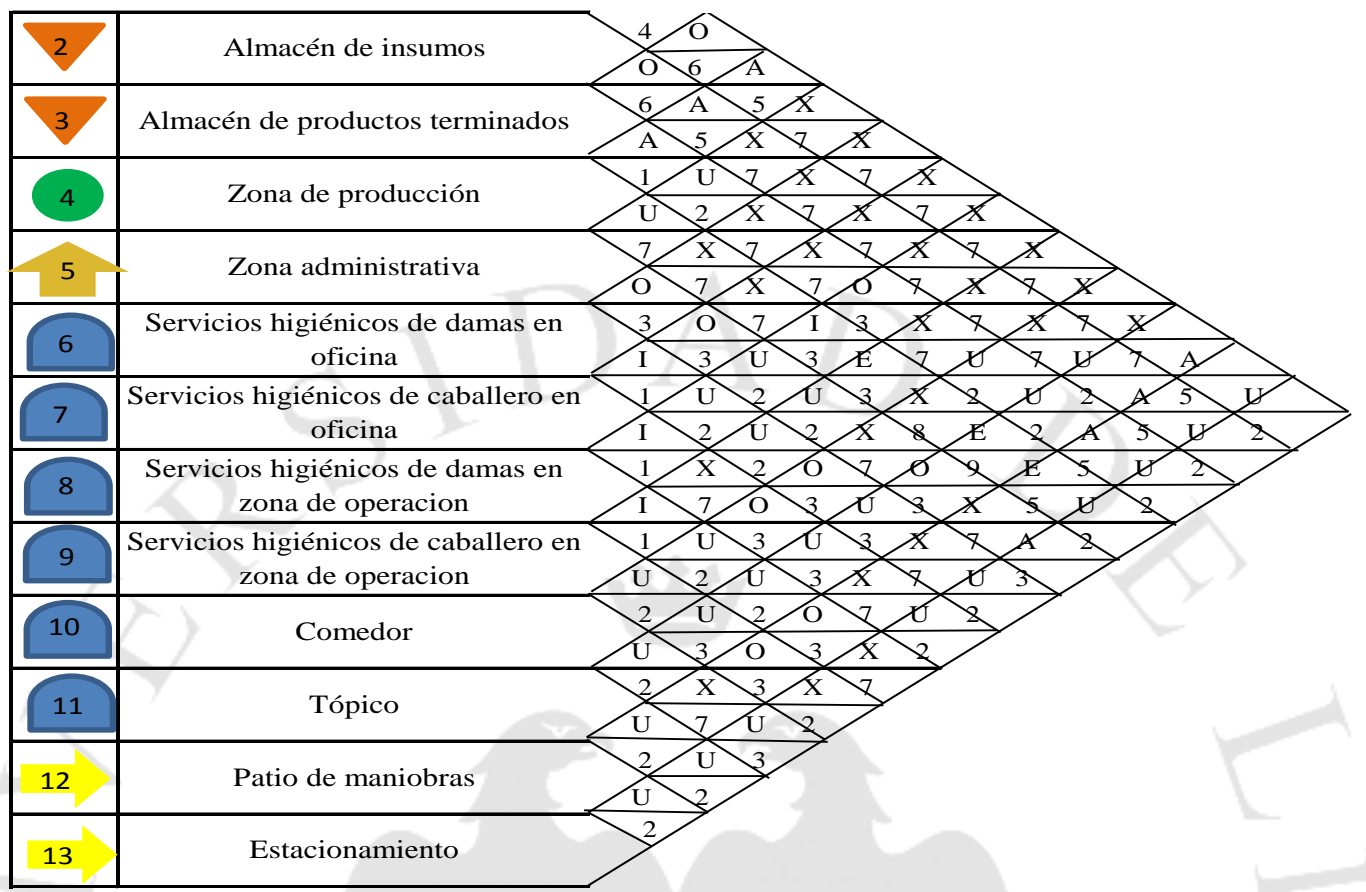

Elaboración propia

En base a estos resultados, en la figura 5.5 de observa el diagrama relacional de actividades.

\section{Figura 5.5}

Diagrama relacional de actividades

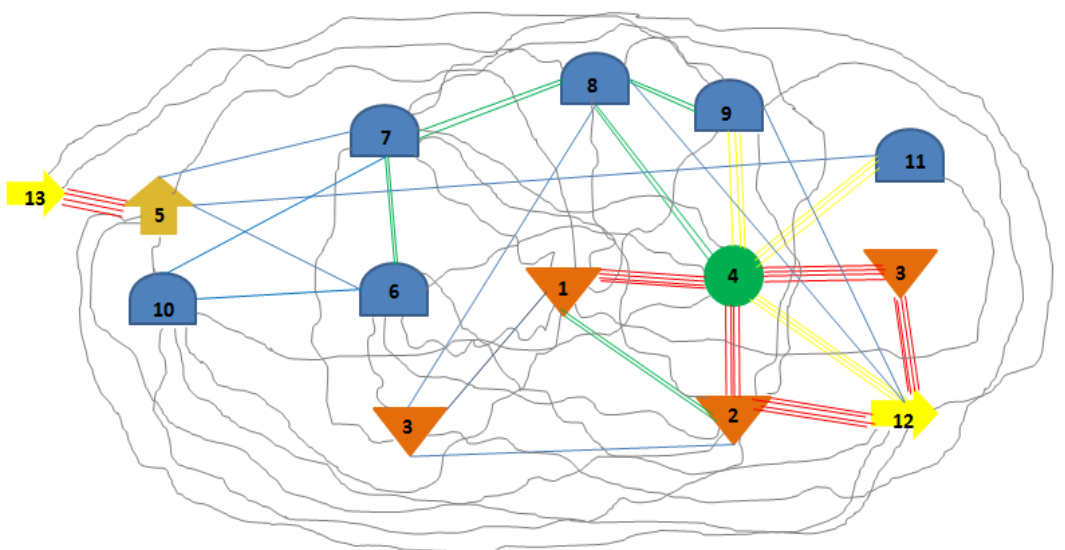

Elaboración propia 


\subsubsection{Disposición al detalle}

Se considera que el terreno estará ubicado en una esquina.

Figura 5. 6

Disposición al detalle $\left(500 \mathrm{~m}^{2}\right)$

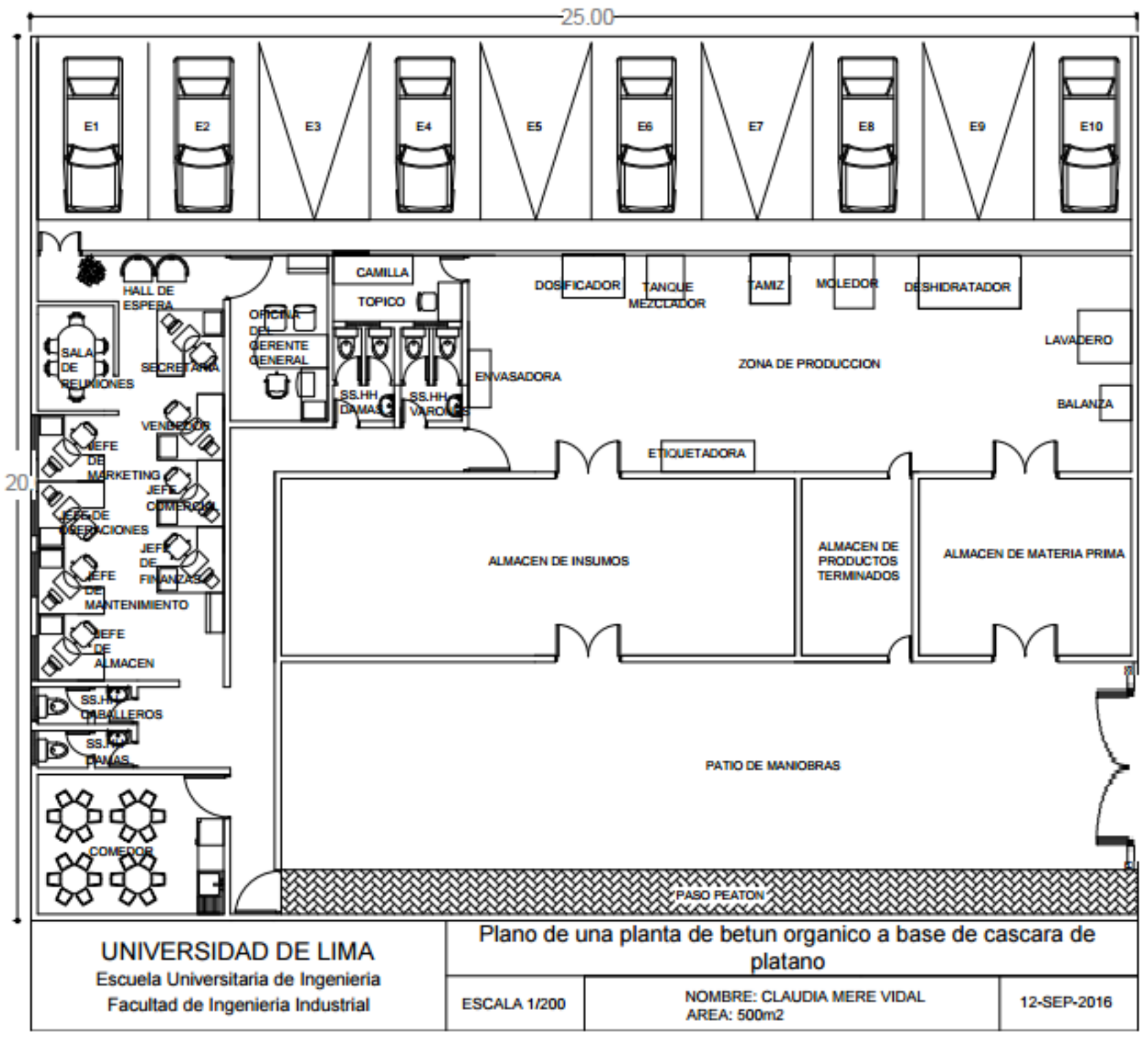

Elaboración propia 


\subsection{Cronograma de implementación del proyecto}

En la figura 5.7 se muestra el cronograma detallado de la implementación del proyecto.

Figura 5.7

Cronograma de implementación del proyecto

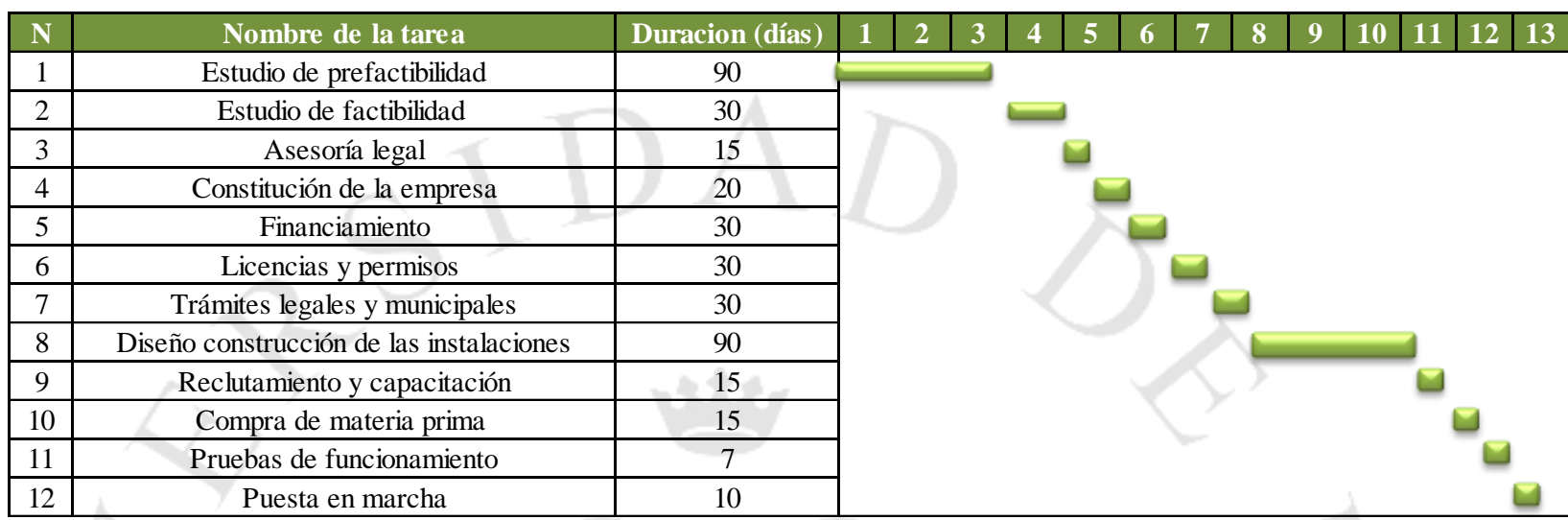

Elaboración propia
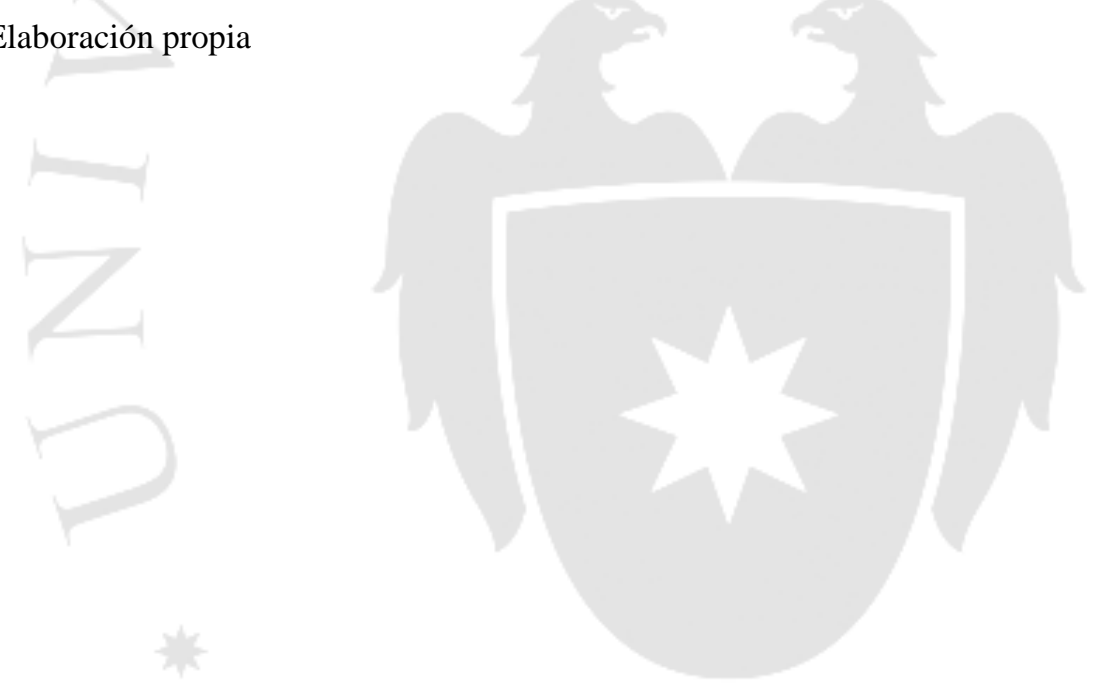


\section{CAPÍTULO VI: ORGANIZACIÓN ADMINISTRATIVA}

\subsection{Formación de la Organización empresarial}

De acuerdo a la descripción de la empresa en estudio, esta tendrá una estructura funcional la cual determina la existencia de diversos supervisores y jefes, cada cual especializado en determinadas áreas.

Las características de esta organización son:

- La autoridad tendrá la mayor capacidad y conocimiento.

- Ningún superior tendrá autoridad total sobre los subordinados, sino autoridad parcial o relativa.

- Siempre habrá línea directa de comunicación entre diferentes niveles, lo que permite una comunicación más fluida y rápida.

- Descentralización de las decisiones, ya que se delegan a los cargos especializados.

- Agrupación de especialistas, lo que permite incrementar el control y la coordinación dentro de la organización.

\subsection{Requerimientos de personal}

Se presentan las funciones de cada puesto de trabajo del organigrama de la empresa en estudio:

\section{Gerente General:}

- Ejercer la dirección del personal de administración y servicio.

- Dirigir la elaboración de los Planes Estratégicos Sectoriales de Gestión.

- Establecer los objetivos de calidad de los distintos servicios y unidades en los que se integra el Personal de Administración y Servicios. 
- Organizar y coordinar los servicios administrativos, económicos y técnicos velando por su correcto funcionamiento.

- Elaborar los criterios para determinar las necesidades de plantilla.

- Ejercer el control de la gestión de los ingresos y gastos.

- Realizar los pagos de las obligaciones de la empresa.

- Controlar y realizar el seguimiento de la ejecución del presupuesto anual.

\section{Jefe de Operaciones y producción:}

- Asumir la responsabilidad de los resultados de la gestión realizada en el área de operación.

- Definir los objetivos y criterios de actuación, en el marco de los objetivos generales de la empresa y los sectoriales de la Gerencia.

- Diseñar y revisar los procedimientos correspondientes al ámbito de su competencia.

- Impulsar nuevas iniciativas para la implantación de nuevos procesos y procedimientos.

- Evaluar los resultados de la gestión en el área de su competencia.

- Velar por la puesta en práctica de las medias de seguridad y salud laboral.

- Velar por el cumplimiento de las disposiciones legales y normas.

- Contribuir al desarrollo profesional de sus colaboradores.

- Supervisar la operatividad de las máquinas y equipos; verificar que los operarios se encuentren en buen estado y que realicen correctamente su trabajo.

- Programar el mantenimiento de la maquinaria.

- Elaborar indicadores de los resultados de producción. 


\section{Jefe de marketing:}

- Diseñar la estrategia de marketing.

- Realizar estudio de mercado para posible ampliación de mercado.

- Establecer indicadores de gestión.

\section{Vendedor}

- Realizar visita a clientes.

- Levantar información de precios y promociones que ofrece la competencia.

- Ejercer la función de vender a los clientes

\section{Jefe de mantenimiento:}

- Realizar coordinaciones con proveedores.

- Verificar el cumplimiento de requisitos de los insumos y materia prima.

- Asegurar el ingreso de mercadería completa.

- Coordinar con transportistas el envío de producto terminado.

- Resguardar los productos almacenados, así como supervisar que la temperatura, humedad e iluminación sean las correctas para mantener los productos.

- Asegurar la limpieza de los almacenes.

- Mantener un control e inventario de las entradas y salidas de productos en los almacenes.

\section{Jefe de almacén}

- Elaborar planes de capacitación de uso y mantenimiento de maquinaria para el personal de planta. 
- Llevar un control de mantenimiento preventivo y reactivo.

- Contar con los materiales necesarios para realizar mantenimientos.

- Realizar un control diario del cumplimiento de mantenimientos.

- Coordinar con proveedores externos los mantenimientos que requieran mayor expertíz.

\section{Jefe de finanzas}

- Llevar un control interno de los ingresos y egresos de la empresa.

- Realizar los estados de cuenta y flujos económicos y financieros.

\subsection{Estructura organizacional}

Figura 6. 1

Organigrama de la empresa

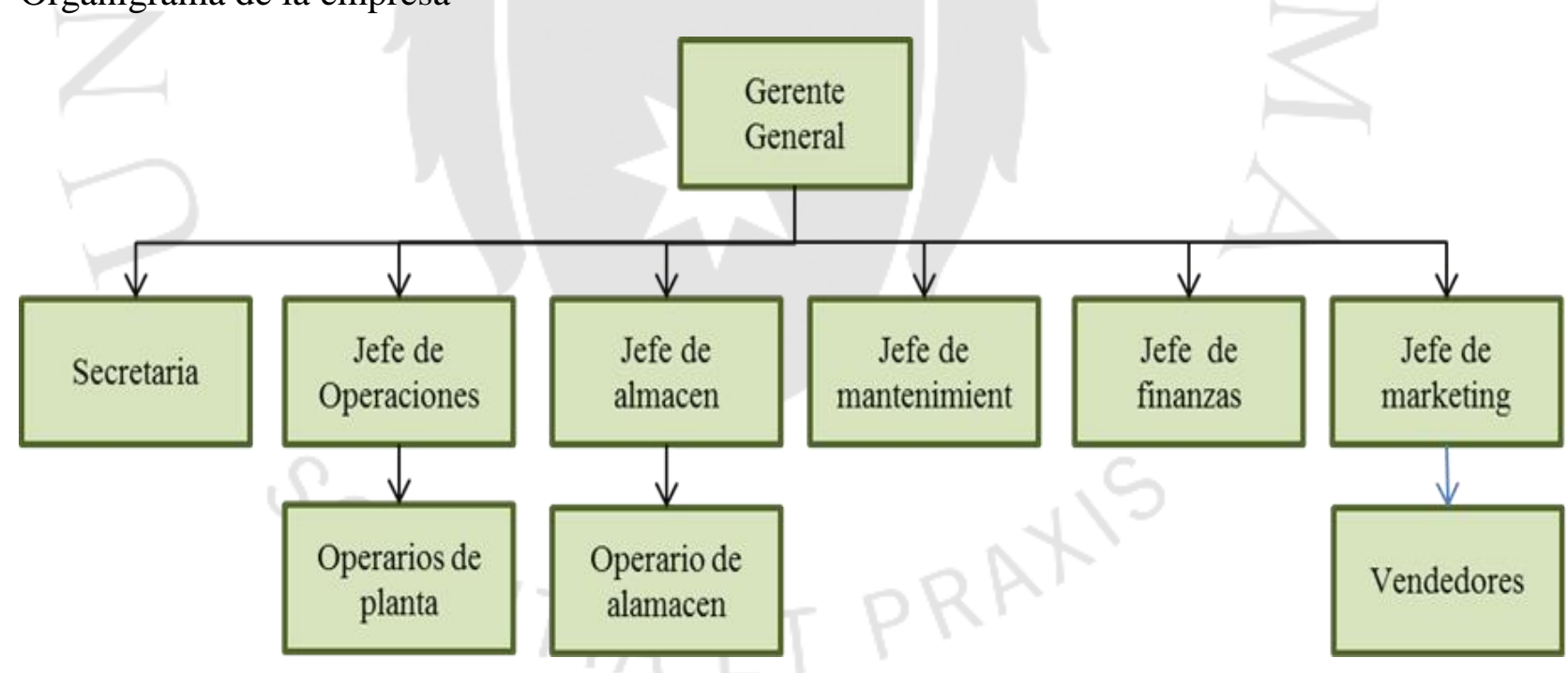

Elaboración propia 


\section{CAPÍTULO VII: ASPECTOS ECONÓMICOS Y FINANCIEROS}

\subsection{Inversiones}

\subsubsection{Estimación de las inversiones de largo plazo (tangibles e intangibles)}

En el presente proyecto se evaluarán las inversiones tangibles e intangibles:

- Inversión fija tangible: La inversión fija tangible está conformada por la compra del terreno, edificaciones, compra e instalación de maquinaria tanto para el área de operaciones como para el área administrativa, así como los imprevistos fabriles y no fabriles. Para determinar la inversión total en maquinaria, se revisarán los costos de los equipos de producción, así como los costos de equipos adicionales y los gastos de instalaciones de máquinas y equipos. En la tabla 7.1 se muestra el valor total de compra de equipos y máquinas para el área de producción.

Tabla 7. 1

Inversión total de la compra e instalación de equipos y maquinaria

\begin{tabular}{|c|r|}
\hline Maquinaria & Valor $(\mathbf{S}$ ) \\
\hline Lavadero & 2,800 \\
\hline Deshidratador & 15,750 \\
\hline Moledor & 6,300 \\
\hline Tamiz & 9,100 \\
\hline Caldera mezcladora & 30,000 \\
\hline Dosificadores (3) & 15,000 \\
\hline Envasadora & 20,000 \\
\hline Etiquetadora & 20,000 \\
\hline Balanza & 3,835 \\
\hline Traspaleta manual (2) & 1,050 \\
\hline Apilador eléctrico & 6,300 \\
\hline Valor total & $\mathbf{1 3 0 , 1 3 5}$ \\
\hline Transporte & 200 \\
\hline Instalación de maquinaria & 20,000 \\
\hline Inversión total equipos & $\mathbf{1 5 0 , 3 3 5}$ \\
\hline
\end{tabular}

Elaboración propia 
En la tabla 7.2 se muestra la inversión por compra del terreno y construcción de la planta.

\section{Tabla 7. 2}

Inversión por compra de terreno y edificación: Terreno $500 \mathrm{~m}^{2}$

\begin{tabular}{|c|c|c|c|}
\hline $\begin{array}{c}\text { Terreno y } \\
\text { edificación }\end{array}$ & $\begin{array}{c}\text { Inversión por } \\
\text { m2 (S/) }\end{array}$ & $\begin{array}{c}\text { Inversión } \\
\text { planta (S/) }\end{array}$ & $\begin{array}{c}\text { Costo de } \\
\text { oficina (S/.) }\end{array}$ \\
\hline Terreno & $2,186.8$ & \multicolumn{2}{|c|}{$1,093,400.0$} \\
\hline Edificación & 450.0 & $157,500.0$ & $67,500.0$ \\
\hline \multicolumn{2}{|c|}{ Total } & \multicolumn{2}{|c|}{$\mathbf{1 , 2 5 0 , 9 0 0 . 0}$} \\
\hline
\end{tabular}

Elaboración propia

En la tabla 7.3 se muestra la inversión por compra de muebles y equipos de oficina y en la tabla 7.4 se muestra el total de la inversión fija tangible.

Tabla 7.3

Inversión por compra de muebles y equipos de oficina

\begin{tabular}{|c|c|c|c|}
\hline Muebles & Cantidad & Precio (S/) & Total $(\mathrm{S} /)$ \\
\hline Laptops & 8 & 1,200 & 9,600 \\
\hline Impresoras & 2 & 600 & 1,200 \\
\hline Cubículos & 7 & 300 & 2,100 \\
\hline Escritorio & 1 & 400 & 400 \\
\hline Mesa de reuniones & 1 & 650 & 650 \\
\hline Sillas de oficina & 14 & 200 & 2,800 \\
\hline Sillas de sala & 2 & 200 & 400 \\
\hline Mesas de comedor & 4 & 350 & 1,400 \\
\hline Sillas de comedor & 24 & 70 & 1,680 \\
\hline Estantes & 9 & 120 & 1,080 \\
\hline Microondas & 1 & 300 & 300 \\
\hline Refrigerador & 1 & 1,200 & 1,200 \\
\hline Meza de trabajo & 1 & 600 & 600 \\
\hline Silla de descanso & 1 & 70 & 70 \\
\hline Camilla & $A$ & 270 & 270 \\
\hline \multicolumn{3}{|c|}{ Total Inversión } & 23,750 \\
\hline
\end{tabular}

Elaboración propia 
Tabla 7. 4

Inversión fija tangible total

\begin{tabular}{|c|c|}
\hline Inversión tangible total & S/. \\
\hline $\begin{array}{c}\text { Compra de instalaciones y } \\
\text { equipos }\end{array}$ & 150,335 \\
\hline Terreno & $1,093,400$ \\
\hline Edificación planta & 157,500 \\
\hline Edificación oficina & 67,500 \\
\hline Muebles y equipos de oficina & 23,750 \\
\hline Vehículos & 25,000 \\
\hline Imprevistos fabriles & 10,000 \\
\hline Imprevistos no fabriles & 5,000 \\
\hline Total & $\mathbf{1 , 5 3 2 , 4 8 5}$ \\
\hline
\end{tabular}

Elaboración propia

El resultado final de la inversión fija tangible es 1, 532,485 nuevos soles.

- Inversión fija intangible: La inversión fija intangible está conformada por los estudios, capacitaciones de personal, puesta en marcha, supervisión, entre otros.

Entre los costos de estudio se consideran los costos de reclutamientos de personal y gastos pre operativos, dentro de los gastos de puesta en marcha están los gastos de constitución de la empresa y otros trámites administrativos como el trámite de formalización como persona jurídica e inscripción de la empresa en la Superintendencia Nacional de Aduanas Administración Tributaria (SUNAT). Además, se considera la licencia Municipal de funcionamiento, registro de contratos de trabajo. También se consideran los gastos de Ingeniería y supervisión para tener control de todas las actividades durante la etapa pre-operativa En la tabla 7.5 se detallan los costos fijos intangibles. 
Tabla 7.5

Costo fijo intangible

\begin{tabular}{|c|c|}
\hline Costos fijos intangibles & Costo (S/) \\
\hline Licencia de edificación & 176 \\
\hline Constitución de la empresa & 500 \\
\hline Registro sanitario & 100 \\
\hline Denominación de origen & 1,000 \\
\hline Registro de marca & 500 \\
\hline Capacitación y asesoría & 1,000 \\
\hline Estudio de pre-factibilidad & 4,500 \\
\hline Software & 500 \\
\hline Seguridad & 6,000 \\
\hline Otros & 500 \\
\hline Total & $\mathbf{1 4 , 7 7 6}$ \\
\hline
\end{tabular}

Elaboración propia

\subsubsection{Estimación de los inversionistas de corto plazo (Capital de trabajo)}

Los gastos como sueldos, compra de materia prima, entre otros que se generan antes de recibir ingresos por ventas, serán cubiertos por el capital de trabajo. Se considerará como ciclo de caja 15 días para conseguir materia prima y 45 que es el tiempo que regularmente se toman los supermercados para pagar.

El capital de trabajo se halla mediante la siguiente fórmula:

$$
K W=(\text { Gastos operación anual/ 365) } * \text { ciclo de caja }
$$

Donde como gasto de operación anual se considerará materia prima, mano de obra, costos indirectos de fabricación, mano de obra indirecta, gastos administrativos y gastos de venta. (Gasto anual) y el ciclo de caja será de 60 días. Con los datos mencionados, se determinó que el Capital de Trabajo será S/. 474, 598.2.

\subsection{Costo de producción}

Los costos de producción son los relacionados al proceso de producción del producto en estudio. 


\subsubsection{Costos de materia prima}

En la tabla 7.6 podemos encontrar los precios de los insumos y materia prima por $\mathrm{kg} \mathrm{o}$ unidad; con la información de esta tabla y la 5.23 en la que se encuentran las cantidades de insumo y materia prima requerida por año para el cumplimiento de la demanda, determinamos el costo total de materia prima. Los costos de materia prima e insumos se han determinado comunicándonos directamente con los proveedores quienes nos han brindado precios al por mayor. Considerándose que la cáscara varía de precio conforme la traen de la selva o de la costa, se tomó un promedio.

\section{Tabla 7. 6}

Costo unitario de insumos y materia prima (S/.)

\begin{tabular}{|c|r|c|}
\hline Cáscara de plátano & 0.4 & $1 \mathrm{~kg}$ \\
\hline Glicerina & 5.2 & $1 \mathrm{~kg}$ \\
\hline Envase & 0.7 & $1 \mathrm{unidad}$ \\
\hline Etiqueta & 0.1 & $1 \mathrm{unidad}$ \\
\hline Benzoato de sodio & 39.0 & $1 \mathrm{~kg}$ \\
\hline Borato de sodio & 40.0 & $1 \mathrm{~kg}$ \\
\hline Colorante orgánico & 212.0 & $1 \mathrm{~kg}$ \\
\hline
\end{tabular}

Elaboración propia

En la tabla 7.7 se muestra el costo total anual de insumos. 
Tabla 7.7

Costo total anual de insumos y materia prima $(\mathrm{S} /$.)

\begin{tabular}{|c|c|c|c|c|c|c|c|c|}
\hline Insumos/ Materiales & $\begin{array}{l}\text { Cantidad (Kg) } \\
\text { requerida para una } \\
\text { unidad ( } 50 \mathrm{gr})\end{array}$ & 2016 & 2017 & 2018 & 2019 & 2020 & 2021 & 2022 \\
\hline Cáscara de plátano & 0.08129 & $32,115.3$ & $34,767.5$ & $37,419.8$ & $40,072.0$ & $42,724.3$ & $45,376.5$ & $48,028.8$ \\
\hline Glicerina & 0.03683 & $214,529.7$ & $232,246.7$ & $249,963.7$ & $267,680.7$ & $285,397.7$ & $303,114.7$ & $320,831.7$ \\
\hline Benzoato de Sodio & 0.00030 & $13,240.7$ & $14,334.2$ & $15,427.6$ & $16,521.1$ & $17,614.6$ & $18,708.1$ & $19,801.6$ \\
\hline Borato de Sodio & 0.00030 & $13,580.2$ & $14,701.7$ & $15,823.2$ & $16,944.7$ & $18,066.3$ & $19,187.8$ & $20,309.3$ \\
\hline Colorante Orgánico & 0.00030 & $71,974.9$ & $77,919.0$ & $83,863.1$ & $89,807.1$ & $95,751.2$ & $101,695.3$ & $107,639.4$ \\
\hline Envases & 1.00000 & $790,164.2$ & $855,420.2$ & $920,676.2$ & $985,932.2$ & $1,051,188.2$ & $1,116,444.1$ & $1,181,700.1$ \\
\hline Etiquetas & 1.00000 & $57,569.1$ & $62,323.5$ & $67,077.8$ & $71,832.2$ & $76,586.6$ & $81,340.9$ & $86,095.3$ \\
\hline Planchas de cartón & 0.08333 & $51,736.9$ & $56,009.7$ & $60,282.4$ & $64,555.1$ & $68,827.8$ & $73,100.5$ & $77,373.2$ \\
\hline
\end{tabular}

Elaboración propia

En la tabla 7.8 se muestra el costo previo de venta unitario considerando los costos variables: Luz, agua, materia prima y materiales. 
Tabla 7.8

Costo de venta unitario

\begin{tabular}{|c|c|}
\hline Suministros & $\begin{array}{c}\text { S/./ } \\
\text { Unidad }\end{array}$ \\
\hline Luz & 0.002 \\
\hline Agua & 0.005 \\
\hline Materia prima e insumos & 1.114 \\
\hline Total & 1.120 \\
\hline
\end{tabular}

Elaboración propia

\subsubsection{Costo de mano de obra directa}

Se considera mano de obra directa a los trabajadores que están en contacto directo con el proceso de producción; en este estudio contamos con 11 operarios de los cuales 1 es de almacén. Para hallar el costo total de mano de otra directa, se considera la remuneración anual, Essalud, gratificación y CTS. Se considera una remuneración mensual de 1200 soles por operario. En la tabla 7.9 se muestra la información de presupuesto de mano de obra directa.

Tabla 7.9

Presupuesto anual de mano de obra directa

\begin{tabular}{|c|c|c|c|c|c|c|c|}
\hline $\begin{array}{c}\text { Puesto de } \\
\text { trabajo }\end{array}$ & $\begin{array}{c}\text { N. } \\
\text { Trabajadores }\end{array}$ & $\begin{array}{c}\text { Remuneración } \\
\text { mensual }\end{array}$ & $\begin{array}{c}\text { Remuneración } \\
\text { anual }\end{array}$ & CTS & Gratificación & $\begin{array}{c}\text { Es } \\
\text { salud } \\
(\mathbf{9} \%)\end{array}$ & \begin{tabular}{c} 
Total \\
\hline Operarios
\end{tabular} \\
\hline Almacén & 1 & 1,200 & 14,400 & 12,600 & 21,600 & 11,664 & 60,264 \\
\hline
\end{tabular}

Elaboración propia

\subsubsection{Costo indirecto de fabricación (materiales indirectos, mano de obra indirecta, $y$ costos generales de la planta)}

Mano de obra indirecta: La mano de obra indirecta hace referencia a todo el personal que no tiene contacto directo con el proceso de producción; estos son: el gerente general, los jefes de las diferentes áreas, secretaría y ventas. En la tabla 7.10 se muestra el presupuesto de la mano de obra indirecta. 
Tabla 7. 10

Presupuesto anual de mano de obra indirecta

\begin{tabular}{|c|c|c|c|c|c|c|c|}
\hline $\begin{array}{c}\text { Puesto de } \\
\text { trabajo }\end{array}$ & $\begin{array}{c}\text { N. } \\
\text { Trabajadores }\end{array}$ & $\begin{array}{c}\text { Remuneración } \\
\text { mensual }\end{array}$ & $\begin{array}{c}\text { Remuneración } \\
\text { anual }\end{array}$ & CTS & Gratificación & $\begin{array}{c}\text { Essalud } \\
(9 \%)\end{array}$ & Total \\
\hline $\begin{array}{c}\text { Gerente } \\
\text { General }\end{array}$ & 1 & 4,000 & 48,000 & 4,667 & 8,000 & 4,320 & 64,987 \\
\hline $\begin{array}{c}\text { Jefe de } \\
\text { operaciones y } \\
\text { producción }\end{array}$ & 1 & 3,000 & 36,000 & 3,500 & 6,000 & 3,240 & 48,740 \\
\hline $\begin{array}{c}\text { Jefe de } \\
\text { almacén }\end{array}$ & 1 & 3,000 & 36,000 & 3,500 & 6,000 & 3,240 & 48,740 \\
\hline $\begin{array}{c}\text { Jefe de } \\
\text { mantenimiento }\end{array}$ & 1 & 3,000 & 36,000 & 3,500 & 6,000 & 3,240 & 48,740 \\
\hline $\begin{array}{c}\text { Jefe de } \\
\text { finanzas }\end{array}$ & 1 & 3,000 & 36,000 & 3,500 & 6,000 & 3,240 & 48,740 \\
\hline $\begin{array}{c}\text { Jefe de } \\
\text { marketing }\end{array}$ & 1 & 3,000 & 36,000 & 3,500 & 6,000 & 3,240 & 48,740 \\
\hline Vendedores & 3 & 2,500 & 30,000 & 2,917 & 5,000 & 2,700 & 56,450 \\
\hline Secretaria & 1 & 2,000 & 24,000 & 2,333 & 4,000 & 2,160 & 32,493 \\
\hline
\end{tabular}

Elaboración propia

\subsection{Presupuestos Operativos}

\subsubsection{Presupuesto de ingreso por ventas}

El presupuesto de ingreso por ventas se calcula considerando la demanda anual en unidades por el precio de venta al cual irá dirigido a los supermercados y bodegas. En la tabla 7.11 se muestra el presupuesto de ingresos por venta.

Tabla 7. 11

Presupuesto de ingresos por ventas

\begin{tabular}{|c|c|c|c|r|r|r|r|}
\cline { 2 - 8 } \multicolumn{1}{c|}{} & \multicolumn{1}{c|}{2016} & \multicolumn{1}{c|}{2017} & 2018 & 2019 & 2020 & 2021 & 2022 \\
\hline $\begin{array}{c}\text { Ventas } \\
\text { (unidades) }\end{array}$ & $1,117,629.7$ & $1,209,929.5$ & $1,302,229.4$ & $1,394,529.2$ & $1,486,829.1$ & $1,579,128.9$ & 1671428.765 \\
\hline Precio & 2.0 & 2.0 & 2.0 & 2.0 & 2.0 & 2.0 & 2.0 \\
\hline Ventas (S/.) & $\mathbf{2 , 2 3 5 , 2 5 9 . 4}$ & $\mathbf{2 , 4 1 9 , 8 5 9 . 1}$ & $\mathbf{2 , 6 0 4 , 4 5 8 . 8}$ & $\mathbf{2 , 7 8 9 , 0 5 8 . 5}$ & $\mathbf{2 , 9 7 3 , 6 5 8 . 2}$ & $\mathbf{3 , 1 5 8 , 2 5 7 . 8}$ & $\mathbf{3 , 3 4 2 , 8 5 7 . 5}$ \\
\hline
\end{tabular}

Elaboración propia

\subsubsection{Presupuesto operativo de costos}

Para hallar el presupuesto operativo de costos se halló primero el presupuesto de depreciación que se muestra en la tabla 7.12. 
Tabla 7.12

Presupuesto de depreciación

\begin{tabular}{|c|c|c|c|c|c|c|c|c|c|}
\hline Activo & $\begin{array}{l}\text { Importe } \\
\text { (S/.) }\end{array}$ & $\begin{array}{c}\text { Deprec. } \\
\text { annual } \\
(\%)\end{array}$ & 2018 & 2019 & 2020 & 2021 & 2022 & Total & $\begin{array}{l}\text { Valor en } \\
\text { libros }\end{array}$ \\
\hline Terreno & $1,093,400.0$ & - & - & - & - & - & & & $1,093,400.0$ \\
\hline $\begin{array}{c}\text { Edificación } \\
\text { de planta }\end{array}$ & $157,500.0$ & 5 & $7,875.0$ & $7,875.0$ & $7,875.0$ & $7,875.0$ & $7,875.0$ & $39,375.0$ & $118,125.0$ \\
\hline $\begin{array}{c}\text { Edificación } \\
\text { de oficina }\end{array}$ & $67,500.0$ & 5 & $3,375.0$ & $3,375.0$ & $3,375.0$ & $3,375.0$ & $3,375.0$ & $16,875.0$ & $50,625.0$ \\
\hline $\begin{array}{c}\text { Maquinaria } \\
\text { y equipo }\end{array}$ & $150,335.0$ & 10 & $15,033.5$ & $15,033.5$ & $15,033.5$ & $15,033.5$ & $15,033.5$ & $75,167.5$ & $75,167.5$ \\
\hline $\begin{array}{c}\text { Muebles de } \\
\text { oficina }\end{array}$ & $23,750.0$ & 10 & $2,375.0$ & $2,375.0$ & $2,375.0$ & $2,375.0$ & $2,375.0$ & $11,875.0$ & $11,875.0$ \\
\hline Vehículo & $25,000.0$ & 10 & $2,500.0$ & $2,500.0$ & $2,500.0$ & $2,500.0$ & $2,500.0$ & $12,500.0$ & $12,500.0$ \\
\hline $\begin{array}{l}\text { Imprevisto } \\
\text { fabril }\end{array}$ & $10,000.0$ & 10 & $1,000.0$ & $1,000.0$ & $1,000.0$ & $1,000.0$ & $1,000.0$ & $5,000.0$ & $5,000.0$ \\
\hline $\begin{array}{c}\text { Imprevisto } \\
\text { no fabril }\end{array}$ & $5,000.0$ & 10 & 500.0 & 500.0 & 500.0 & 500.0 & 500.0 & $2,500.0$ & $2,500.0$ \\
\hline Total & $1,532,485.0$ & -2 & $32,658.5$ & $32,658.5$ & $32,658.5$ & $32,658.5$ & $32,658.5$ & & $1,369,192.5$ \\
\hline $\begin{array}{c}\text { Depreciación } \\
\text { fabril }\end{array}$ & & & $26,408.5$ & $26,408.5$ & $26,408.5$ & $26,408.5$ & $26,408.5$ & 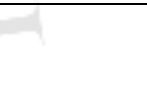 & \\
\hline $\begin{array}{c}\text { Depreciación } \\
\text { no fabril }\end{array}$ & & & $6,250.0$ & $6,250.0$ & $6,250.0$ & $6,250.0$ & $6,250.0$ & 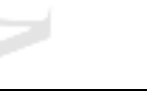 & \\
\hline
\end{tabular}

Elaboración propia

Considerando que el $50 \%$ del valor en libros se vende al mercado, tenemos un valor de salvamento de S/. 684, 596.3.

En la tabla 7.13 se muestra el detalle de presupuesto operativo de costos considerando los costos de mano de obra indirecta, depreciación fabril, costo de producción, costos indirectos de fabricación (limpieza, entre otros).

Tabla 7. 13

Presupuesto operativo de costos

\begin{tabular}{|c|r|r|r|r|r|}
\cline { 2 - 6 } \multicolumn{1}{c|}{} & \multicolumn{1}{c|}{2018} & \multicolumn{1}{c|}{2019} & \multicolumn{1}{c|}{2020} & \multicolumn{1}{c|}{2021} & \multicolumn{1}{c|}{2022} \\
\hline Mano de obra directa & $76,510.7$ & $76,510.7$ & $76,510.7$ & $76,510.7$ & $76,510.7$ \\
\hline Depreciación fabril & $26,408.5$ & $26,408.5$ & $26,408.5$ & $26,408.5$ & $26,408.5$ \\
\hline Costo de producción & $1,459,146.7$ & $1,562,568.6$ & $1,665,990.5$ & $1,769,412.3$ & $1,872,834.2$ \\
\hline Costos indirectos de fabricación & $21,887.2$ & $23,438.5$ & $24,989.9$ & $26,541.2$ & $28,092.5$ \\
\hline Costo total & $1,583,953.1$ & $1,688,926.3$ & $1,793,899.5$ & $1,898,872.7$ & $2,003,845.9$ \\
\hline
\end{tabular}

Elaboración propia 


\subsubsection{Presupuesto operativo de gastos}

Para determinar el presupuesto operativo de gastos administrativos, se ha hallado la amortización total de los activos fijos intangibles, los cuales se muestran en la tabla 7.14. Con esta información, en la tabla 7.15 se detalla el presupuesto operativo de gastos administrativos.

Tabla 7.14

Presupuesto de amortización

\begin{tabular}{|c|r|c|r|r|r|r|r|r|r|}
\hline $\begin{array}{c}\text { Activo fijo } \\
\text { intangible }\end{array}$ & $\begin{array}{c}\text { Import } \\
\text { e (S/.) }\end{array}$ & $\begin{array}{c}\text { \% } \\
\text { Dep. }\end{array}$ & 2018 & $\mathbf{2 0 1 9}$ & 2020 & 2021 & 2022 & $\begin{array}{c}\text { Amort. } \\
\text { total }\end{array}$ & $\begin{array}{c}\text { Valor } \\
\text { en } \\
\text { libros }\end{array}$ \\
\hline $\begin{array}{c}\text { Puesta en } \\
\text { marcha }\end{array}$ & $2,276.0$ & 10 & 227.6 & 227.6 & 227.6 & 227.6 & 227.6 & $1,138.0$ & $1,138.0$ \\
\hline $\begin{array}{c}\text { Estudios } \\
\text { previos }\end{array}$ & $4,500.0$ & 10 & 450.0 & 450.0 & 450.0 & 450.0 & 450.0 & $2,250.0$ & $2,250.0$ \\
\hline Capacitación & $1,000.0$ & 10 & 100.0 & 100.0 & 100.0 & 100.0 & 100.0 & 500.0 & 500.0 \\
\hline Supervisión & $6,000.0$ & 10 & 600.0 & 600.0 & 600.0 & 600.0 & 600.0 & $3,000.0$ & $3,000.0$ \\
\hline Software & 500.0 & 10 & 50.0 & 50.0 & 50.0 & 50.0 & 50.0 & 250.0 & 250.0 \\
\hline Otros & 500.0 & 10 & 50.0 & 50.0 & 50.0 & 50.0 & 50.0 & 250.0 & 250.0 \\
\hline Total & $\begin{array}{r}\mathbf{1 3 , 7 7 6 .} \\
\mathbf{0}\end{array}$ & & $\mathbf{1 , 3 7 7 . 6}$ & $\mathbf{1 , 3 7 7 . 6}$ & $\mathbf{1 , 3 7 7 . 6}$ & $\mathbf{1 , 3 7 7 . 6}$ & $\mathbf{1 , 3 7 7 . 6}$ & $\mathbf{7 , 3 8 8 . 0}$ & $\mathbf{7 , 3 8 8 . 0}$ \\
\hline
\end{tabular}

Elaboración propia 
Tabla 7.15

Presupuesto operativo de gastos administrativos

\begin{tabular}{|c|r|r|r|r|r|}
\cline { 2 - 6 } \multicolumn{1}{c|}{} & \multicolumn{1}{c|}{2018} & \multicolumn{1}{c|}{2019} & \multicolumn{1}{c|}{2020} & \multicolumn{1}{c|}{2021} & \multicolumn{1}{c|}{2022} \\
\hline $\begin{array}{c}\text { Mano de obra } \\
\text { indirecta }\end{array}$ & $397,630.0$ & $397,630.0$ & $397,630.0$ & $397,630.0$ & $397,630.0$ \\
\hline $\begin{array}{c}\text { Suministros } \\
\text { (Agua, Luz, } \\
\text { Internet, Teléfono) }\end{array}$ & $10,774.0$ & $10,774.0$ & $10,774.0$ & $10,774.0$ & $10,774.0$ \\
\hline $\begin{array}{c}\text { Gasto total de } \\
\text { administración }\end{array}$ & $\mathbf{4 0 8 , 4 0 4 . 0}$ & $\mathbf{4 0 8 , 4 0 4 . 0}$ & $\mathbf{4 0 8 , 4 0 4 . 0}$ & $\mathbf{4 0 8 , 4 0 4 . 0}$ & $\mathbf{4 0 8 , 4 0 4 . 0}$ \\
\hline $\begin{array}{c}\text { Gastos en } \\
\text { publicidad }\end{array}$ & $24,000.0$ & $24,000.0$ & $24,000.0$ & $24,000.0$ & $24,000.0$ \\
\hline $\begin{array}{c}\text { Gastos de } \\
\text { distribución }\end{array}$ & $24,000.0$ & $24,000.0$ & $24,000.0$ & $24,000.0$ & $24,000.0$ \\
\hline $\begin{array}{c}\text { Gastos de ventas } \\
\text { Amortización de } \\
\text { intangibles }\end{array}$ & $\mathbf{4 8 , 0 0 0 . 0}$ & $\mathbf{4 8 , 0 0 0 . 0}$ & $\mathbf{4 8 , 0 0 0 . 0}$ & $\mathbf{4 8 , 0 0 0 . 0}$ & $\mathbf{4 8 , 0 0 0 . 0}$ \\
\hline $\begin{array}{c}\text { Depreciación no } \\
\text { fabril }\end{array}$ & $6,250.0$ & $6,250.0$ & $6,250.0$ & $6,250.0$ & $6,250.0$ \\
\hline $\begin{array}{c}\text { Total de gastos } \\
\text { generales }\end{array}$ & $464,031.6$ & $464,031.6$ & $464,031.6$ & $464,031.6$ & $464,031.6$ \\
\hline
\end{tabular}

Elaboración propia

\subsection{Presupuestos financieros}

\subsubsection{Presupuesto de Servicio a la Deuda}

Para el presente estudio se considera que el $60 \%$ de la inversión total será financiado por el banco, y el $40 \%$ restante será capital propio.

Para el financiamiento, el Banco otorga una TEA de $13.45 \%$ para pequeñas empresas con periodo de pago mayor a un año. En la tabla 7.16 se presenta el servicio a la deuda considerando cuotas crecientes, ya que durante los primeros años consideraremos mayor liquidez para cumplir con cuotas crecientes. Se considerará un periodo de gracia total, ya que, por ser un proyecto nuevo, la liquidez suficiente la tendremos a partir del segundo año e ira en crecimiento. 
Tabla 7. 16

Servicio a la deuda

\begin{tabular}{|r|r|r|r|c|}
\hline Año & Deuda & Interés & Amortización & Cuota \\
\hline 2018 & $1,169,514.5$ & $162,562.5$ & - & \\
\hline 2019 & $1,332,077.0$ & $185,158.7$ & $177,610.3$ & $362,769.0$ \\
\hline 2020 & $1,154,466.7$ & $160,470.9$ & $230,893.3$ & $391,364.2$ \\
\hline 2021 & $923,573.4$ & $128,376.7$ & $246,286.2$ & $374,662.9$ \\
\hline 2022 & $677,287.1$ & $94,142.9$ & $225,762.4$ & $319,905.3$ \\
\hline
\end{tabular}

Elaboración propia

Para determinar el costo promedio ponderado de capital, se considera la TEA 13.45 y el COK 20\%, además una tasa de impuesto de 35\%, en la tabla 7.17 determinamos el CPPC.

Tabla 7.17

Distribución de la inversión

\begin{tabular}{|c|r|r|r|r|}
\cline { 2 - 5 } \multicolumn{1}{c|}{} & Importe & \% Participación & Tasa & \multirow{2}{*}{ CPPC } \\
\hline Financiamiento & $1,169,514.5$ & $60 \%$ & $13.45 \%$ & $5.65 \%$ \\
\hline Capital propio & $779,676.3$ & $40 \%$ & $20 \%$ & $8 \%$ \\
\hline
\end{tabular}

Elaboración propia

\subsubsection{Presupuesto de estado de resultados}

En la tabla 7.18 se muestra el estado de Ganancias y Pérdidas. 
Tabla 7.18

Estado de Ganancias y Pérdidas

\begin{tabular}{|c|r|r|r|r|r|}
\multicolumn{1}{c|}{} & \multicolumn{1}{c|}{$\mathbf{2 0 1 8}$} & \multicolumn{1}{c|}{$\mathbf{2 0 1 9}$} & \multicolumn{1}{c|}{$\mathbf{2 0 2 0}$} & \multicolumn{1}{c}{2021} & \multicolumn{2}{c}{2022} \\
\hline Ventas & $2,604,458.8$ & $2,789,058.5$ & $2,973,658.2$ & $3,158,257.8$ & $3,342,857.5$ \\
\hline Costo de ventas & $1,459,146.7$ & $1,562,568.6$ & $1,665,990.5$ & $1,769,412.3$ & $1,872,834.2$ \\
\hline Utilidad bruta & $\mathbf{1 , 1 4 5 , 3 1 2 . 1}$ & $\mathbf{1 , 2 2 6 , 4 8 9 . 9}$ & $\mathbf{1 , 3 0 7 , 6 6 7 . 7}$ & $\mathbf{1 , 3 8 8 , 8 4 5 . 5}$ & $\mathbf{1 , 4 7 0 , 0 2 3 . 3}$ \\
\hline Gastos de administración y ventas & $464,031.6$ & $464,031.6$ & $464,031.6$ & $464,031.6$ & $464,031.6$ \\
\hline Utilidad operativa & $681,280.5$ & $762,458.3$ & $843,636.1$ & $924,813.9$ & $1,005,991.7$ \\
\hline Ingresos financieros & - & & - & - & - \\
\hline Gastos financieros & - & $185,158.7$ & $160,470.9$ & $128,376.7$ & $94,142.9$ \\
\hline Utilidad de explotación & $\mathbf{6 8 1 , 2 8 0 . 5}$ & $\mathbf{7 6 2 , 4 5 8 . 3}$ & $\mathbf{8 4 3 , 6 3 6 . 1}$ & $\mathbf{9 2 4 , 8 1 3 . 9}$ & $\mathbf{1 , 0 0 5 , 9 9 1 . 7}$ \\
\hline Valor de recupero & & & & $684,596.3$ \\
\hline Valor en libros & & & & $7,388.0$ \\
\hline Utilidad antes de impuesto y & $\mathbf{6 8 1 , 2 8 0 . 5}$ & $\mathbf{7 6 2 , 4 5 8 . 3}$ & $\mathbf{8 4 3 , 6 3 6 . 1}$ & $\mathbf{9 2 4 , 8 1 3 . 9}$ & $\mathbf{1 , 6 8 3 , 2 0 0 . 0}$ \\
\hline participación & $54,502.4$ & $60,996.7$ & $67,490.9$ & $73,985.1$ & $134,656.0$ \\
\hline Participaciones (8\%) & $626,778.0$ & $701,461.6$ & $776,145.2$ & $850,828.8$ & $1,548,544.0$ \\
\hline Utilidad antes de impuestos & $\mathbf{1 8 8 , 0 3 3 . 4}$ & $\mathbf{2 1 0 , 4 3 8 . 5}$ & $\mathbf{2 3 2 , 8 4 3 . 6}$ & $\mathbf{2 5 5 , 2 4 8 . 6}$ & $\mathbf{4 6 4 , 5 6 3 . 2}$ \\
\hline Impuesto a la renta (30\%) & $438,744.6$ & $491,023.1$ & $543,301.6$ & $595,580.1$ & $1,083,980.8$ \\
\hline Utilidad antes de reserva legal & $43,874.5$ & $49,102.3$ & $54,330.2$ & $59,558.0$ & $108,398.1$ \\
\hline Reserva legal (10\%) & $\mathbf{3 9 4 , 8 7 0 . 2}$ & $\mathbf{4 4 1 , 9 2 0 . 8}$ & $\mathbf{4 8 8 , 9 7 1 . 5}$ & $\mathbf{5 3 6 , 0 2 2 . 1}$ & $\mathbf{9 7 5 , 5 8 2 . 7}$ \\
\hline Utilidad libre disposición & & &
\end{tabular}

Elaboración propia

\subsection{Flujo de fondos netos}

\subsubsection{Flujo de fondos económicos}

En la tabla 7.19 se muestra el flujo de fondos económicos.

Tabla 7. 19

Flujo de fondos Económicos

\begin{tabular}{|c|r|r|r|r|r|r|}
\cline { 2 - 6 } \multicolumn{1}{c|}{} & $\mathbf{2 0 1 7}$ & \multicolumn{1}{c|}{$\mathbf{2 0 1 8}$} & \multicolumn{1}{c|}{$\mathbf{2 0 1 9}$} & \multicolumn{1}{c|}{$\mathbf{2 0 2 0}$} & \multicolumn{1}{c}{$\mathbf{2 0 2 1}$} & \multicolumn{2}{c}{$\mathbf{2 0 2 2}$} \\
\hline Utilidad antes de reserva legal & & $438,744.6$ & $491,023.1$ & $543,301.6$ & $595,580.1$ & $1,083,980.8$ \\
\hline Depreciación & & $32,658.5$ & $32,658.5$ & $32,658.5$ & $32,658.5$ & $32,658.5$ \\
\hline Amortización & & $1,377.6$ & $1,377.6$ & $1,377.6$ & $1,377.6$ & $1,377.6$ \\
\hline Gastos financieros & & - & $129,611.1$ & $112,329.6$ & $89,863.7$ & $65,900.0$ \\
\hline Participaciones & & $54,502.4$ & $60,996.7$ & $67,490.9$ & $73,985.1$ & $134,656.0$ \\
\hline Capital de trabajo & & & & & & $401,929.8$ \\
\hline Inversiones & $-1,949,190.8$ & & & & & \\
\hline Valor residual & & & & & & $684,596.3$ \\
\hline Flujo de fondos económicos & $\mathbf{- 1 , 9 4 9 , 1 9 0 . 8}$ & $\mathbf{5 2 7 , 2 8 3 . 2}$ & $\mathbf{7 1 5 , 6 6 7 . 0}$ & $\mathbf{7 5 7 , 1 5 8 . 2}$ & $\mathbf{7 9 3 , 4 6 5 . 0}$ & $\mathbf{2 , 4 0 5 , 0 9 8 . 9}$ \\
\hline
\end{tabular}

Elaboración propia 


\subsubsection{Flujo de fondos financieros}

En la tabla 7.20 se muestran el flujo de fondos financieros.

Tabla 7. 20

Flujo de fondos financieros

\begin{tabular}{|c|r|r|r|r|r|r|}
\cline { 2 - 7 } \multicolumn{1}{c|}{} & \multicolumn{1}{c|}{$\mathbf{2 0 1 7}$} & \multicolumn{1}{c|}{$\mathbf{2 0 1 8}$} & \multicolumn{1}{c|}{$\mathbf{2 0 1 9}$} & \multicolumn{1}{c|}{$\mathbf{2 0 2 0}$} & \multicolumn{1}{c|}{2021} & \multicolumn{1}{c|}{2022} \\
\hline Utilidad antes de reserva legal & & $438,744.6$ & $491,023.1$ & $543,301.6$ & $595,580.1$ & $1,083,980.8$ \\
\hline Depreciación & & $32,658.5$ & $32,658.5$ & $32,658.5$ & $32,658.5$ & $32,658.5$ \\
\hline Amortización & & $1,377.6$ & $1,377.6$ & $1,377.6$ & $1,377.6$ & $1,377.6$ \\
\hline Participaciones & & $54,502.4$ & $60,996.7$ & $67,490.9$ & $73,985.1$ & $134,656.0$ \\
\hline Inversiones & $-1,949,190.8$ & & & & & \\
\hline Prestamos & $1,169,514.5$ & & & & & \\
\hline Amortización del préstamo & & & $-177,610.3$ & $-230,893.3$ & $-246,286.2$ & $-225,762.4$ \\
\hline Capital de trabajo & & & & & & $401,929.8$ \\
\hline Valor residual & & & & & & $684,596.3$ \\
\hline $\begin{array}{c}\text { Flujo neto de Fondo } \\
\text { Financiero }\end{array}$ & $\mathbf{- 7 7 9 , 6 7 6 . 3}$ & $\mathbf{5 2 7 , 2 8 3 . 2}$ & $\mathbf{4 0 8 , 4 4 5 . 6}$ & $\mathbf{4 1 3 , 9 3 5 . 3}$ & $\mathbf{4 5 7 , 3 1 5 . 1}$ & $\mathbf{2 , 1 1 3 , 4 3 6 . 5}$ \\
\hline
\end{tabular}

Elaboración propia 


\section{CAPÍTULO VIII: EVALUCIÓN ECÓNOMICA Y FINANCIERA DEL PROYECTO}

\subsection{Evaluación económica: VAN, TIR, B/C, PR}

En la tabla 8.1 se puede observar los resultados de la evaluación económica.

Tabla 8. 1

Evaluación económica: VAN, TIR, B/C, PR

\begin{tabular}{|c|c|}
\hline VAN Económico & $774,579.39$ \\
\hline Tasa Interna de retorno & $33 \%$ \\
\hline Relación B/C & 1.4 \\
\hline Periodo de recupero & $2.9 \sim 2$ años y 11 meses \\
\hline
\end{tabular}

Elaboración propia

\subsection{Evaluación financiera: VAN, TIR, B/C, PR}

En la tabla 8.2 se puede observar los resultados de la evaluación financiera.

Tabla 8. 2

Evaluación financiera: VAN, TIR, B/C, PR

\begin{tabular}{|c|c|}
\hline VAN Financiero & $1,686,488.1$ \\
\hline Tasa Interna de retorno & $66.4 \%$ \\
\hline Relación B/C & 3.2 \\
\hline Periodo de recupero & $1.6 \sim 1$ año y 7 meses \\
\hline
\end{tabular}

Elaboración propia

8.3. Análisis de ratios (liquidez, solvencia, rentabilidad) e indicadores económicos y financieros del proyecto

\section{A. Indicadores económicos:}

- El Valor Actual Neto (VAN) nos permite calcular el valor presente de cajas futuros originados por la inversión. Cuando la VAN es mayor a cero, podernos definir que 
el proyecto es rentable; para el presente proyecto resultó 774,579.4 lo que nos permite decir que es rentable.

- La Tasa Interna de Retorno (TIR): Si la TIR es alta y mayor al Costo de Capital, podemos decir que el proyecto es factible, en el presente proyecto el resultado fue $33 \%$, lo cual es mayor al CPPC determinado anteriormente. Se concluye que el proyecto es factible.

- Para el presente proyecto, el costo beneficio es 1.4 , lo que significa que por cada sol que se invierte de capital propio, se recibe como beneficio 1.40 soles.

- El periodo para recuperar la inversión es de 2 años y once meses.

\section{B. Indicadores financieros:}

- El VAN financiero es 1, 686,488.1, lo que nos indica que el proyecto es rentable.

- La TIR es $66.4 \%$, y supera la tasa mínima exigida por los accionistas.

- La relación beneficio costo es 3.2, lo cual indica que por cada sol de capital propio que se invierta, se recibe 3.2 soles.

- El periodo de recupero es de 1 año y 7 meses.

Analizando los indicadores económicos y financieros, para el presente proyecto, se puede concluir que es más conveniente financiar.

En base a los resultados de VAN >0 y TIR > Costo de capital tanto en la evaluación económica como financiera, se concluye que el proyecto es viable.

\subsection{Análisis de sensibilidad del proyecto}

El análisis de sensibilidad nos permite analizar las variaciones de los resultados en caso ocurrieran cambios en el precio, costo de venta, y la TEA (Tasa Efectiva Anual); este análisis se realiza ya que estas variables pueden variar según las condiciones en las que se encuentre el mercado. 
En las tablas 8.3, 8.4 y 8.5 veremos las variaciones que ocurren cuando el precio, los costos de venta y la tasa de interés anual (TEA) aumentan y disminuyen $3 \%$.

Tabla 8.3

Análisis de sensibilidad por variación de precios

\begin{tabular}{|c|c|c|r|r|r|r|r|r|r|}
\hline $\begin{array}{c}\text { Variación } \\
(\%)\end{array}$ & $\begin{array}{c}\text { Valor } \\
\text { variable }\end{array}$ & $\begin{array}{c}\text { Van financiero } \\
(\mathbf{S} / .)\end{array}$ & $\begin{array}{c}\text { Var } \\
(\%)\end{array}$ & TIR & $\begin{array}{c}\text { Var } \\
(\%)\end{array}$ & $\mathbf{B} / \mathrm{C}$ & $\begin{array}{c}\text { Var } \\
(\%)\end{array}$ & $\begin{array}{c}\text { Periodo de } \\
\text { recupero }\end{array}$ & $\begin{array}{c}\text { Var } \\
(\%)\end{array}$ \\
\hline-3 & 1.94 & $1,465,286.4$ & $-13 \%$ & $59 \%$ & $-11 \%$ & 2.9 & $-9 \%$ & 1.9 & $17 \%$ \\
\hline 0 & 2.00 & $1,686,488.1$ & $0 \%$ & $66 \%$ & $0 \%$ & 3.2 & $0 \%$ & 1.6 & $0 \%$ \\
\hline 3 & 2.06 & $1,907,689.9$ & $13 \%$ & $74 \%$ & $11 \%$ & 3.4 & $9 \%$ & 1.4 & $-14 \%$ \\
\hline
\end{tabular}

Elaboración propia

Tabla 8. 4

Análisis de sensibilidad por variación de costo unitario de venta

\begin{tabular}{|c|c|c|c|c|c|c|c|c|c|}
\hline $\begin{array}{c}\text { Variación } \\
(\%)\end{array}$ & $\begin{array}{c}\text { Valor } \\
\text { variable }\end{array}$ & $\begin{array}{c}\text { Van financiero } \\
(\mathbf{S} / .)\end{array}$ & $\begin{array}{c}\text { Var } \\
(\%)\end{array}$ & TIR & $\begin{array}{c}\text { Var } \\
(\%)\end{array}$ & B/C & $\begin{array}{c}\text { Var } \\
(\%)\end{array}$ & $\begin{array}{c}\text { Periodo de } \\
\text { recupero }\end{array}$ & $\begin{array}{c}\text { Var } \\
(\%)\end{array}$ \\
\hline-3 & 1.09 & $1,799,988.4$ & $7 \%$ & $70 \%$ & $6 \%$ & 3.3 & $5 \%$ & 1.5 & $-7 \%$ \\
\hline 0 & 1.12 & $1,686,488.1$ & $0 \%$ & $66 \%$ & $0 \%$ & 3.2 & $0 \%$ & 1.6 & $0 \%$ \\
\hline 3 & 1.15 & $1,576,701.7$ & $-7 \%$ & $63 \%$ & $-6 \%$ & 3.0 & $-5 \%$ & 1.7 & $7 \%$ \\
\hline
\end{tabular}

Elaboración propia

Tabla 8.5

Análisis de sensibilidad por variación de costo unitario de venta

\begin{tabular}{|c|c|c|c|c|c|c|c|c|c|}
\hline $\begin{array}{c}\text { Variación } \\
(\%)\end{array}$ & $\begin{array}{c}\text { Valor } \\
\text { variable }\end{array}$ & $\begin{array}{c}\text { Van } \\
\text { financiero } \\
(\mathrm{S} / \mathrm{)}\end{array}$ & $\begin{array}{c}\text { Var } \\
(\%)\end{array}$ & TIR & $\begin{array}{c}\text { Var } \\
(\%)\end{array}$ & $\mathrm{B} / \mathrm{C}$ & $\begin{array}{c}\text { Var } \\
(\%)\end{array}$ & $\begin{array}{c}\text { Periodo de } \\
\text { recupero }\end{array}$ & $\begin{array}{c}\text { Var } \\
(\%)\end{array}$ \\
\hline-3 & $13.0 \%$ & $1,725,790.6$ & $0.1 \%$ & $66.5 \%$ & $0.1 \%$ & 3.2 & $0.1 \%$ & 1.6 & $-0.02 \%$ \\
\hline 0 & $13.45 \%$ & $1,686,488.1$ & $0.0 \%$ & $66.0 \%$ & $0.0 \%$ & 3.2 & $0.0 \%$ & 1.6 & $0.00 \%$ \\
\hline 3 & $13.9 \%$ & $1,652,426.8$ & $-2.1 \%$ & $66.0 \%$ & $0.0 \%$ & 3.1 & $-1.4 \%$ & 1.6 & $0.00 \%$ \\
\hline
\end{tabular}

Elaboración propia 


\section{CAPÍTULO IX: EVALUACIÓN SOCIAL DEL PROYECTO}

\subsection{Identificación de las zonas y comunidades de influencia del proyecto}

Este proyecto se desarrollará en la ciudad de Lima en el distrito de Villa María del Triunfo, donde se encuentra un gran porcentaje de población a nivel departamental; además la planta se ubicará en una zona industrial. El insumo principal se obtendrá de la Costa Norte y Selva del Perú.

\subsection{Impacto en la zona de influencia del proyecto}

Para la obtención de la cáscara de plátano se realizarán negociaciones con productores y comercializadores de plátano o productos derivados, a quienes se les brindará una nueva alternativa de negocio e ingreso; esto llevará a un bienestar general en su mayoría en las zonas de Costa Norte y Selva del Perú; buscando nuevas maneras de abastecimiento y crecimiento económico en el futuro.

También se realizará un crecimiento económico en el distrito de lima al brindar trabajo, considerando que es la ciudad del Perú con mayor porcentaje de PEA desocupadas.

\subsection{Impacto social del proyecto}

El proyecto generará nuevos puestos de trabajo sobre todo en la zona de influencia. Este impacto se cuantificará en la tabla 9.1 . 
Tabla 9. 1

Valor agregado del proyecto

\begin{tabular}{|c|r|r|r|r|r|}
\cline { 2 - 6 } \multicolumn{1}{c|}{} & \multicolumn{1}{c|}{$\mathbf{2 0 1 8}$} & \multicolumn{1}{c|}{$\mathbf{2 0 1 9}$} & \multicolumn{1}{c|}{2020} & \multicolumn{1}{c|}{2021} & \multicolumn{1}{c|}{2022} \\
\hline $\begin{array}{c}\text { Utilidad antes de } \\
\text { impuestos }\end{array}$ & $681,280.5$ & $762,458.3$ & $843,636.1$ & $924,813.9$ & $1,683,200.0$ \\
\hline $\begin{array}{c}\text { Salarios (directos e } \\
\text { indirectos) }\end{array}$ & 474,141 & 474,141 & 474,141 & 474,141 & 474,141 \\
\hline $\begin{array}{c}\text { Gastos operativos } \\
\text { Gastos financieros }\end{array}$ & $1,459,146.7$ & $1,562,568.6$ & $1,665,990.5$ & $1,769,412.3$ & $1,872,834.2$ \\
\hline $\begin{array}{c}\text { Servicios } \\
\text { nepreciación fabril y } \\
\text { no fabril }\end{array}$ & $10,774.00$ & $10,774.00$ & $10,774.00$ & $10,774.00$ & $10,774.00$ \\
\hline $\begin{array}{c}\text { Amortización de } \\
\text { intangibles }\end{array}$ & $1,37,658.5$ & $32,658.5$ & $32,658.5$ & $32,658.5$ & $32,658.5$ \\
\hline Valor agregado & $\mathbf{2 , 6 5 9 , 3 7 7 . 9}$ & $\mathbf{3 , 0 2 2 , 4 3 4 . 1}$ & $\mathbf{3 , 1 8 3 , 2 3 9 . 6}$ & $\mathbf{3 , 3 3 6 , 9 0 6 . 8}$ & $\mathbf{4 , 1 6 5 , 7 2 0 . 2}$ \\
\hline Valor presente & & $1,377.6$ & $1,377.6$ & $1,377.6$ & $1,377.6$ \\
\hline
\end{tabular}

Elaboración propia

El valor presente obtenido a una tasa de $20 \%$ (COK) mostrado en la tabla 9.1 es S/. 9, 44, 556.6, importe que representa el valor que se añade al proceso productivo. Al relacionar el valor presente con la inversión inicial del proyecto, se obtienen los indicadores de intensidad de capital y relación producto capital.

En la tabla 9.2, 9.3 y 9.4 se muestran los indicadores de intensidad de capital, densidad de capital y relación producto capital.

Tabla 9. 2

Intensidad de capital

\begin{tabular}{|c|c|}
\cline { 2 - 2 } \multicolumn{1}{c|}{} & Valor \\
\hline Valor agregado & $\mathrm{S} / .9,440,556.6$ \\
\hline Inversión total & $\mathrm{S} / .1,949,190.8$ \\
\hline Intensidad de capital & 0.2 veces \\
\hline
\end{tabular}

Elaboración propia

Con la información de intensidad de capital podemos decir que para generar S/. 1 de valor agregado, necesitamos S/. 0.2. 
Tabla 9. 3

Densidad de capital

\begin{tabular}{|c|c|}
\cline { 2 - 2 } \multicolumn{1}{c|}{} & Valor \\
\hline Inversión total & $\mathrm{S} / .1,949,190.8$ \\
\hline Número de trabajadores & 20 \\
\hline Inversión/Número de trabajadores & $\mathrm{S} / .97,459.5$ \\
\hline
\end{tabular}

Elaboración propia

Con la información de densidad de capital, se observa que se requiere de S/. 97,459.5 de inversión para generar un puesto de trabajo.

Tabla 9.4

Relación producto capital

\begin{tabular}{|c|c|}
\cline { 2 - 2 } \multicolumn{1}{c|}{} & Valor \\
\hline Valor agregado & $\mathrm{S} / .9,440,556.6$ \\
\hline Inversión total & $\mathrm{S} / .1,949,190.8$ \\
\hline $\mathrm{P} / \mathrm{C}$ & 4.84 veces \\
\hline
\end{tabular}

Elaboración propia

Con este indicador podemos decir que el proyecto es sociablemente viable ya que por cada sol que se invierte se ganan 4.84. 


\section{CONCLUSIONES}

- Se concluye que la elaboración de betún para calzado a base de cáscara de plátano es factible debido a su viabilidad técnica, económica, medioambiental y de mercado.

- El betún para calzado a base de cáscara de plátano será un producto innovador ya que será el primer producto de limpieza elaborado a base de cáscara de una fruta y a la vez tendrá las mismas propiedades de limpieza que un betún tradicional.

- La estrategia de diferenciación será la principal ventaja, ya que cada día crece la tendencia de consumo de productos orgánicos amigables con el medio ambiente.

- La planta de producción y oficinas se ubicará en el distrito de Villa María del Triunfo, ya que es un distrito que cuenta con grandes zonas industriales, está cerca al mercado y a la vez cuanta con mayor cantidad de mano de obra.

- La inversión total del proyecto será 1, 949,190.8 soles para la puesta en marcha. La inversión incluye compra de activos fijos tangibles e intangibles y capital de trabajo. ingeniero 


\section{RECOMENDACIONES}

- Para determinar correctamente el requerimiento de cada uno de los insumos para la elaboración de betún a base de cáscara de plátano, es necesario realizar pruebas de laboratorio.

- Se recomienda contar con asesoría técnica para definir correctamente el equipo a utilizar, ya que es fundamental para determinar la maquinaria correcta que se adquirirá.

- Para evitar la capacidad ociosa de la planta, se recomienda implementar estrategias de crecimiento de mercado.

- Se recomiendo implementar correctamente los programas de seguridad y mantenimiento para aplicar las buenas prácticas de manufacturas, evitar accidentes laborales, así como pérdidas en el proceso de producción. 


\section{REFERENCIAS}

Acofarma. (2016). Fichas de información técnica. Recuperado de http://www.acofarma.com/admin/uploads/descarga/4056ad0f6747fbffc2ee07d82de 08097bdd043f5e5ba/main/files/Glicerina.pdf

A\&A METALICOS. (2016). Lavaderos con escurridores. Recuperado de http://departamentodehuanuco.locanto.com.pe/ID_1223544785/LAVADEROSCON-ESCURRIDORES-SUPERIORES-A-A-METALICOS.html

Asia Sur. (2015). Parque industrial de Chikca albergará a más de 100 fábricas. Recuperado de http://asiaelsur.com/parque-industrial-de-chilca-albergara-a-mas-de100-fabricas-n1584.html.

APEIM. (2015). Niveles Socioeconómicos 2015. Recuperado de http://www.apeim.com.pe/wp-content/themes/apeim/docs/nse/APEIM-NSE2015.pdf

DRAFPACK. (2016). Maquinaria industrial. Recuperado de http://drafpack.com/product-category

ETDISA. (2016). Equipos de cocina. Recuperado de http://www.etdisa.com.pe/-/e/equipos-de-cocina

Euromonitor. (2016). (s.f.). Polishes in Perú. Recuperado de http://www.portal.euromonitor.com/portal/analysis/tab

Google Maps. (2016). Recuperado de https://www.google.com.pe/maps

GYGINDUSTRIAL. (2016). Equipos de filtración. Recuperado de http://www.gygindustrial.com/fil01-a.htm

Indecopi. (2008). Índice de acceso al Mercado 2007-2008. Recuperado de http://repositorio.indecopi.gob.pe/handle/11724/4066

INEI. (2015). Perú: Anuario de Estadísticas Ambientales 201. Recuperado de https://www.inei.gob.pe/media/MenuRecursivo/publicaciones_digitales/Est/Lib134 2/libro.pdf

INEI. (2016). Población 2000 al 2015. Recuperado de http://proyectos.inei.gob.pe/web/poblacion/ 
Intradevco Industrial S.A. (s.f.). (2016). Memoria anual 2015. Recuperado de http://www.bvl.com.pe/eeff/TI0002/20160413192002/METI00022015AIA01.PDF

Ipsos Apoyo Opinión y Mercado. (2015). Informe gerencial de marketing: Liderazgo en productos de cuidado personal y limpieza del hogar. Marketing Data Plus.

KLIMATECHNIK S.A.C. (2016). Equipos deshidratadores. Recuperado de http://www.ktperu.com/product-category/equipos-de-deshidratado/

MarketView. (2011). Mercado Industrial-Lima. Recuperado de http://innovasupplychain.pe/system/archivos/712/original/CBRE\%20Industrial\%20 2T.pdf?1319163522

Medegrephic. (2014). Propiedades funcionales del plátano (Musa sp).Recuperado de http://www.medigraphic.com/pdfs/veracruzana/muv-2014/muv142d.pdf

Mendoza, R. (2014). Elaboración de betún a base de cáscara de plátano. (Trabajo gerencial de Marketing). Universidad Nacional del Callao

Ministerio de Agricultura y Riego. (2014). El banano Peruano "Producto Estrella de Exportación". (C. A. Romero, Ed.). Recuperado de file:///C:/Users/claudia/Downloads/boletin-banano\%20(6).pdf

Ministerio de Comercio Exterior y Turismo. (2009). Guia de orientación al usuario del transporte terrestre. Recuperado de http://www.siicex.gob.pe/siicex/documentosportal/188937685rad04264.pdf

Ministerio de Economía y Finanzas. (s.f.). (2016). Norma Internacional de Contabilidad 38 Activos intengibles. Recuperado de https://www.mef.gob.pe/contenidos/conta_publ/con_nor_co/vigentes/nic/38_NIC.p df

Ministerio de Educación y Trabajo. (2015). Estadística de la calidad educativa. Recuperado de http://escale.minedu.gob.pe/

Ministerio de Producción. (2015). Parques industriales.

Ministerio de Vivienda, Construcción y Saneamiento. (2015). Ley de Impuesto a la Renta DECRETO SUPREMO $N^{o}$ 179-2004-EF . Recuperado de http://www.vivienda.gob.pe/normas_oga/Documentos/Tesoreria/DS_179_2004_EF. pdf

Natursan. (2016). Banana y plátano: diferencias. Recuperado de https://www.natursan.net/banano-y-platano-diferencias-nutricionales/ 
Azcárate Llanes, F. y Fernández Chulián, M. (2015). Operaciones contables avanzadas: Supuestos prácticos (Primera edición). Madrid: Ediciones Pirámide.

OSINERGMIN. (2015). La industria de los hidrocarburos líquidos en el Perú. Recuperado de

http://www.osinergmin.gob.pe/seccion/centro_documental/Institucional/Estudios_E conomicos/Libros/Libro-industria-hidrocarburos-liquidos-Peru.pdf

PESATEC. (2016). Balanza industrial de plataforma. Recuperado de http://www.pesatec.com/productos.php

Plaza Vea. (2016). Cuidado del hogar. Recuperado de http://www.plazavea.com.pe/limpieza/cuidado-del-hogar/betun

Protokimica. (s.f.). (2016). Ficha técnica (Betún color negro). Recuperado de http://www.protokimica.com/archivos/Tarjetas/FICHA\%20TECNICA\%20Betun\% 20Negro.pdf

Repsol. (2015). Memoria anual Refinería la Pampilla. Recuperado de https://imagenes.repsol.com/pe_es/REPSOL_MEMORIAANUAL_RLP_2015F_tc m18-733817.pdf

RPP Noticias. (2014). rpp.pe. Recuperado de http://rpp.pe/lima/actualidad/el-17-de-peruanos-no-practica-habitos-para-cuidar-elmedio-ambiente-noticia-753503

Seguridad Ciudadana. (2015). Informe anual 2015. Recuperado de http://www.seguridadidl.org.pe/sites/default/files/INFORME\%20ANUAL\%2020 $15 \_\% 20$ I DL-SC.pdf

SENASA. (2016). Normas Legales 2006: Reglamento técnico para los productos orgánicos. Recuperado de http://www.senasa.gob.pe/senasa/wp-content/uploads/jer/SUB_SECC/DS_0442006-AG.pdf

SUNAFIL. (2016). Normas Legales: Ley de seguridad y salud en el trabajo. Recuperado de http://www.sunafil.gob.pe/portal/images/docs/normatividad/LEYDESEGURIDAD SALUDTRABAJO-29783.pdf

SUNASS. (2016). Consulta de tarifas. Recuperado de http://www.sunass.gob.pe/websunass/index.php/eps/tarifas-vigentes

Veritrade. (2016). Importaciones y Exportaciones. Recuperado de http://business.veritrade.info/Veritrade/MisBusquedas.aspx 


\section{BIBLIOGRAFÍA}

Abad Díaz, J., y Benavides, J. (2007). Estudio de prefactibilidad para la obtención de betún a partir de la cáscara de plátano. (Tesis para optar el título de Ingeniero Químico). Universidad Nacional de Ingeniería.

Diaz Garay, B.,Jarufe, B. y Noriega, M. T. (2007). Disposición de planta (Segunda edición). Fondo editorial. Lima, Universidad de Lima.

Rojas Manayalle, M., Ruestas Gonzales, P. y Armijos Mendoza, J. (2011). Producción y elaboración de Betún Ecológico en la planta industrial USS-Departamento de Lambayeque. (Proyecto de investigación-Ingeniería Industrial). Universidad Señor de Sipan.

Sapag Chain, N. (2014). Preparación y evaluación de proyectos (Sexta edición edición). México D. F. McGraw-Hill, 2014.

Silva Bertolotti, J. A. y Maruy Saito, B. (2014). Estudio de prefactibilidad para implementar una fábrica de crema de calzado con envase giratorio. (Tesis para optar el título de Ingeniero Industrial) Universidad de Lima.
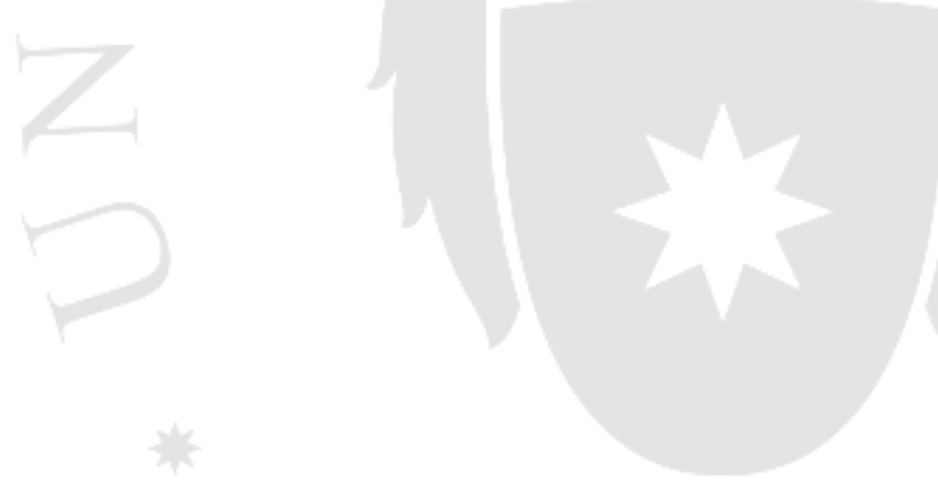


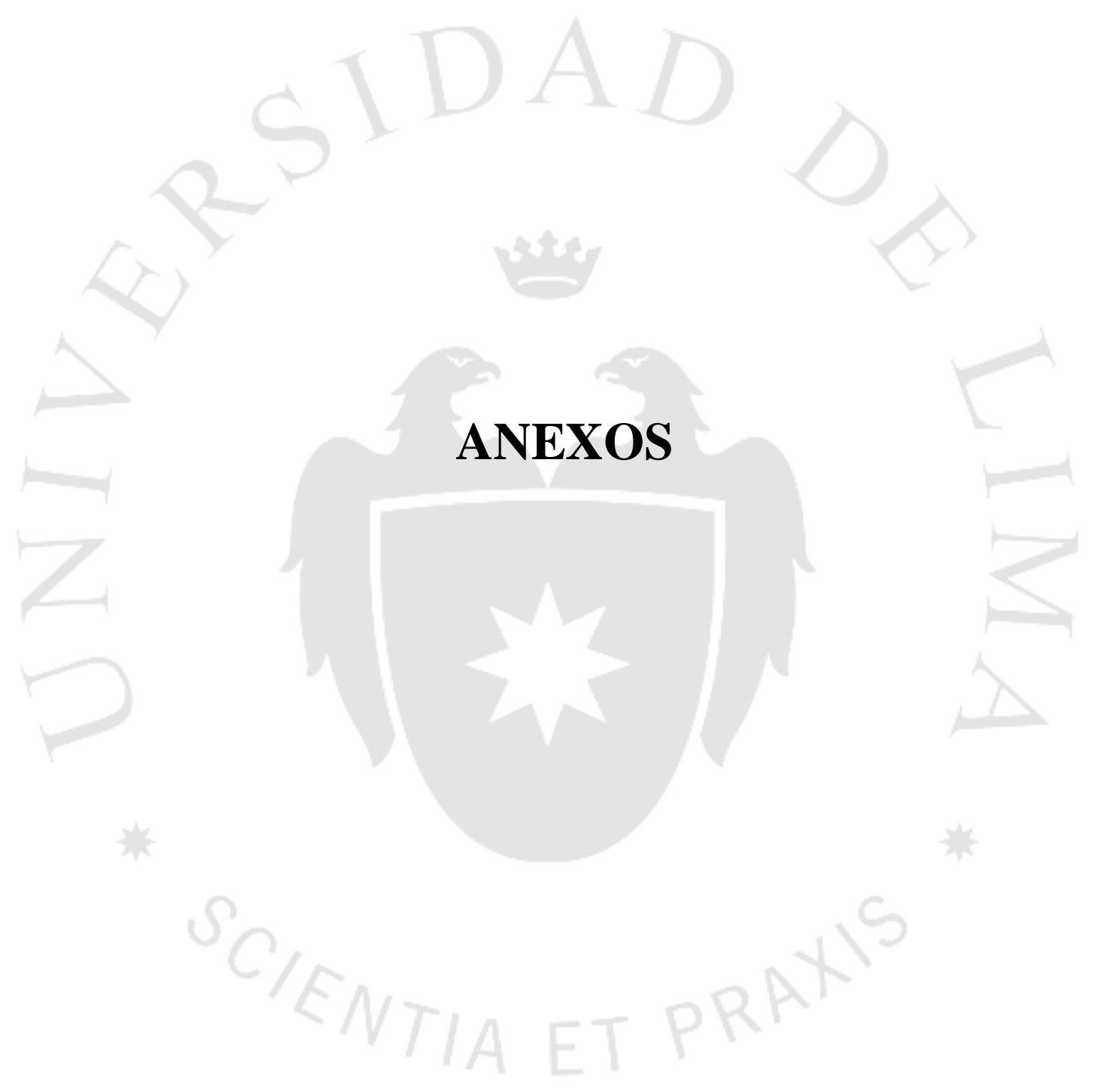




\section{ANEXO 1: Encuesta}

Estamos realizando un estudio de mercado para la introducción de un nuevo producto. Por favor, les solicito contesten las siguientes preguntas: (Marque con un aspa donde sea correspondiente)

1) Datos: Sexo: $\mathrm{M} / \mathrm{F}$

Edad:

Distrito:

Ingreso familiar promedio mensual:

Ocupación:

2) ¿Utiliza calzado que requiere betún para ser limpiado? $\square$ Si

$\square$ No

(Si su respuesta es No, por favor continúe con la pregunta 10 y 11).

3) A la semana ¿Cuántas veces usa este tipo de calzado?:

$\square$ Todos los días

$\square$ De lunes a viernes

Interdiario

$\square 3$ veces por semana

1 vez por semana

Cada 2 semanas

$\square$ Otro (especifique)

4) ¿Cada cuánto tiempo limpia con betún este tipo de calzado?

$\square$ Más de una vez al día. $\square$ Cada vez que se los coloca.

$\square$ Después de 2 o 3 días de uso. $\quad \square$ Rara vez. $\square$ Nunca (si su respuesta es nunca, terminó la encuesta).

5) ¿Cuál es la marca de betún que compra con mayor frecuencia?

$\square$ Kiwi $\square$ Sapolio $\square$ Nugget $\square$ Virginia $\square$ Otro

6) Motivo por el que elije esa marca:

$\square$ Mejor precio $\square$ Mejor calidad $\square$ Fácil acceso $\square$ Diseño $\square$ Otro (indique)

7) ¿Qué tamaño de betún adquiere frecuentemente?

$\square$ Grande $\square$ Mediano $\square$ Pequeño

8) ¿Qué color adquiere con mayor frecuencia?

$\square$ Negro $\square$ Marrón $\quad \square$ Otro color (indique) 
9) Tipo de betún que adquiere frecuentemente: $\square$ Pasta $\square$ Líquido

10) Si usted tiene algún familiar que consume betún, por favor indique:

\begin{tabular}{|l|l|l|l|}
\hline $\begin{array}{l}\text { Relación con el } \\
\text { familiar }\end{array}$ & Edad & Motivo & Frecuencia \\
\hline & & & \\
\hline & & & \\
\hline & & & \\
\hline
\end{tabular}

11) Si alguna vez, usted o alguien de su familia ha tenido alguna incidencia con el betún, por favor marque una de las alternativas:

Ensució o malogró alguna prenda de vestir. $\square$ No tuvo la cantidad apropiada.

$\square$ Se secó, inservible por secado. $\square$ Dañó la piel o los ojos.

$\checkmark$ Otro (indique)

12) ¿Consumiría un betún ecológico a base de productos naturales y orgánicos? $\square$ Sí No

(Si la respuesta es No, terminó la encuesta. En caso sea Sí, por favor continúe).

- Marque en una escala del 1 al 10 su intensidad de compra, donde 1 es un nivel muy bajo de deseo de compra y 10 significa que de todas maneras lo compraría.

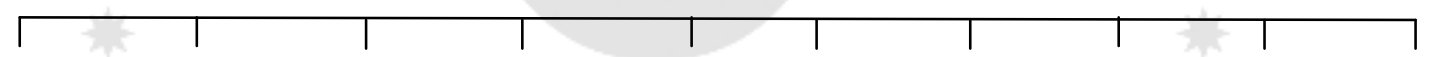

$\begin{array}{lllllllllll}1 & 2 & 3 & 4 & 5 & 6 & 7 & 8 & 9 & 10\end{array}$




\section{ANEXO 2: Pruebas experimentales de laboratorio}

Se realizaron cuatro pruebas de laboratorio distintas con el objetivo de encontrar el proceso, las temperaturas y los insumos adecuados para elaborar un betún orgánico que al untar sobre el cuero de calzado le de lustrocitad y protección a este; además, se busca un producto resistente a la temperatura ambiente que no se descomponga, seque o que con el transcurso del tiempo pierda su funcionalidad, así también, determinar las cantidades necesarias de materia prima e insumos a utilizar para la elaboración de betún con lo cual se pueda realizar un balance de materia preciso; y, finalmente, se requiere determinar los tiempos de secado, molienda y mezcla de la cáscara con los diferentes insumos.

Los insumos y materiales que se usaron para poder realizar estas pruebas fueron:

\section{Insumos:}

- Cáscara de plátano

- Glicerina

- Benzoato de Sodio

- Borato de Sodio

- Trementina

\section{Materiales:}

- Fuente

- Espátula

- Horno $\left(60^{\circ} \mathrm{C}\right)$

- Plancha de cocina

- Molino de cuchilla.

- Tubo de ensayo

- Probeta

- Beaker

- Escobilla 
- Pinzas para cristal

- Tamiz

- Termometro

\section{Pruebas: (Inicio: abril del 2016)}

1. Para empezar las pruebas y determinar el porcentaje de cáscara con respecto al plátano, se pesó 7 plátanos enteros y luego sólo la cáscara entera y partida.
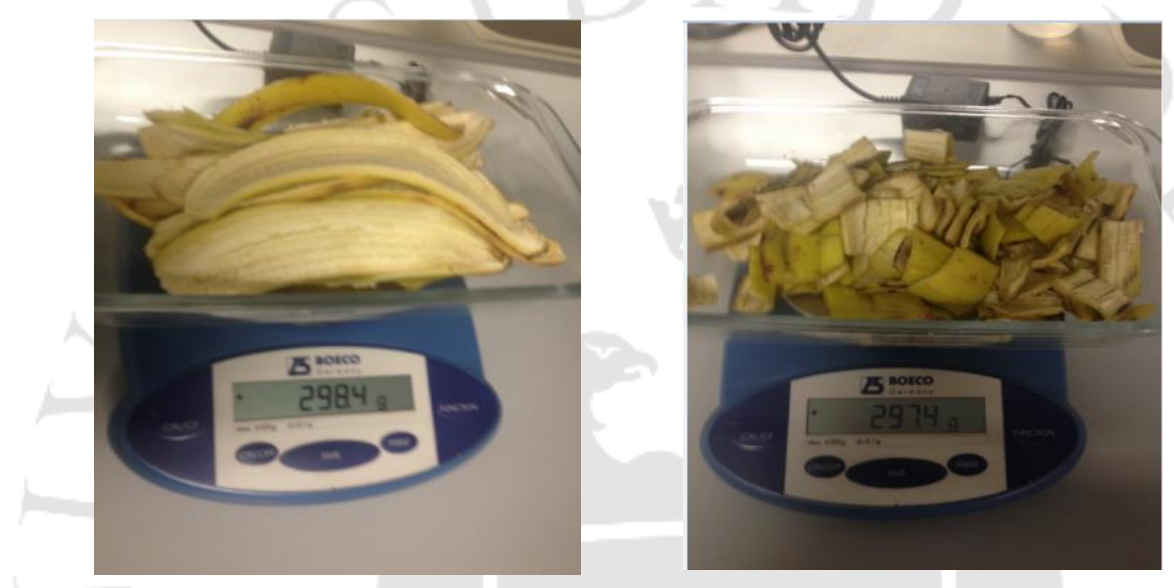

Elaboración propia

2. Se procedió a deshidratar la cáscara de plátano en un horno a $60^{\circ} \mathrm{C}$. Donde se pudo observar que su valor en peso disminuyó en $74.4 \%$.

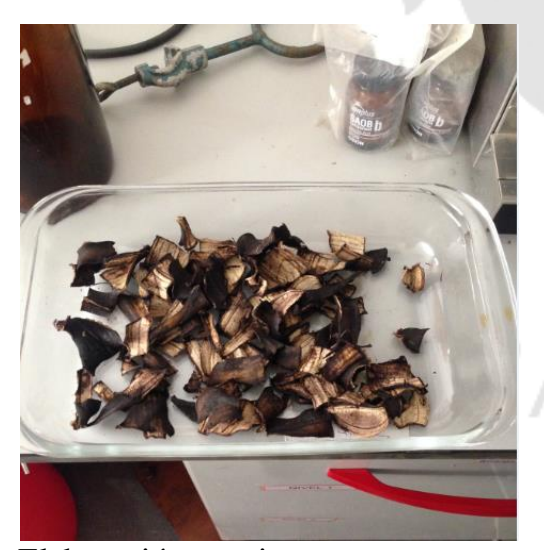

Elaboración propia

3. Se realizó la molienda en un molino de cuchillas y el resultado se zarandeó en un tamiz de $0.25 \mathrm{~mm}$. Las partes de cáscara molida que no pasaron por el tamiz se volvieron a moler con el objetivo de mejorar la eficiencia. 

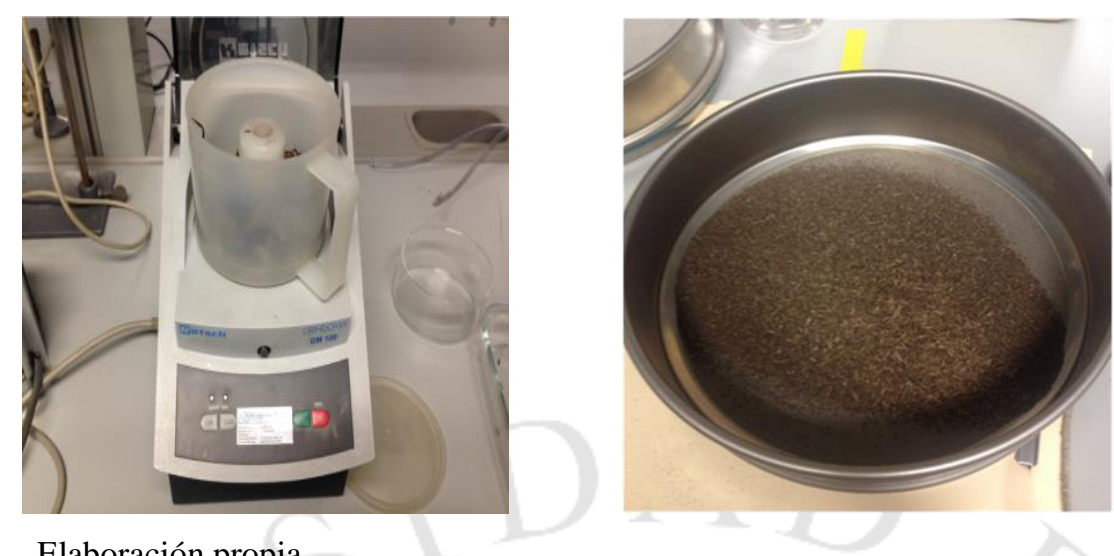

Elaboración propia

4. La cáscara molina, tamizada y pesada es llevada a una plancha de calor, donde se mezcla con glicerina a $100{ }^{\circ} \mathrm{C}$ por 15 minutos, hasta obtener una pasta.
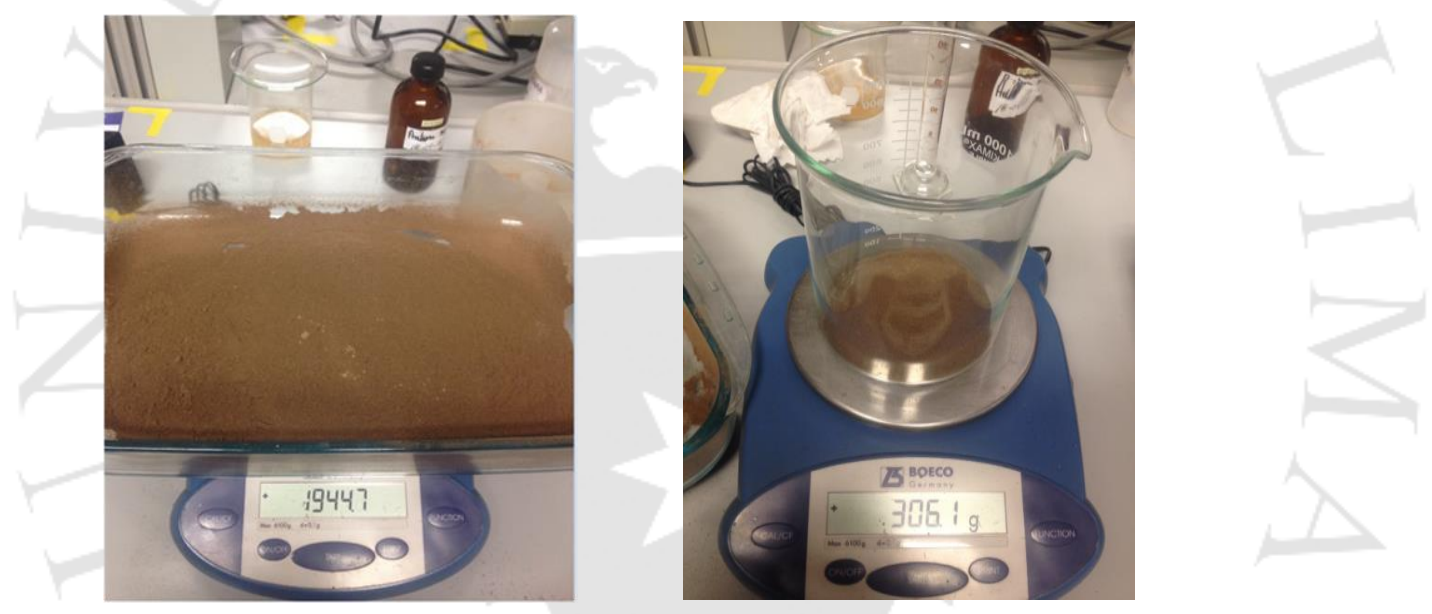

Elaboración propia

5. A esta mezcla se le agrega benzoato de sodio, borato de sodio y colorante orgánico en polvo y se continuó mezclando durante 5 minutos hasta que los insumos se hayan disuelto completamente. Finalmente se vierte en un recipiente plástico y se pesa. 


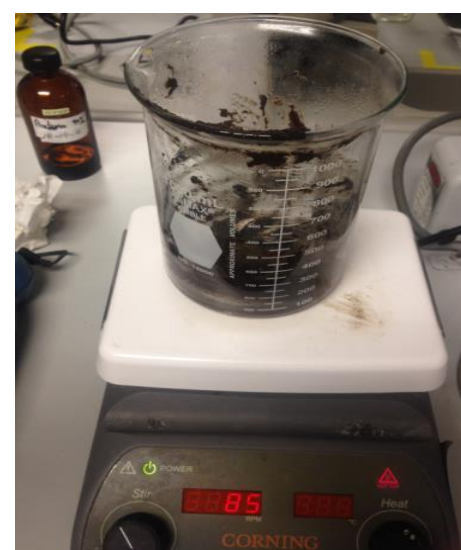

Elaboración propia

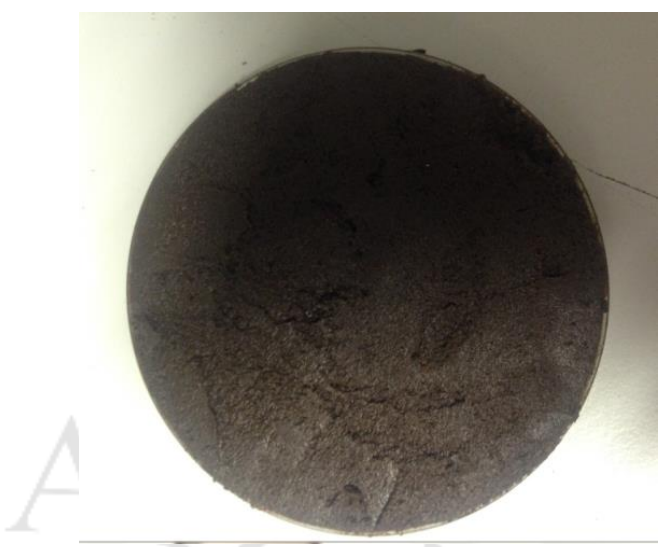

Con este experimento se demostró que, a base de cáscara de plátano, se podía elaborar un producto con el cual se puede realizar la limpieza del calzado de cuero o similares.

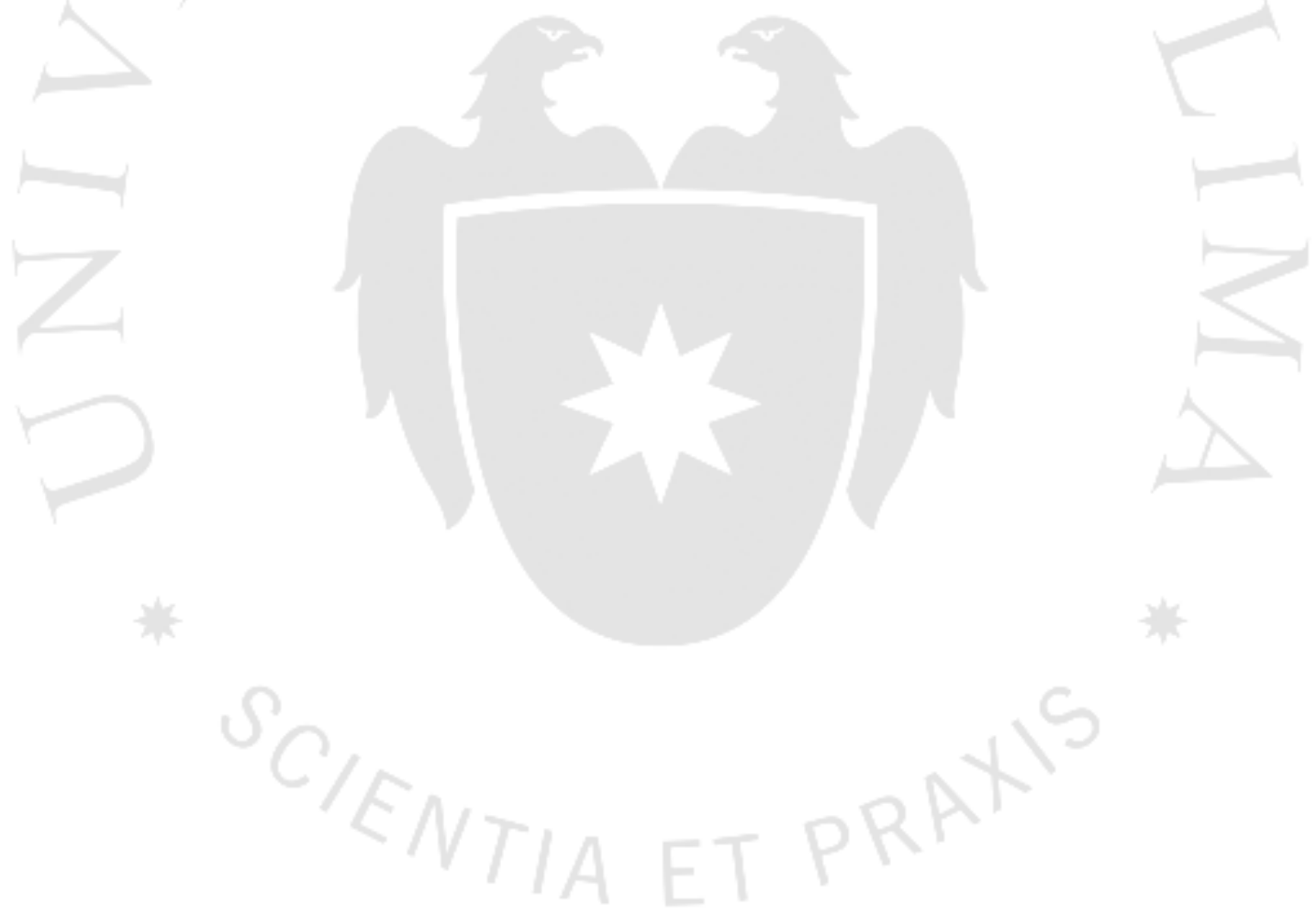




\section{ANEXO 3: Población anual de Lima y Perú}

\begin{tabular}{|c|c|c|}
\hline Año & Perú & Lima \\
\hline 2000 & $25,983,588$ & $7,767,873$ \\
\hline 2001 & $26,366,533$ & $7,913,690$ \\
\hline 2002 & $26,739,379$ & $8,057,558$ \\
\hline 2003 & $27,103,457$ & $8,199,172$ \\
\hline 2004 & $27,460,073$ & $8,338,208$ \\
\hline 2005 & $27,810,540$ & $8,474,342$ \\
\hline 2006 & $28,151,443$ & $8,605,145$ \\
\hline 2007 & $28,481,901$ & $8,730,820$ \\
\hline 2008 & $28,807,034$ & $8,855,022$ \\
\hline 2009 & $29,132,013$ & $8,981,440$ \\
\hline 2010 & $29,461,933$ & $9,113,684$ \\
\hline 2011 & $29,797,694$ & $9,252,401$ \\
\hline 2012 & $30,135,875$ & $9,395,149$ \\
\hline 2013 & $30,475,144$ & $9,540,996$ \\
\hline 2014 & $30,814,175$ & $9,685,490$ \\
\hline 2015 & $31,151,643$ & $9,834,631$ \\
\hline Total & $457,872,425$ & $140,745,621$ \\
\hline
\end{tabular}

Fuente: INEI, (2016) 


\section{ANEXO 4: Producción per cápita de betún para calzado}

\begin{tabular}{|c|c|c|c|}
\hline Año & $\begin{array}{c}\text { Producción de } \\
\text { betún }\end{array}$ & Población & $\begin{array}{c}\text { Producción per } \\
\text { cápita }\end{array}$ \\
\hline 2000 & $1,608,266.7$ & $25,983,588$ & 0.06 \\
\hline 2001 & $1,743,987.4$ & $26,366,533$ & 0.07 \\
\hline 2002 & $1,650,330.5$ & $26,739,379$ & 0.06 \\
\hline 2003 & $1,440,401.3$ & $27,103,457$ & 0.05 \\
\hline 2004 & $1,339,116.7$ & $27,460,073$ & 0.05 \\
\hline 2005 & $1,391,945.5$ & $27,810,540$ & 0.05 \\
\hline 2006 & $1,410,059.0$ & $28,151,443$ & 0.05 \\
\hline 2007 & $1,503,110.0$ & $28,481,901$ & 0.05 \\
\hline & & Tendencia & $\mathbf{0 . 0 5}$ \\
\hline
\end{tabular}

Fuente: Ministerio de Producción, (2016)

\section{ANEXO 5: Cantidad de trabajadores por sector laboral tomado para la determinación de la demanda}

\begin{tabular}{|l|c|}
\hline \multicolumn{1}{|c|}{ Puesto } & No $^{\circ}$ Trabajadores \\
\hline VIGILANTE DE SEGURIDAD (PRIVADOS) & 86,554 \\
\hline EMPLEADO DE OFICINA, OTROS & 62,409 \\
\hline EMPLEADO DE OFICINA EN GENERAL & 63,890 \\
\hline EMPLEADO, BANCOS & 43,045 \\
\hline VIGILANTE & 31,315 \\
\hline GERENTE DE ADMINISTRACIÓN & 23,476 \\
\hline MOZO & 21,358 \\
\hline REPRESENTANTE, VENTAS/COMERCIO & 14,695 \\
\hline PILOTO Y COPILOTO DE AVIACIÓN COMERCIAL $^{\circ}$ & 720 \\
\hline JUECES-CARRERA JUDICIAL-LEY N $^{\circ}$ & 4 \\
\hline FISCALES - D. LEG. N. $^{\circ}$ & 2 \\
\hline SERVICIO DIPLOMÁTICO DE LA REPÚBLICA - LEY N. ${ }^{\circ}$ & 460 \\
\hline MILITARES & 47,115 \\
\hline POLICIA NACIONAL DEL PERÚ - LEY N. $^{\circ}$ & 110,855 \\
\hline ESPECIAL GER. PÚBLICOS DECRETO LEGISLATIVO N. $^{\circ}$ & 261 \\
\hline
\end{tabular}

Fuente: Ministerio de Educación y Trabajo, (2015) 


\section{ANEXO 6: Población escolar}

\begin{tabular}{|c|c|}
\hline DPTO & Cantidad de Alumnos \\
\hline Lima & $1,632,634.0$ \\
\hline Piura & $383,816.0$ \\
\hline La Libertad & $350,452.0$ \\
\hline Cajamarca & $314,258.0$ \\
\hline Cusco & $280,144.0$ \\
\hline Junín & $268,456.0$ \\
\hline Loreto & $245,400.0$ \\
\hline Puno & $242,477.0$ \\
\hline Arequipa & $236,599.0$ \\
\hline Lambayeque & $227,483.0$ \\
\hline Ancash & $226,579.0$ \\
\hline San Martin & $182,365.0$ \\
\hline Callao & $172,315.0$ \\
\hline Huánuco & $171,840.0$ \\
\hline Ica & $153,381.0$ \\
\hline Ayacucho & $146,930.0$ \\
\hline Ucayali & $117,933.0$ \\
\hline Amazonas & $101,504.0$ \\
\hline Huancavelica & $98,905.0$ \\
\hline Apurímac & $98,607.0$ \\
\hline Tacna & $59,230.0$ \\
\hline Pasco & $54,787.0$ \\
\hline Tumbes & $44,751.0$ \\
\hline Madre de dios & $31,118.0$ \\
\hline Moquegua & $30,957.0$ \\
\hline Total & $\mathbf{5 , 8 7 2 , 9 2 1 . 0}$ \\
\hline
\end{tabular}

Fuente: Ministerio de Educación y Trabajo, (2015) 